\title{
Modulation of synaptic transmission by the voltage-gated potassium channel
}

\author{
Eag1
}

Dissertation

In partial fulfilment of the requirements

for the degree "Doktor rerum naturalium" (Dr. rer. nat.)

in the Neuroscience Program

at the Georg August Universität Göttingen,

Faculty of Biology

submitted by

Lena Sünke Mortensen

born in

Scherzingen, Switzerland

Göttingen, 2012 


\section{Thesis committee}

Prof. Walter Stühmer, Max-Planck Institute of Experimental Medicine, Göttingen (Reviewer)

Dr. Takeshi Sakaba, Max-Planck Reseach Group Biophysics of Synaptic Transmission (Reviewer)

Prof. Anastassia Stoykova, Max-Planck Institute for Biophysical Chemistry

\section{Date of the defense}

April 17th, 2012 


\section{Declaration}

I hereby declare that this thesis has been written independently and with no other aids or sources than quoted.

Lena Sünke Mortensen

Göttingen, March $5^{\text {th }} 2012$ 


\section{Table of contents}

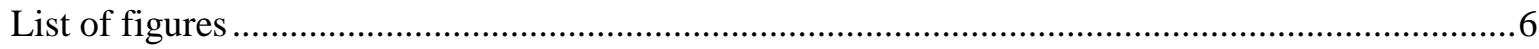

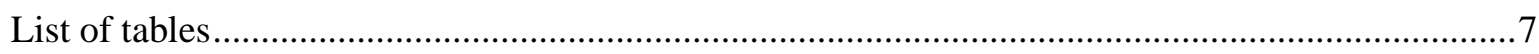

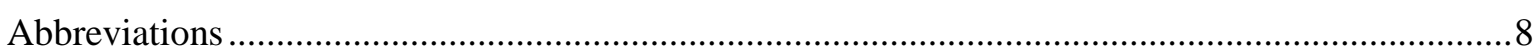

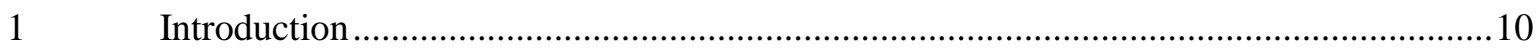

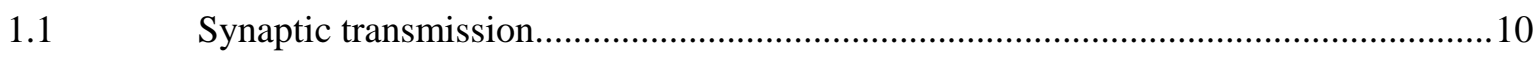

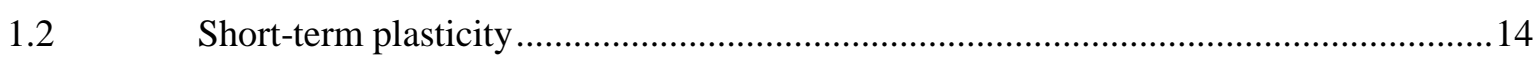

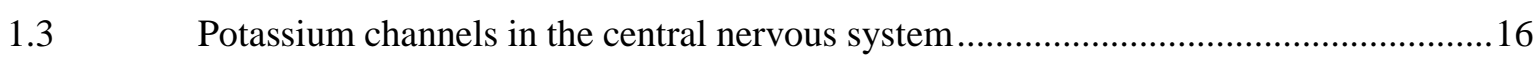

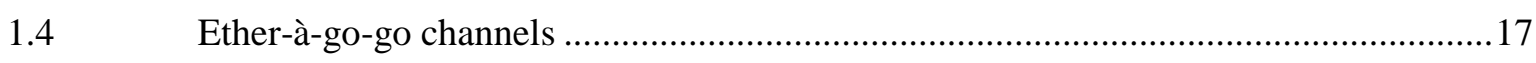

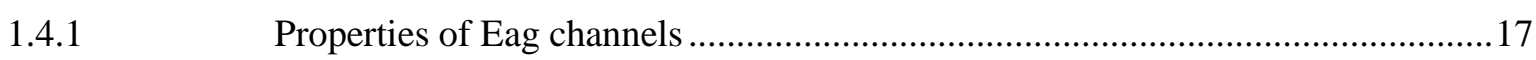

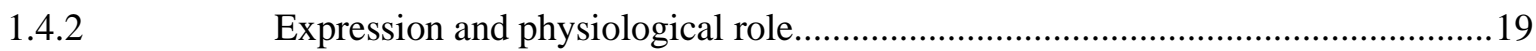

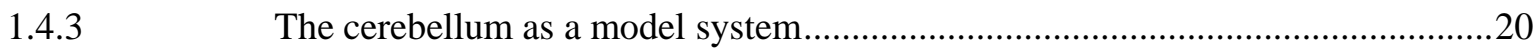

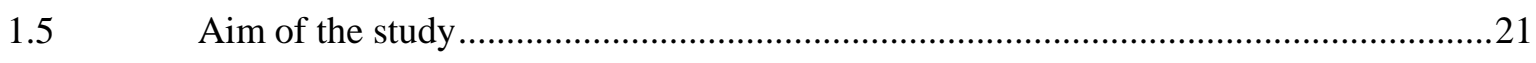

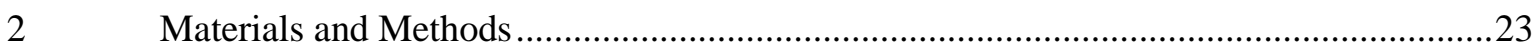

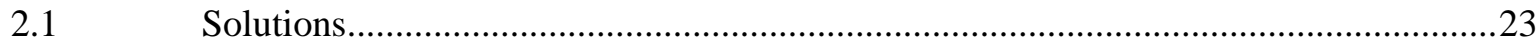

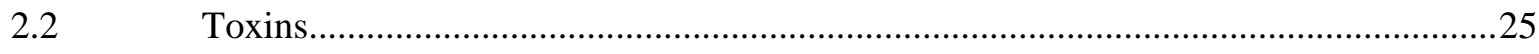

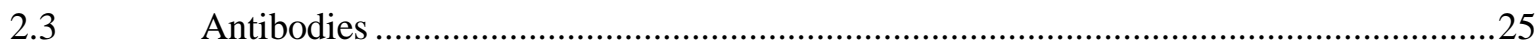

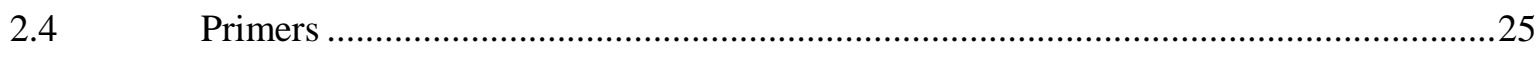

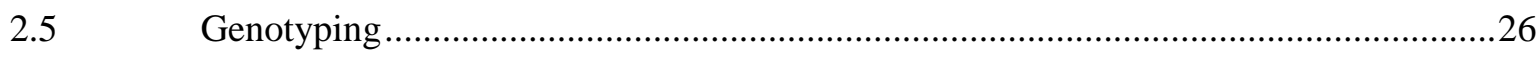

2.5.1 DNA isolation from mouse tails and Polymerase Chain Reaction (PCR) …........26

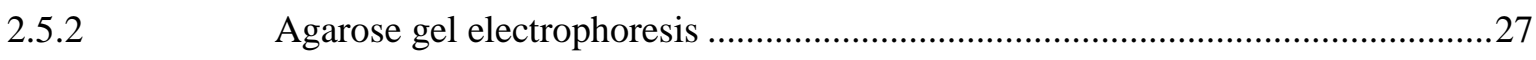

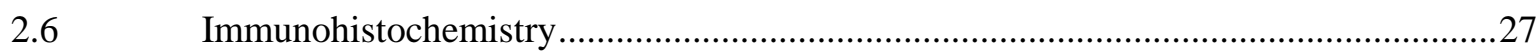

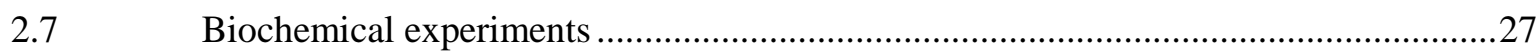

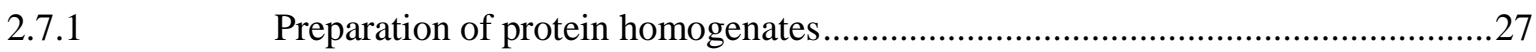

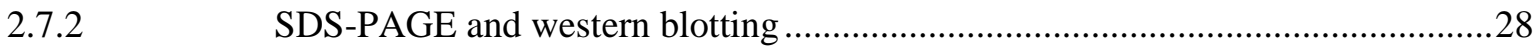

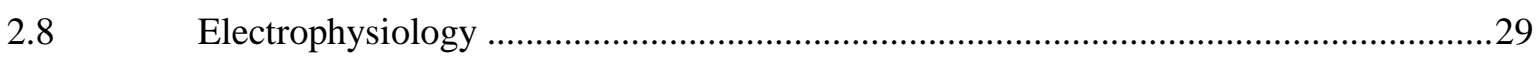

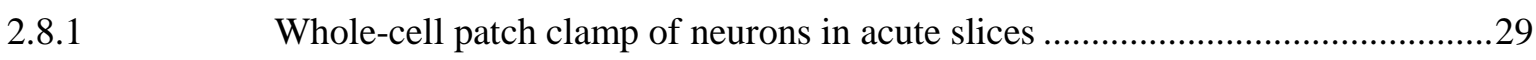

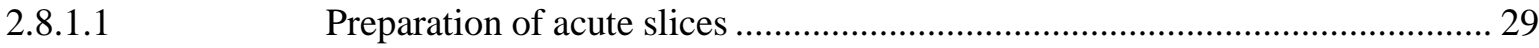

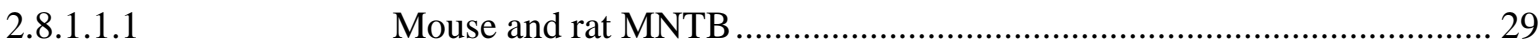

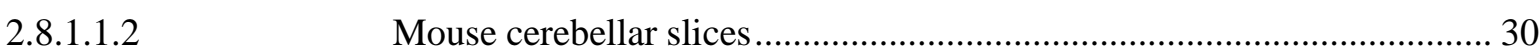

2.8.1.2 Whole-cell patch clamp of the Calyx of Held .............................................. 30

2.8.1.3 Whole-cell patch clamp of neurons of the cerebellar cortex ........................... 31 
2.9 Two-photon calcium imaging in the parallel fibre ........................................................

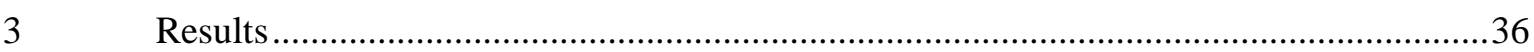

3.1 Eag1 is enriched in the synaptic plasma membrane ....................................................36

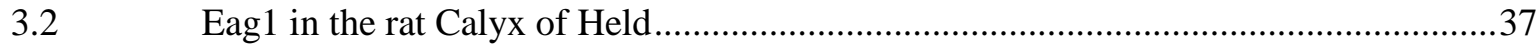

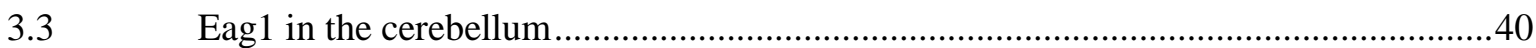

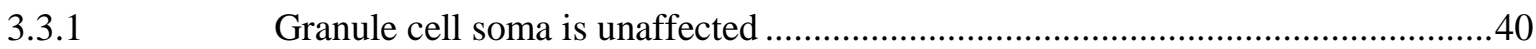

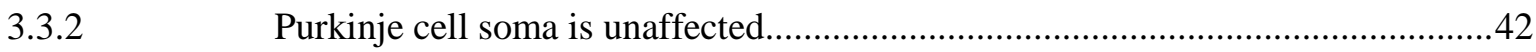

3.3.3 Synaptic transmission in cerebella of WT and Eag1 KO mice ...............................44

3.3.4 Calcium dependence of synaptic transmission in WT and Eag1 KO cells ...........46

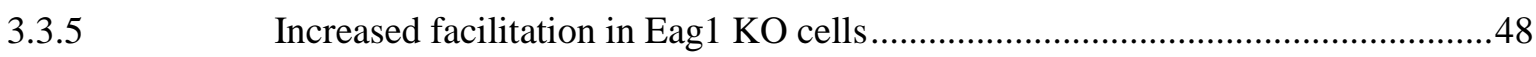

3.3.6 Target-dependent plasticity in the cerebellar cortex ...........................................54

3.3.7 EGTA application does not rescue increased facilitation ....................................55

3.3.8 Increased calcium influx into the presynaptic terminal........................................57

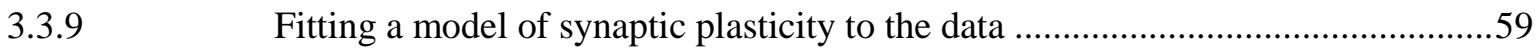

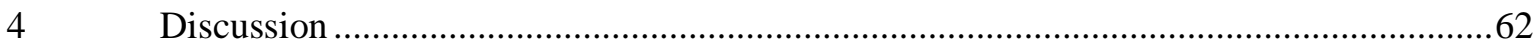

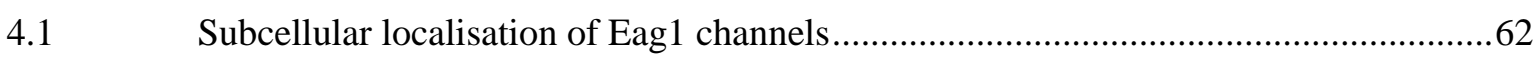

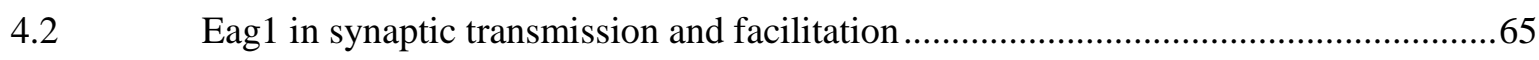

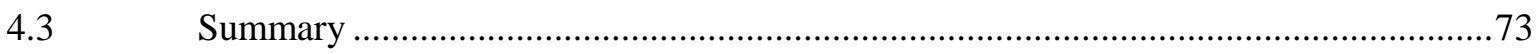

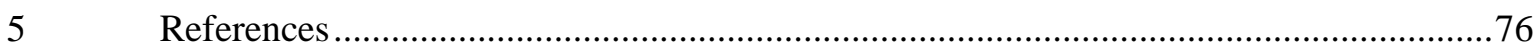

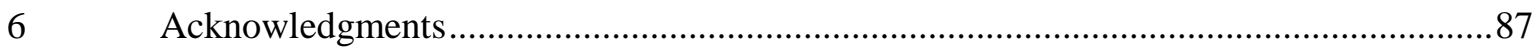

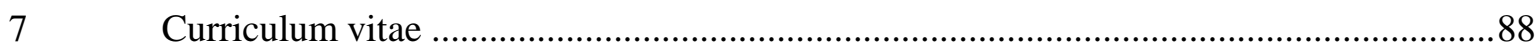

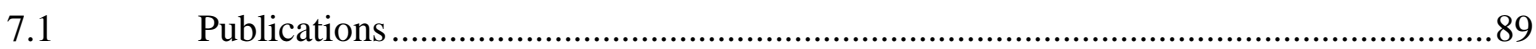




\section{List of figures}

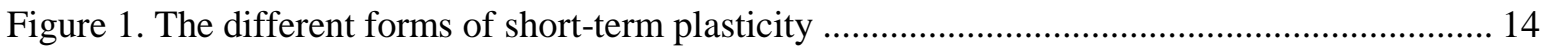

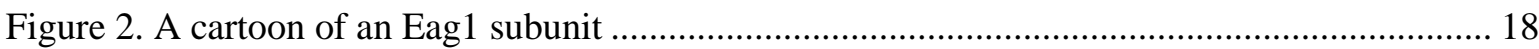

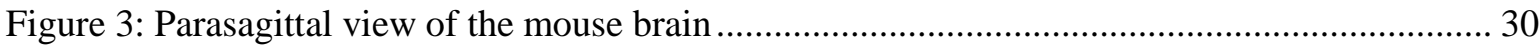

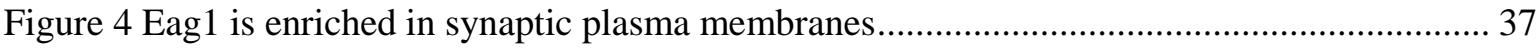

Figure 5. An Eag1 compatible current in the rat calyx of Held ...................................................... 38

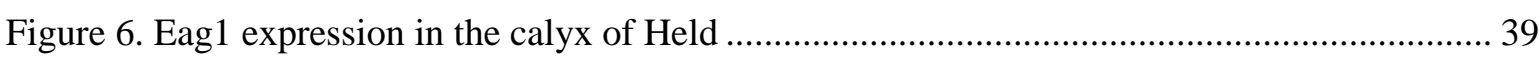

Figure 7: Electroresponsiveness of cerebellar granule cells of WT and Eag1 KO mice ................ 41

Figure 8: Action potential properties are not altered in Eag1 KO mice............................................. 42

Figure 9. Action potential properties in Purkinje cells of WT and Eag1 KO mice.......................... 43

Figure 10. Electroresponsiveness of cerebellar Purkinje cells of WT and Eag1 KO mice ............... 44

Figure 11. Extracellular stimulation causes EPSCs in Purkinje cells .............................................. 45

Figure 12 EPSC kinetics in PF-PC synapses of WT and Eag1 KO mice ........................................ 46

Figure 13 Dependence of transmitter release on extracellular calcium ............................................. 47

Figure 14. Facilitation is increased in Eag1 KO mice in a frequency dependent manner ................ 48

Figure 15. Facilitation is increased in Eag1 KO mice in a frequency- and pulse number-

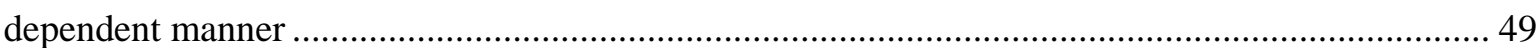

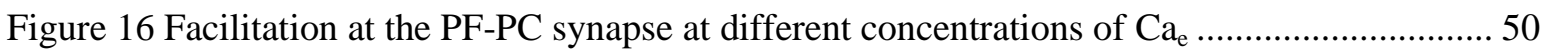

Figure 17: Facilitation decays during a stimulus train .................................................................. 51

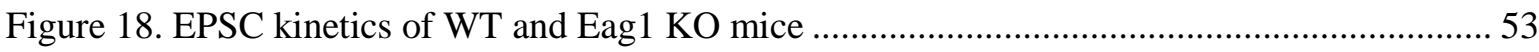

Figure 19. Eag1 does not alter facilitation at PF - BC and PF - SC synapses ................................ 54

Figure 20. Alteration of calcium dynamics with EGTA-AM reduces facilitation in the WT and

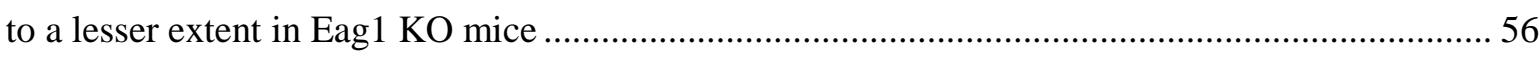

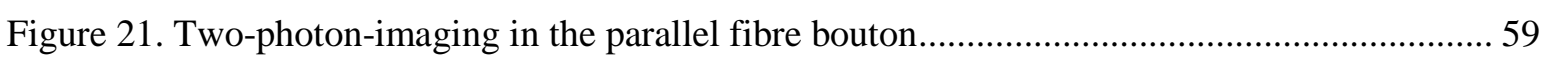

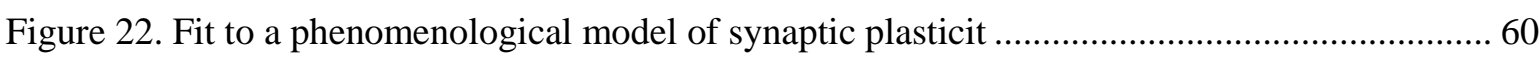




\section{List of tables}

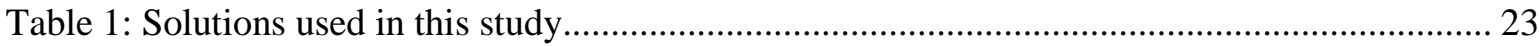

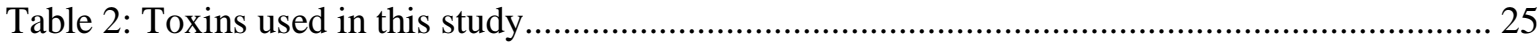

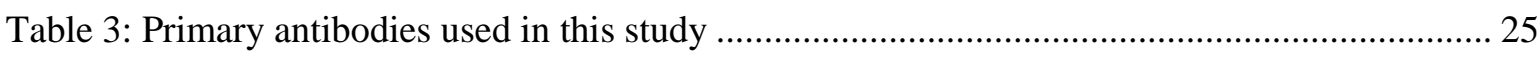

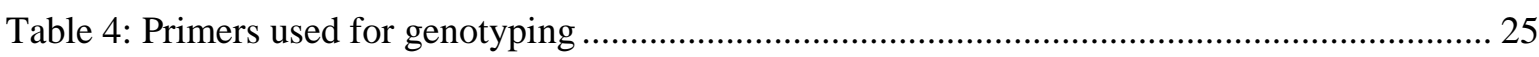

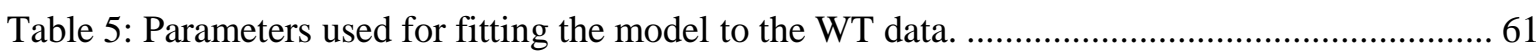




\section{Abbreviations}

aCSF

AM

AMPA

AP

$\mathrm{BC}$

BCA

CA

$\mathrm{Ca}_{\mathrm{e}}$

$\mathrm{Ca}_{\mathrm{i}}$

CamBD

CamKII

$\mathrm{Ca}_{\text {res }}$

cNBD

CNS

DNA

dNTP

Eag

EDTA

EGTA

elk

EP

EPSC

erg

GABA

GC

GFAP

HEK

$\mathrm{Hz}$

ISI

I-V

$\mathrm{KO}$

LSM

$\min$

MNTB

mRNA

OGB

$\mathrm{p}$

PAS

PAC

PBS

PC

PCR

PF

rpm

RRP

$\mathrm{SC}$ artificial cerebrospinal fluid

aceoxymethylester

2-amino-3-(5-methyl-3-oxo-1,2- oxazol-4-yl)propanoic acid

action potential

basket cell

bicinchoninic acid

cornus ammonum

external calcium concentration

internal calcium concentration

calmodulin binding domain

calmodulin kinase II

residual calcium

cyclic nucleotide binding domain

central nervous system

desoxyribunucleic acid

desoxy nucleoside triphosphate

ether-à-go-go

ethylene diamine tetraacetic acid

ethylene glycol tetraacetic acid

eag-like $\mathrm{K}+$ channel

electrophysiology

excitatory postsynaptic current

eag- related gene

$\gamma$-amino-butyric acid

granule cell

glial fibrillary acidic protein

human embryonic kidney

Hertz

interstimulus interval

current-voltage

knock-out

Laser-scanning microscope

minute

medial nucleus of the trapezoid body

messenger ribonucleic acid

oregon green BAPTA-1

postnatal day

Per-Arnt-Sim domain

C-terminal to PAS domain

phosphate buffered saline

Purkinje cell

polymerase chain reaction

parallel fibre

rounds per minute

readily releasable pool

stellate cell 
SDS-PAGE sodium dodecyl sulphate polyacrylamid gel electrophoresis

STP short-term plasticity

TBE Tris-borate-EDTA buffer

TBST Tris-buffered-saline Tween-20

TEA tetraethylammonium

TTX tetrodotoxin

UV ultraviolet

$\mathrm{V}_{\text {mem }} \quad$ membrane potential

WB western blot

WT wildtype 


\section{Introduction}

\subsection{Synaptic transmission}

The brain is a highly complex organ, built to receive and process input from the outer world to elicit an appropriate response of the body to the external stimulus. The computational units of the brain are neurons, specialised cells that communicate with each other and form a huge, highly organised network in which information in form of electrical discharges is constantly exchanged between the cells. A central feature of this network is its nonlinearity, i.e. the ability to modulate and process information while it is passed along (reviewed in (Silver, 2010)). There are two main ways of computing and modulating signals in the brain. Firstly, the active and passive conducting properties of neurons influence how a cell reacts to input and generates output. Secondly, the sites were information is passed along between cells, the synapses, are sites of signal modulation and processing. Synapses have been discovered by Santiago Ramón y Cajal towards the end of the XIX ${ }^{\text {th }}$ century and supported the "neuron doctrine", according to which the brain is made of discrete units, which only communicate with each other at certain contact points. This was in contrast to the "reticular theory", favoured by Ramón y Cajal's colleague Camillo Golgi, stating that the nervous system worked as a continuous network of cellular material, similar to a syncytium (Katz-Sidlow, 1998).

Two fundamentally different types of synapses are known to exist in the brain. At electrical synapses, the gap junctions, the electrical or chemical signal is directly relayed to the receiver neurons (Bennett and Zukin, 2004). At chemical synapses though, the signal can be strengthened or weakened during transmission. The majority of synaptic contacts in the brain are chemical synapses, which use a variety of chemical compounds, amino acids or small peptides to transmit the information from the pre- to the postsynaptic terminal. After neurotransmitter molecules are released, they diffuse over the synaptic cleft and bind to receptors on the postsynaptic membrane, causing either a depolarisation (excitatory transmission) or hyperpolarisation (inhibitory transmission). The most common excitatory neurotransmitter in the mammalian central nervous system (CNS) is glutamate, while the majority of inhibitory transmission is mediated by $\gamma$-aminobutyric acid (GABA) (Kandel et al., 2000). I will focus from now on glutamatergic synapses. 


\section{The synaptic vesicle cycle and the roles of calcium ions}

The pre- and postsynaptic terminals are highly specialised and organised compartments. Presynaptic boutons form and at the end and alongside of an axon (then called varicosities). When an action potential (AP) enters a presynaptic terminal, the depolarisation opens voltagegated calcium channels, thus leading to an influx of calcium. The elevated calcium levels subsequently cause the release of neurotransmitter (Katz and Miledi, 1969). Neurotransmitters are stored in vesicles, which have to undergo a series of preparatory steps ("docking" and "priming") before fusing with the membrane at specialised areas called active zones. Many of the maturation steps of a vesicle are intrinsically slow. It may take up to several minutes until a newly generated vesicle is attached to the membrane and ready to fuse (Sorensen, 2004). To enable fusion of vesicles on the observed microsecond time scale after elevation of $\mathrm{Ca}^{2+}$ in the terminal (Borst and Sakmann, 1996; Sabatini and Regehr, 1996), synapses contain a set of primed vesicles that are ready to fuse as soon as calcium ions bind to the sensor. This set of vesicles is called the "readily releasable pool" (RRP).

After fusion, the membrane is retrieved via endocytosis, fuses with the endosome and buds off again to form new vesicles (reviewed in Südhof (2004)).

Calcium ions play a variety of roles in the regulation of neurotransmitter release (reviewed in (Neher and Sakaba, 2008)). The depolarisation of the synaptic membrane during an action potential opens voltage gated-calcium channels, mainly of the P/Q and $\mathrm{N}$ type. At most synapses, the membrane voltage is so positive during the peak of the action potential that the driving force for calcium is relatively low. Substantial calcium entry thus occurs during the falling phase of the action potential and causes a part of the synaptic delay (Lisman et al., 2007). Interestingly, at cerebellar synapses, relevant calcium entry occurs already at the peak of the action potential. A possible explanation might be that fast $\mathrm{K}^{+}$channels prevent a high overshoot, thus keeping the driving force for $\mathrm{Ca}^{2+}$ ions high (Sabatini and Regehr, 1996; Sabatini and Regehr, 1999). After an action potential, release of synaptic vesicles occurs first in a brief burst, the so-called synchronous release, followed by a decaying tail of asynchronous release.

The fast synchronous vesicle release from a synapse is also possible because the $\mathrm{Ca}^{2+}$ concentration does not need to rise uniformly throughout the cytoplasm. The elevated concentration in close vicinity to the clustered $\mathrm{Ca}^{2+}$ channels at the active zone form a very short lived microdomain, where calcium concentrations can reach levels of up to $200 \mu \mathrm{M}$ in the squid giant synapse and up to 10-25 $\mathrm{M}$ at mammalian central synapses (Llinas et al., 1992; Mintz et al., 1995; Naraghi and Neher, 1997; Bollmann et al., 2000; Schneggenburger and Neher, 2000; Serulle et al., 2007). Determining the exact spatial and temporal dimensions of such a microdomain is not straightforward, due to their very small size and short duration. By calcium uncaging experiments in the calyx of Held, it was possible to measure the relationship between 
intracellular $\mathrm{Ca}^{2+}$ and vesicle release. These results were used to deduce the amplitude and temporal half-width of the microdomains caused by an action potential (Bollmann et al., 2000; Schneggenburger and Neher, 2000). The very fast time course $(400 \mu$ s half width) of the elevation was confirmed by Bollmann and Sakmann (2005), who showed that longer $\mathrm{Ca}^{2+}$ transients would result in prolonged rise times of excitatory postsynaptic currents (EPSCs).

This already indicates that the waveform and the time course of the ESPSC is tightly coupled to the action potential waveform (Bollmann and Sakmann, 2005).

Studies in Aplysia found that serotonin closes potassium channels and thus broadens the action potential, leading to enhanced calcium influx and neurotransmitter release (Augustine, 1990; Byrne and Kandel, 1996). The influence that spike broadening has on transmitter release depends on the presynaptic calcium channels and on the sensitivity of the release apparatus. In the squid, the main effect of an increased action potential width is the opening of more calcium channels. In the synapses formed by cerebellar granule cells of the rat, spike broadening caused an increased calcium influx by increasing the opening time of the channels without affecting greatly the peak amplitude (Sabatini and Regehr, 1997). Use-dependent changes in the action potential wave form influence the synaptic strength also in the hippocampal mossy fibre synapse and in the calyx of Held (Wheeler et al., 1996; Borst and Sakmann, 1999; Geiger and Jonas, 2000; Ishikawa et al., 2003).

Sabatini and Regehr (1997) showed that release at the parallel fibre - Purkinje cell synapse depends more on the total calcium influx than on the peak current and that there is a linear relationship between AP width and calcium entry in this terminal, while the calcium entry and release were best fitted with by a power law (Mintz et al., 1995). The power law of the form

$$
\text { Release }=k \cdot\left(C a_{\text {influx }}^{2+}\right)^{n}
$$

reflects that multiple calcium ions work together to trigger release (Dodge and Rahamimoff, 1967). Here, $k$ is a constant and $n$ is the slope of the linear fit when plotted on a doublelogarithmic scale. Depending on the study, it ranges between 2.5 and 4 (Mintz et al., 1995; Sabatini and Regehr, 1997; Foster et al., 2005). Formula (1) was determined by modulating presynaptic calcium entry in a variety of ways, such as reducing the extracellular calcium concentration, blocking $\mathrm{Ca}^{2+}$ channels with $\mathrm{Cd}^{2+}$ or selectively blocking families of channels with toxins. Like this, it was found that the set of $\mathrm{Ca}^{2+}$ channels in the presynaptic terminal is different from that in the granule cell soma and that $\omega$-Aga-VIA sensitive channels are more efficient at triggering release at this synapse. The parallel fibre - Purkinje cell synapse is very small, so a direct control over intracellular calcium levels is difficult. In the calyx of Held, $\mathrm{Ca}^{2+}$ uncaging studies were used to assess the calcium dependence of transmitter release (Bollmann et al., 2000; Schneggenburger and Neher, 2000). The relationship between intracellular $\mathrm{Ca}^{2+}$ $\left(\mathrm{Ca}_{\mathrm{i}}\right)$ and release was highly non-linear, with a high cooperativity in the range of $2-10 \mu \mathrm{M}$ and 
a low cooperativity for concentrations $\leq 1 \mu \mathrm{M}$. Like in the cerebellum, the relationship could be fitted with a power law with exponents between 3 and 6 . However, for low concentrations the power law did not provide an accurate explanation. Lou et al. (2005) suggested an allosteric model with five calcium-binding-sites, which adds a rate constant that allows fusion of vesicles without bound calcium. In this model, only one calcium sensor is needed. Another study by Sun et al. (2007) explained the deviations from the power law with the actions of a second highaffinity calcium sensor.

The quantal theory introduced by Jose del Castillo and Bernard Katz (1954) lead to the establishment of the concept of synaptic strength, which states that the postsynaptic response $\mathrm{R}$ is the product of three basal parameters of a synapse; the number of releasable quanta $(\mathrm{N})$, the probability to release a synaptic vesicle $\mathrm{p}_{\mathrm{r}}$ and the quantal size $\mathrm{q}$ (Zucker, 1973). The identity of $\mathrm{N}$ is still not well defined; it can refer to the number of releasable vesicles, the number of release sites or the number of active zones. The quantal size $\mathrm{q}$ is the postsynaptic response to the release of a single vesicle. The release of a vesicle following an action potential is a binomial process with release probability $\mathrm{p}_{\mathrm{r}}$. Based on the observation that the number of quantal peaks in the postsynaptic response amplitude histogram was equal to the anatomically observed synaptic connections, it was postulated that only one vesicle can be released per release site and action potential (Korn et al., 1981; Stevens and Wang, 1995; Buhl et al., 1997; Silver et al., 2003; Biró et al., 2005). This reduces the computational power of a synapse and makes transmission crucially dependent on vesicle replenishment (Stevens and Wang, 1995; Dobrunz and Stevens, 1997). At other synapses, it is well-established that multiple vesicles can be released by one action potential, e.g. at the ribbon synapse on AII amacrine cells (Singer et al., 2004), some synapses in the hippocampus (Tong and Jahr, 1994; Oertner et al., 2002), the climbing fibre Purkinje cell synapse (Wadiche and Jahr, 2001), and the parallel fibre - Purkinje cell synapse (Foster et al., 2005).

The amount of neurotransmitter that is released is proportional to the fraction of occupied postsynaptic receptors. If this fraction is large, the additional release of vesicles does not lead to a further increase of the postsynaptic current; the receptors are saturated. Further, AMPA receptors show desensitisation upon prolonged exposure to glutamate (Trussell and Fischbach, 1989; Jones and Westbrook, 1996), thus adding a further mechanism to limiting the size of the postsynaptic EPSC.

The reliable transmission of a train of action potentials requires a constant replenishment of releasable vesicles. Dittman and Regehr (1998) found that recovery from depression at the climbing fibre - Purkinje cell synapse occurs on three time scales, the fastest of which is dependent on residual calcium that remains in the terminal after an action potential. They suggest an involvement of $\mathrm{Ca}^{2+}$ in endocytosis of vesicular membrane, as this has been described as the rate-limiting factor in recovery from exocytosis and the time courses are 
identical. Alternatively, residual calcium might drive the shift of a temporarily refractory release site (Dobrunz et al., 1997) to a release-competent site.

\subsection{Short-term plasticity}

The ability of a neuron to adapt its output as response to changes in the input frequency or intensity enables the nervous system to perform the ultra-fast computations necessary to react to the ever-changing environment. The modulation of synaptic strength on a milliseconds to seconds time scale is called short-term plasticity and was first described in the neuromuscular junction (Eccles et al., 1941). During prolonged stimulation, an increase in the postsynaptic response was observed. This "facilitation" is one of the two manifestations of short-term plasticity (STP). The other form represents a decrease in the postsynaptic response after a first pulse and is called depression. Facilitation and depression are interlaced processes in a synapse, and they both shape the response measured on the postsynaptic side. This leads to a broad variety of possible outcomes, in which either facilitation or depression dominates, or where a postsynaptic response is first enhanced and later depressed (Figure 1). During the years since the first description of facilitation, a variety of other short term modulations of synaptic strength have been described, which differ in their specific outcome and time scale and will not be further addressed in this thesis.
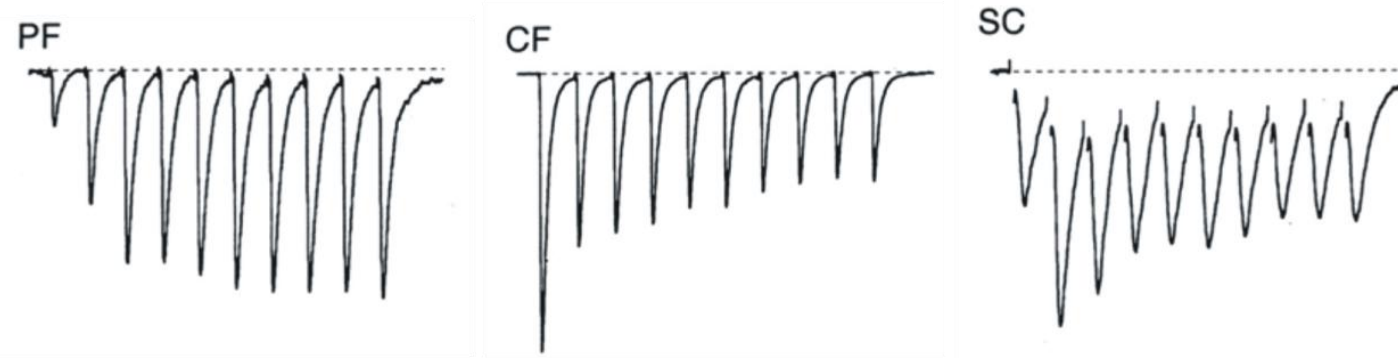

$40 \mathrm{msec}$

Figure 1. The different forms of short-term plasticity. Three different synapses show three different forms of short-term-plasticity upon stimulation with a $50 \mathrm{~Hz}$ train. The parallel fibre - Purkinje cell synapse (PF, left) shows robust facilitation, the climbing fibre - Purkinje cell synapse (CF, middle) depresses and the Schaffer collateral (SC, right) first facilitates and then depresses. Adapted from Dittman et al. (2000).

A transient increase in $\mathrm{p}_{\mathrm{r}}$, leading to an enhanced release of transmitter-containing vesicles has been shown to be the basis of facilitation. If this increase is not accompanied by 
replenishment of the pool of releasable vesicles, the synapse will start to depress as the vesicle pool is depleted (Zucker and Regehr, 2002). This already points to the finding that STP is of presynaptic origin, however postsynaptic mechanisms like receptor saturation (Tong and Jahr, 1994) or desensitisation (Trussell and Fischbach, 1989; Jones and Westbrook, 1996) also shape the response to a stimulus train and can lead to a decrease in the response amplitude.

Since the release of neurotransmitter is so tightly related to intracellular $\mathrm{Ca}^{2+}$ concentrations, a role for $\mathrm{Ca}^{2+}$ in facilitation is not surprising. The experiments by Katz and Miledi (1968) laid the basis for the theory of calcium-dependence of facilitation. Several possibilities to increase the $\mathrm{Ca}^{2+}$ concentration during repeated activity are imaginable. Firstly, the action potential could be broadened during a stimulus train (e.g.(Klein and Kandel, 1980; Augustine, 1990). This would lead to an increased $\mathrm{Ca}^{2+}$ influx and thus to enhanced transmitter release. In the mammalian nervous system, this was found at pituitary terminals (Jackson et al., 1991), at hippocampal mossy fibre terminals (Wheeler et al., 1996; Geiger and Jonas, 2000), and in the calyx of Held (Borst and Sakmann, 1999; Ishikawa et al., 2003) but not at the parallel fibre Purkinje cell synapse (Sabatini and Regehr, 1997). Secondly, an increased $\mathrm{Ca}^{2+}$ influx through voltage-gated $\mathrm{Ca}^{2+}$ channels was described in the calyx of Held (Borst and Sakmann, 1998; Cuttle et al., 1998), however, also this mechanisms were found not to be sufficient to explain the sometimes very high facilitation rates of up to 500\% (Zucker and Regehr, 2002). The most widely accepted hypothesis is that $\mathrm{Ca}^{2+}$ remaining in the terminal after an action potential causes facilitation (Katz and Miledi, 1968; Kamiya and Zucker, 1994; Regehr et al., 1994; Atluri and Regehr, 1996). In the beginning of the "residual calcium hypothesis" it was proposed that residual calcium $\left(\mathrm{Ca}_{\text {res }}\right)$ simply adds up to the $\mathrm{Ca}^{2+}$ entering during a depolarisation (Katz and Miledi, 1968). The idea was soon questioned, since $\mathrm{Ca}_{\text {res }}$ is two orders of magnitude smaller than the local $\mathrm{Ca}^{2+}$ signal triggering release. This led to the idea of a second calcium sensor with a high affinity that acts at some spatial distance to the main sensor and correspondingly gets activated after the microdomain $\mathrm{Ca}^{2+}$ has equilibrated with the cytosol (Yamada and Zucker, 1992).

The residual calcium hypothesis was supported by the finding that EGTA in the presynaptic terminal removed most of the facilitation and greatly reduced $\mathrm{Ca}_{\text {res }}$. Due to its slow kinetics, EGTA does not interfere with the peak $\mathrm{Ca}^{2+}$ signal triggering phasic release but buffers $\mathrm{Ca}_{\text {res }}$ in a dose-dependent manner.

Facilitation depends on the interval with which the stimuli arrive at the synapse and has been shown to decay nearly exponentially in the parallel fibre - Purkinje cell synapse. This decay has a very similar time course to the decay of $\mathrm{Ca}_{\text {res }}$, adding further evidence to the importance of $\mathrm{Ca}_{\mathrm{res}}$. However, a small fraction of facilitation persisted, which was attributed to the intrinsic kinetics of a high-affinity $\mathrm{Ca}^{2+}$ sensor for facilitation (Regehr and Atluri, 1995; Atluri and Regehr, 1996). 
Changing $\mathrm{Ca}^{2+}$ influx by alterations of external $\mathrm{Ca}^{2+}\left(\mathrm{Ca}_{\mathrm{e}}\right)$ or block of $\mathrm{Ca}^{2+}$ channels has also been used to evaluate the relation of STP and $\mathrm{Ca}_{\mathrm{i}}$. Less $\mathrm{Ca}_{\mathrm{i}}$ reduced the release probability and with that depression caused by depletion of vesicles. This can resemble facilitation, although a genuine increase in facilitation due to desaturation of the release machinery is also possible. At synapses whose release apparatus is far from saturation and with little depression due to depletion, a reduction of $\mathrm{Ca}_{\mathrm{e}}$ can also cause a decrease of facilitation, as $\mathrm{Ca}_{\text {res }}$ driving facilitation is consequently also reduced (Zucker and Regehr, 2002).

Endogenous $\mathrm{Ca}^{2+}$ binding proteins can influence STP. The genetic deletion of the $\mathrm{Ca}^{2+}$ binding protein parvalbumin increased facilitation at cerebellar interneuron - Purkinje cell synapses (Caillard et al., 2000). When endogenous buffers like parvalbumin get saturated, additional $\mathrm{Ca}^{2+}$ will add nonlinearly to the microdomain $\mathrm{Ca}^{2+}$ and have an impact of STP (Neher, 1998; Blatow et al., 2003).

Taken together, STP is highly complex and the processes that govern it are far from understood. By purely postsynaptic recordings, it is difficult to understand and identify the molecular processes that cause a change in STP. As facilitation and depression are intermingled, changing one of them will result in a different behaviour of the other, as shown above on the example of changed extracellular calcium. Therefore, incorporating additional techniques like presynaptic calcium imaging into a study of synaptic plasticity is of high usefulness.

\subsection{Potassium channels in the central nervous system}

Potassium channels are the largest and most diverse family of ion channels, with more than 80 genes identified in mammals. This large variety enables each cell type to select a specific subset of channels that meets its specific needs. Potassium channels can be divided in classes depending on their structure and function. A large class is formed by the voltage-gated potassium channels. In neurons, they are important modulators of the resting potential, control excitability and repolarise the membrane after an action potential (Hille, 2001). The first potassium channel cloned was a Drosophila channel of the Shaker family (Papazian et al., 1987), a group of channels whose mutation caused leg shaking in anaesthetised flies (Kaplan and Trout, 1969).When expressed in Xenopus oocytes, the channel turned out to conduct a fastinactivating $\mathrm{K}^{+}$current. This A-type current has also in mammals a very important function in repolarising the action potential. However, as described in section 1.2, A-type currents can show cumulative inactivation during trains of action potentials, thus causing a widening of the pulse. Soon after the discovery of Shaker, related channels were cloned and named accordingly Shal, Shab, and Shaw. They correspond to the mammalian families Kv1 to Kv4 and encode currents that range from fast inactivating to slow delayed rectifier. The delayed rectifier channels are the 
most common voltage gated $\mathrm{K}^{+}$channels in mammalian axonal membranes. Their activation speed varies from very fast to rather slow and they generally do not show inactivation.

Potassium channels which open close to the resting potential or and/or show little voltage dependence are important for setting the membrane potential. The membrane potential governs for example the resting $\mathrm{Ca}^{2+}$ level and thus indirectly modulates the probability of neurotransmitter release (Awatramani et al., 2005; Hori and Takahashi, 2009; Christie et al., 2011)

\subsection{Ether-à-go-go channels}

\subsubsection{Properties of Eag channels}

Ether-à-go-go 1 ( $\mathrm{K}_{\mathrm{V}} 10.1, K C N H 1$, referred to as Eag1 from now on) is the founding member of the EAG-family of potassium channels. This family comprises three subfamilies: the EAG subfamily with Eag1 and Eag2 (KCNH5), the ERG (Eag-related-gene) subfamily with Erg1-3 and the ELK (eag-like- $\mathrm{K}^{+}$-channels) subfamily with Elk1a, 1b and 3 (Bauer and Schwarz, 2001).

An Eag channel was first described in Drosophila melanogaster, where its mutation caused leg-shaking under ether anaesthesia (Kaplan and Trout, 1969). Cloning and analysis of the locus revealed a protein with characteristics resembling voltage-gated ion channels (Bruggemann et al., 1993; Warmke and Ganetzky, 1994). Homologues of the channel have been identified in mammals (rat (Ludwig et al., 1994), mouse (Warmke and Ganetzky, 1994; Robertson et al., 1996), human (Occhiodoro et al., 1998) and bovine forms (Frings et al., 1998)) and in nematodes (egl-2, (Weinshenker et al., 1999)). All of them have in common that they form tetramers, each subunit consisting of six transmembrane segments (S1-S6) with long intracellular N- and C-termini (Bauer and Schwarz, 2001). On both termini, several regulatory domains are found, which differ in their composition and functionality between the species. The C-terminus of Drosophila Eag (dEag) can bind to CaMKII (Wang et al., 2002) and serve as a platform for CaMKII-activation in the absence of calmodulin (Sun et al., 2004). dEag channels are further regulated by cyclic nucleotides and permeable to calcium ions (Bruggemann et al., 1993). Mammalian Eag channels on the other hand have a shorter C-terminus, which lacks the residues responsible for CaMKII interaction, are not regulated by cyclic nucleotides and are non-permeable to calcium (Ludwig et al., 1994; Warmke and Ganetzky, 1994; Robertson et al., 1996; Brelidze et al., 2009). They have, however, three calmodulin binding domains (Ziechner et al., 2006). A cartoon of an Eag1 subunit is shown in Figure 2. The closely related Eag2 channel (Saganich et al., 1999; Ludwig et al., 2000) shows $73 \%$ sequence identity to Eag1 and has been shown to form heteromers (Schönherr et al., 2002a). 
In heterologous expression systems, mammalian Eag1-mediated currents are rather slowly activating outward currents that do not inactivate (Ludwig et al., 1994; Robertson et al., 1996). They are regulated by a range of agents such as extracellular $\mathrm{Mg}^{2+}$ and $\mathrm{H}^{+}$-ions (Terlau et al., 1996) and submicromolar levels of intracellular calcium via several calmodulin molecules binding to the N- and C-terminus (Stansfeld et al., 1996; Meyer and Heinemann, 1998; Ziechner et al., 2006; Gonçalves and Stühmer, 2010). Unlike most other potassium channels, Eag1 is permeable to caesium ions (Pardo et al., 1998).

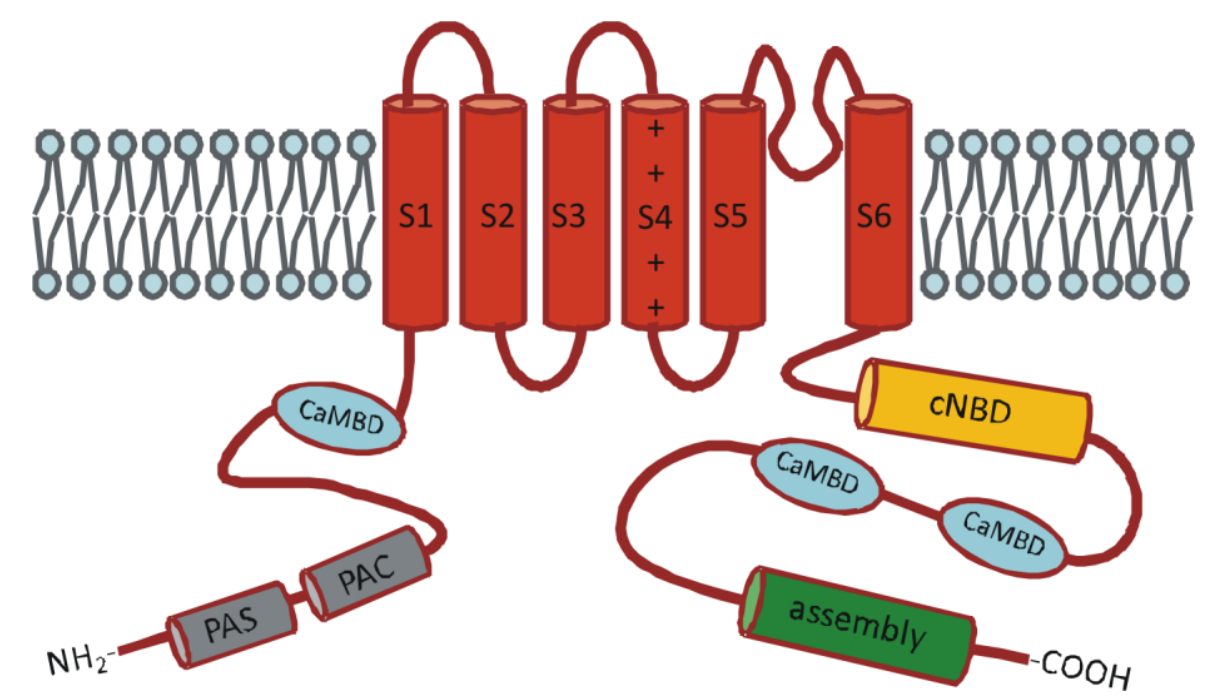

Figure 2. A cartoon of an Eag1 subunit. Some of its regulatory regions are included. S1 - S4, transmembrane segments. PAS/PAC, the Per-Arnt-Sim domain. CaMBD, Calmodulin binding domains. cNBD, non-functional cyclic nucleotide binding domain. Assembly, the coiled-coil tetramerisation domain.

The most remarkable property of Eag1 currents is the strong dependence of the activation kinetics on the holding potential, an effect reminiscent of the one described by Cole and Moore (Cole and Moore, 1960; Ludwig et al., 1994). The effect is so strong that it can serve as a hallmark to identify native Eag currents (Meyer and Heinemann, 1998) and positively correlated with concentration of extracellular $\mathrm{Mg}^{2+}$ ions (Terlau et al., 1996). The Cole-Moore shift is thought to be due to the existence of more than one voltage-gated closed state that has to be passed during opening from more hyperpolarised potentials, while at less polarised potentials only one state transition has to take place. For human Eag1 channels, two gating modes have been proposed; one slow, sigmoidal transition taking place at hyperpolarised potentials and a faster transition at more depolarised potentials (Schönherr et al., 2002b).

Current through Eag1 channels is blocked by extracellular TEA with an $\mathrm{IC}_{50}$ between 7 and 28mM, (Ludwig et al., 1994; García-Ferreiro et al., 2004). No highly specific chemical blockers are available; the H1 Histamine-receptor antagonist astemizole is the only compound showing a selective blockade of all channels of the EAG family. It permeates the lipid bilayer and can bind to the open channel from the intracellular side. Imipramine and other organic compounds provide a reliable, but unspecific block of Eag channels (García-Ferreiro et al., 2004). 
The only known way to specifically block Eag1 currents is application of a monoclonal antibody against the extracellular pore region (mAB56), which binds only during the open state of a channel and blocks $60 \%$ of the current after 20 minutes incubation with regularly repeated 1-s depolarisations of the cell (Gómez-Varela et al., 2007).

\subsubsection{Expression and physiological role}

\section{Drosophila melanogaster}

The loss of functional Eag channels in Drosophila (Kaplan and Trout, 1969) causes rhythmic leg-shaking under ether anaesthesia, which gave the channel its name. Work by Ganetzky and $\mathrm{Wu}$ (1983) and Wu et al (1983) showed that deletion of Eag causes high frequency firing of spontaneous action potentials in the motor neurons and an increase in the amplitude and duration of the endplate potential at the neuromuscular junction, thus causing enhanced neurotransmitter release. It is present in the axons and terminals of motor nerves innervating body wall muscles of third instar larvae (Wang et al., 2002) and colocalises with synaptobrevin (Sun et al., 2004). Further, dEag has been implicated in transducing a subset of odours in the antennae (Dubin et al., 1998) and a form of associative learning (Griffith et al., 1994).

\section{Mammalian Eag1}

The expression of mammalian Eag1 is normally restricted to the CNS (Ludwig et al., 1994; Saganich et al., 2001; Martin et al., 2008), except for a transient expression immediately before the fusion of human myoblasts (Bijlenga et al., 1998) and ectopic expression in about $75 \%$ of human tumours (Pardo et al., 1999). In the brain, both RNA and protein are widely distributed. Highest expression of RNA is seen in the cerebral cortex, the olfactory bulb, the CA2 and CA3 region and the dentate gyrus of the hippocampus and the granule layer of the cerebellum (Ludwig et al., 2000; Saganich et al., 2001). The latter study did not observe a signal in inhibitory interneurons as determined by immunostaining. An immunohistochemistry study (Martin et al., 2008) revealed some interesting differences between mRNA and protein expression. In many regions, the observed staining matched the mRNA expression, for example in the cerebral cortex and the olfactory bulb. In the hippocampus, protein was detected in all regions, while mRNA was obviously weaker in the CA1 than in CA2 and CA3 regions. Further, a staining was observed in the brainstem, where no mRNA had been detected and, most strikingly, in the Purkinje layer of the cerebellum, but no protein in the granule cell layer. This is exactly opposite to the observed mRNA pattern. 
There are controversial results concerning the exact subcellular localisation of Eag1. A study by Jeng et al. (2005) reported Eag1 mainly in postsynaptic regions of hippocampal neurons. This was concluded from the staining observed "opposite" of presynaptic markers. Gómez-Varela et al. (2010) used single particle tracking on cultured hippocampal neurons to determine the subcellular localisation of the channel and its mobility. The majority of the Eag1 was detected in axonal regions, and it was shown that the lateral diffusion of the channel is greatly diminished once it entered synaptic regions. This was suggested to be mediated by fast interaction with cytoskeletal components. The same study also showed electron micrographs of synapses, where Eag1 was labelled with gold particle-coupled antibodies and detected in the presynaptic terminals.

The predominantly cytoplasmic signal for Eag1 as seen by Martin et al. (2008) and partly also in the immunocytochemistry study by Jeng et al. (2005) might be due to the very high turnover rate of the channel. About $1 \%$ of surface molecules per minute get internalised, and about $30 \%$ of these are reinserted into the membrane within 30 minutes (Kohl et al., 2011).

Most research concerning Eag1 is focused on its role in oncogenesis, very few studies deal with Eag1 and its function in the central nervous system. In fact, the only studies about mammalian Eag1 investigate its expression after transient ischemia (de Oliveira et al., 2012) and in brains of isolated reared rats (Martin et al., 2010) and did not show any involvement of the channel.

In summary, there is no knowledge about the physiological function of the channel, while the precise subcellular localisation remains under debate.

\subsubsection{The cerebellum as a model system}

The largest part of the experimental work presented here was performed in the cerebellar cortex, which is very suitable for electrophysiological recordings in acute slices with the aim to evaluate synaptic properties.

The cerebellum is thought to underlie fine-tuning of movements and posture as well as motor learning. The cerebellar cortex has a three-layered structure and is stereotypically organised throughout the organ. The layers are easily identifiable even at low magnification and contain specific cell types at specific locations. All input to the cerebellum arrives via the mossy fibres to the granule cells. The granule cells send their axons into the molecular layer, where they bifurcate to form parallel fibres. Theses fibres can run up to several millimetres along the horizontal axis of the cortex, thereby forming excitatory synapses on Purkinje cell dendrites and molecular layer interneurons; stellate cells and basket cells (Palay and Chan-Palay, 1974). These interneurons form a feed-forward inhibitory circuit on Purkinje cells as well as other 
interneurons (Bao et al., 2010). Purkinje cells are the largest neurons in the mammalian brain and form a monolayer between the granule- and molecular layer. They have an extensive dendritic tree that extends in the molecular layer, perpendicular to the direction of the parallel fibres. One Purkinje cell can receive input from up to 180,000 granule cells, while in general each granule cell makes only one synapse on a given Purkinje cell. Purkinje cells are the only output cells in the cerebellar cortex and send their axons to the deep cerebellar nuclei, where they inhibit the tonically firing neurons of the nuclei. They receive further excitatory input via the climbing fibre from the inferior olive. Each climbing fibre innervates a single Purkinje cell and forms multiple synapses on the soma and proximal dendrite (Kandel et al., 2000).

\subsection{Aim of the study}

The majority of research concerning Eag1 deals with its implication in oncogenesis (e.g. Pardo et al., 1999; Gómez-Varela et al., 2007; Downie et al., 2008) or its biophysical properties (e.g. Ludwig et al., 1994; Terlau et al., 1996; Schönherr et al., 2002b; Lörinczi et al., 2009), while the studies about Eag1 in the CNS are sparse. The existing studies focused mainly on its expression pattern in the brain (Saganich et al., 2001; Jeng et al., 2005; Martin et al., 2008). While the expression in neurons is undebated, there are two contradicting studies regarding the exact subcellular localisation of the channel. While Jeng et al. (2005) claim postsynaptic expression, Gómez-Varela et al. (2010) report preferably presynaptic localisation in hippocampal neurons. Both studies used immunostainings, the only study based on functional properties reported Eag1-like currents in the inner nuclear membrane of transfected cells (Chen et al., 2011). Two studies about Eag1 function in the mammalian CNS found no participation of Eag1 in stress- or ischemia-related pathways (Martin et al., 2010; de Oliveira et al., 2012). No study has dealt with the physiological role of Eag1 in brain or reported a native Eag1-current in a neuron.

The first step in elucidating the physiological role of Eag1 in the CNS was therefore to determine the site of functional Eag1 expression in neurons. This was accomplished by western blot and by electrophysiological measurements on the pre- and postsynaptic terminals in the rat calyx of Held synapse in the brainstem.

To further analyse Eag1 function in neurons, the cerebellum was used as a model system. Since mRNA or protein was reported in the cell bodies of granule- and Purkinje cells, their electrophysiological properties were evaluated and compared between WT and Eag1 knockout (KO) mice. 
Synaptic transmission between several types of cerebellar neurons was analysed concerning EPSC kinetics and short-term plasticity. Further, two-photon calcium imaging was employed to visualize and evaluate calcium influx into presynaptic terminals of WT and Eag1 KO mice.

To my knowledge, this is the first study measuring an Eag1 compatible current in a neuron. In addition, no study exists that probes the physiological function of Eag1 in the mammalian CNS. It was possible to describe the consequences of the loss of Eag1 using a combination of electrophysiology and imaging, showing the importance of Eag1 in synaptic transmission. 


\section{Materials and Methods}

\subsection{Solutions}

Table 1: Solutions used in this study

\begin{tabular}{|c|c|c|}
\hline $\begin{array}{l}\text { Name } \\
\end{array}$ & Component & Concentration \\
\hline \multicolumn{3}{|l|}{ Immunohistochemistry } \\
\hline PBS & $\begin{array}{l}\mathrm{NaCl} \\
\mathrm{Na}_{2} \mathrm{HPO}_{4} \\
\mathrm{KCl} \\
\mathrm{KH}_{2} \mathrm{PO}_{4} \\
\mathrm{pH} 7.3\end{array}$ & $\begin{array}{l}137 \mathrm{mM} \\
43 \mathrm{mM} \\
27 \mathrm{mM} \\
15 \mathrm{mM}\end{array}$ \\
\hline Fixation solution & $\begin{array}{l}\text { Paraformaldehyde } \\
\text { PBS }\end{array}$ & $4 \%$ \\
\hline Blocking solution & $\begin{array}{l}\text { Horse serum } \\
\text { TritonX-100 } \\
\text { PBS }\end{array}$ & $\begin{array}{l}4 \% \\
0.2 \%\end{array}$ \\
\hline Permeabilization solution & $\begin{array}{l}\text { TritonX-100 } \\
\text { PBS }\end{array}$ & $0.4 \%$ \\
\hline Solution for primary antibody & $\begin{array}{l}\text { Horse serum } \\
\text { TritonX-100 } \\
\text { PBS }\end{array}$ & $\begin{array}{l}1 \% \\
0.05 \%\end{array}$ \\
\hline Solution for secondary antibody & $\begin{array}{l}\text { Horse serum } \\
\text { PBS }\end{array}$ & $1,5 \%$ \\
\hline
\end{tabular}

\section{Biochemistry}

TBE

Tris

$89 \mathrm{mM}$

Boric acid

$89 \mathrm{mM}$

EDTA

$\mathrm{pH} 8,0$

$1 \mathrm{mM}$

Lysis buffer for protein extraction

$\begin{array}{ll}\text { Tris- } \mathrm{HCl} & 25 \mathrm{mM} \\ \mathrm{NaCl} & 75 \mathrm{mM} \\ \text { TritonX-100 } & 0.5 \% \\ \text { EDTA } & 2.5 \mathrm{mM} \\ \text { pH } 8.0 & \end{array}$

NuPAGE LDS Sample Buffer (4x)

TrisHCl

$106 \mathrm{mM}$

Tris base

$141 \mathrm{mM}$

LDS

$2 \%$

Glycerol

$10 \%$

EDTA

$0.51 \mathrm{mM}$

SERVA Blue G250

$0.22 \mathrm{mM}$

Phenol Red

$0.175 \mathrm{mM}$ 


\begin{tabular}{|c|c|c|}
\hline Loading buffer & $\begin{array}{l}\text { NuPage LDS Sample Buffer } \\
(4 \mathrm{x}) \\
\mathrm{NuPage} \text { Reducing Agent (10x) } \\
\mathrm{ddH}_{2} \mathrm{O} \\
\text { sample }\end{array}$ & $\begin{array}{l}2.5 \mu 1 \\
1 \mu 1 \\
6.5-x \mu 1 \\
x \mu 1\end{array}$ \\
\hline Running buffer upper chamber & $\begin{array}{l}\text { Tris-Acetate buffer }(20 x) \\
\mathrm{ddH}_{2} \mathrm{O} \\
\text { NuPage Antioxidant }\end{array}$ & $\begin{array}{l}10 \mathrm{ml} \\
190 \mathrm{ml} \\
500 \mu \mathrm{l} \\
\end{array}$ \\
\hline Running buffer lower chamber & $\begin{array}{l}\text { Tris-Acetate buffer (20x) } \\
\mathrm{ddH}_{2} \mathrm{O}\end{array}$ & $\begin{array}{l}40 \mathrm{ml} \\
760 \mathrm{ml}\end{array}$ \\
\hline Transfer buffer & $\begin{array}{l}\mathrm{ddH}_{2} \mathrm{O} \\
\text { Methanol } \\
\mathrm{NaHCO}_{3} \\
\mathrm{Na}_{2} \mathrm{CO}_{3} \\
\mathrm{SDS} \\
\end{array}$ & $\begin{array}{l}800 \mathrm{ml} \\
200 \mathrm{ml} \\
10 \mathrm{mM} \\
3 \mathrm{mM} \\
0.01 \% \\
\end{array}$ \\
\hline TBST & $\begin{array}{l}\text { Tris } \\
\mathrm{NaCl} \\
\text { Tween-20 }\end{array}$ & $\begin{array}{l}20 \mathrm{mM} \\
150 \mathrm{mM} \\
0.05 \%\end{array}$ \\
\hline
\end{tabular}

\section{Electrophysiology}

\begin{tabular}{|c|c|c|}
\hline Sucrose slicing solution & $\begin{array}{l}\mathrm{NaCl} \\
\text { Sucrose } \\
\mathrm{NaCO}_{3} \\
\mathrm{NaH}_{2} \mathrm{PO}_{4} \\
\mathrm{KCl} \\
\mathrm{Glucose} \\
\mathrm{CaCl}_{2} \\
\mathrm{MgCl}_{2} \\
\text { Magic supplement }\end{array}$ & $\begin{array}{l}60 \mathrm{mM} \\
120 \mathrm{mM} \\
25 \mathrm{mM} \\
1.25 \mathrm{mM} \\
2.5 \mathrm{mM} \\
25 \mathrm{mM} \\
0.1 \mathrm{mM} \\
3 \mathrm{mM} \\
5 \mathrm{ml} \\
\end{array}$ \\
\hline Artificial cerebrospinal fluid (aCSF) & $\begin{array}{l}\mathrm{NaCl} \\
\mathrm{KCl} \\
\mathrm{NaHCO}_{3} \\
\mathrm{NaH}_{2} \mathrm{PO}_{4} \\
\mathrm{Glucose} \\
\mathrm{CaCl}_{2} \\
\mathrm{MgCl}_{2} \\
\text { Magic } \text { supplement }\end{array}$ & $\begin{array}{l}125 \mathrm{mM} \\
2.5 \mathrm{mM} \\
25 \mathrm{mM} \\
1.25 \mathrm{mM} \\
25 \mathrm{mM} \\
2 \mathrm{mM} \\
1 \mathrm{mM} \\
5 \mathrm{ml} \\
\end{array}$ \\
\hline $\begin{array}{l}\text { Magic supplement } \\
\text { (final concentration) }\end{array}$ & $\begin{array}{l}\text { L-ascorbic acid } \\
\text { Myo-inositol } \\
\text { Na-pyruvate }\end{array}$ & $\begin{array}{l}0.4 \mathrm{mM} \\
3 \mathrm{mM} \\
2 \mathrm{mM} \\
\end{array}$ \\
\hline $\mathrm{Cs}^{+}$-based intracellular solution (CIS) & $\begin{array}{l}\text { Cs-gluconate } \\
\mathrm{CsCl} \\
\text { Hepes } \\
\text { MgATP } \\
\text { NaGTP }\end{array}$ & $\begin{array}{l}135 \mathrm{mM} \\
5 \mathrm{mM} \\
10 \mathrm{mM} \\
5 \mathrm{mM} \\
0.5 \mathrm{mM}\end{array}$ \\
\hline
\end{tabular}


K-based intracellular solution

K-gluconate

$\mathrm{KCl}$

5

Hepes

10

MgATP

5

NaGTP

0.5

EGTA

$0.1-1$

intracellular solution for $\mathrm{Ca}^{2+}$-imaging

(K1)

K-gluconate

$150 \mathrm{mM}$

$\mathrm{NaCl}$

$10 \mathrm{mM}$

MgATP

3

$\mathrm{Na}_{3}$ GTP

0.3

Hepes

10

Oregon Green BAPTA-1

0.1

\subsection{Toxins}

Table 2: Toxins used in this study

\begin{tabular}{ll}
\hline \multicolumn{1}{c}{ Name } & Obtained from \\
\hline \hline Tetrodotoxin & Alomone \\
TEA-Cl & Merck \\
QX-314 (chloride salt) & Sigma \\
SR95531 (gabazine) & Tocris \\
\hline
\end{tabular}

\subsection{Antibodies}

Table 3: Primary antibodies used in this study. ${ }^{*} E P$, electrophysiology; WB, western blotting; IHC, immunohistochemistry

\begin{tabular}{|c|c|c|c|c|c|c|}
\hline Name & Host & epitope & clonality & dilution & application & obtained from \\
\hline mAB56 & Mouse & pore region of Eag1 & monoclonal & $1: 20$ & EP* & $\begin{array}{l}\text { L.A. Pardo (Gómez- } \\
\text { Varela et al., 2007) }\end{array}$ \\
\hline 9391 & Rabbit & C-terminus of Eag1 & polyclonal & $1: 1500$ & WB* & $\begin{array}{l}\text { L.A. Pardo (Napp et al., } \\
\text { 2005) }\end{array}$ \\
\hline actin & goat & actin & polyclonal & $1: 2000$ & WB & Abcam \\
\hline mAB62 & Mouse & Pore region of Eag1 & monoclonal & $1: 100$ & $\mathrm{IHC}^{*}$ & $\begin{array}{l}\text { L.A. Pardo (Gómez- } \\
\text { Varela et al., 2010) }\end{array}$ \\
\hline VGlut1 & $\begin{array}{l}\text { Guinea- } \\
\text { pig }\end{array}$ & $\begin{array}{l}\text { Vesicular glutamate } \\
\text { transporter } 1\end{array}$ & polyclonal & $1: 2000$ & IHC & Chemicon \\
\hline
\end{tabular}

\subsection{Primers}

Table 4: Primers used for genotyping

\begin{tabular}{ll}
\hline Primer 1 & CATGATGATTGGCTGTGAGTATG \\
Primer 2 & TGCGTACATGGTGCTTGATTTC \\
Primer 3 & CCCTCTTTCCACTAACAGCATC \\
\hline
\end{tabular}




\subsection{Genotyping}

\subsubsection{DNA isolation from mouse tails and Polymerase Chain Reaction (PCR)}

Mouse tails were incubated with $20 \mathrm{mg} / \mathrm{ml}$ protein kinase $\mathrm{K}$ for at least two hours at $56^{\circ} \mathrm{C}$, 1000rpm. After that, they were centrifuged at 16000x $g$ in an Eppendorf table centrifuge and the supernatant was transferred into a new tube. $400 \mu \mathrm{l}$ ice-cold ethanol were added and the sample mixed thoroughly. After centrifugation for $20 \mathrm{~min}$ at $16000 \mathrm{xg}$, the supernatant was discarded and the pellet was washed twice with $800 \mu$ of $70 \%$ ethanol. The sample was again centrifuged for $5 \mathrm{~min}$ at 16000x $\mathrm{g}$ and the supernatant discarded carefully to remove all ethanol. The pellet was dissolved in $80-100 \mu 1 \mathrm{H}_{2} \mathrm{O}$ and incubated a few minutes at $60^{\circ} \mathrm{C}, 300 \mathrm{rpm}$, to let any residual ethanol evaporate. The DNA was stored in the refrigerator until further usage. The concentration was not determined after isolation.

All primers for the genotyping PCR were obtained from Metabion (Table 4). Eag1 WT alleles were amplified by primers 1 and 3, Eag1 KO alleles by primers 2 and 3. The amplification procedure was identical for both genotypes as follows:

Step 1: 4 minutes at $95^{\circ} \mathrm{C}$

Step 2: $5 \times$ Touchdown cycle:

30 seconds at $95^{\circ} \mathrm{C}$

30 s at 64 to $60^{\circ} \mathrm{C}$, decreasing each round by $1^{\circ} \mathrm{C}$

30 s at $72^{\circ} \mathrm{C}$

Step 3: $25 \times$ amplification cycle:

30 s at $95^{\circ} \mathrm{C}$

30 s at $60^{\circ} \mathrm{C}$

30s at $72^{\circ} \mathrm{C}$

Step 4: 7 min at $72^{\circ} \mathrm{C}$

Step 5: maintaining the sample at $4^{\circ} \mathrm{C}$

The reaction mixture for each sample $(0.5 \mu 1 \mathrm{DNA})$ contained:

$0.5 \mu 1 \mathrm{dNTP}$ mixture, $10 \mathrm{mM}$ of each dNTP (Genecraft by Biotherm)

$2.5 \mu 1 \mathrm{Mg}^{2+}$ containing buffer (Qiagen)

$0.5 \mu 1$ primer $1(10 \mathrm{mM})$

$0.5 \mu 1$ primer $2(10 \mathrm{mM})$

$0.5 \mu 1$ primer $3(10 \mathrm{mM})$

$0.5 \mu 1$ Taq polymerase (Genecraft by Biotherm)

$20 \mu 1 \mathrm{H}_{2} \mathrm{O}$ 


\subsubsection{Agarose gel electrophoresis}

Agarose gel electrophoresis was used to separate DNA fragments obtained by PCR. Briefly, $1.5 \mathrm{~g}$ of agarose (Invitrogen) were mixed with TBE buffer and heated in a microwave until the agarose was completely dissolved. The agarose was poured in a chamber containing a comb with the desired number of pockets and $0.5 \mathrm{mg} / \mathrm{ml}$ ethidium bromide were added and thoroughly distributed. The gel was allowed to solidify for at least 20 minutes. The PCR product was mixed with $8 \mu 1$ running buffer (TBE), and loaded on the gel. The gel was run at $120 \mathrm{~V}$ for 10 to $15 \mathrm{~min}$ in TBE buffer. The ethidium bromide labelled DNA fragments were visualised under UV light.

\subsection{Immunohistochemistry}

For immunohistochemistry staining in the rat calyx of Held, $\mathrm{p} 9$ rats were decapitated, their brains extracted and immediately placed in fixation solution. After 24 hours, $60 \mu \mathrm{m}$ thick slices were cut on a vibratome (Campden Instruments) and collected in a 24-well plate containing PBS. The tissue was permeabilised in $0.4 \%$ Triton in PBS for $30 \mathrm{~min}$, followed by $30 \mathrm{~min}$ to $1 \mathrm{~h}$ blocking in blocking solution (Table 1). The primary antibodies were applied in $1 \%$ horse serum, $0.05 \%$ Triton in PBS overnight at $4{ }^{\circ} \mathrm{C}$. The next day, the slices were washed twice in PBS for ten minutes and the secondary antibodies (Alexa-488 coupled goat-anti-mouse and Alexa-564 coupled goat-anti-guinea pig, Invitrogen) were applied in 1.5\% horse serum for two hours at room temperature during gentle agitation. After washing twice with PBS for ten minutes, the slices were dipped in $\mathrm{ddH}_{2} \mathrm{O}$, mounted on glass slides and covered with the mounting medium Immu-Mount (Thermo Scientific) under a glass coverslip. Samples were allowed to dry for at least 12 hours at $4^{\circ} \mathrm{C}$. Imaging was performed with a Leica SP2 laser scanning confocal microscope and the obtained images were analysed with Fiji software package.

\subsection{Biochemical experiments}

\subsubsection{Preparation of protein homogenates}

For preparation of whole-brain homogenate, mice were killed by $\mathrm{CO}_{2}$ inhalation and their brains quickly removed and placed in an Eppendorf cup in liquid nitrogen. A Styrofoam bowl was filled with liquid nitrogen and a mortar placed inside. Like this, the brain was powdered at the lowest possible temperature to help preservation of membrane proteins. The powder was transferred to a glass tube containing $2.5 \mathrm{ml}$ lysis buffer (Table 1) per brain and homogenised by 
a motor-driven glass-teflon homogeniser. The sample was incubated on ice for 20 to 30 minutes and afterwards centrifuged at $14,000 \mathrm{x} g$ at $4^{\circ} \mathrm{C}$ for 15 minutes. The supernatant was transferred to a new tube and again centrifuged under the same conditions. This was repeated once more and the final supernatant frozen until used.

For lysis of cultured cells, cells were mechanically detached using a cell scraper and transferred with the medium to a centrifugation tube. After 2 minutes centrifugation at $600 \mathrm{~g}$, the supernatant was discarded and the cells resuspended in $1 \mathrm{ml}$ phosphate buffered saline (PBS, Table 1). The cells were centrifuged for 3 minutes at $600 \mathrm{x} g$ and the pellet again resuspended in $1 \mathrm{ml}$ PBS. These two steps were repeated and the triple volume of lysis buffer was added to the pellet. After 30 minutes incubation at room temperature, the cells were centrifuged for 15 minutes at maximal speed at $4^{\circ} \mathrm{C}$. The supernatant was collected and frozen until further use.

The protein concentrations were determined by using the BCA protocol according to the directions provided by the producer (Pierce).

Subcellular fractions were kindly provided by Dr. C. Biesemann, Dept. Molecular Neurobiology who performed subcellular fractionation according to the protocol reported in (Kalla et al., 2006).

\subsubsection{SDS-PAGE and western blotting}

With sodium-dodecyl-sulphate polyacrylamide gel electrophoresis (SDS-PAGE), proteins can be separated according to their molecular weight as they migrate through the pores of the gel in an electrical field. To prepare samples for separation in a SDS-PAGE, protein samples were mixed with LDS-loading-buffer (Table 1) and boiled for ten minutes before $15 \mu \mathrm{g}$ total protein were loaded on a 3-8\% gradient NuPAGE Tris-Acetate gel (Invitrogen). The gel chamber was filled with running buffer (Table 1) and the electrophoresis was performed at $150 \mathrm{~V}, 45 \mathrm{~mA}$ for 90 minutes. After separation, the proteins were transferred to a nitrocellulose membrane by a gradient electrophoresis. The starting voltage of $10 \mathrm{mV}$ was raised to $50 \mathrm{mV}$ in steps of $10 \mathrm{mV}$ every 10 minutes, followed by 30 minutes at $50 \mathrm{mV}$. The membrane was then rinsed in $\mathrm{ddH}_{2} \mathrm{O}$ and dried overnight for western blotting.

Western blotting is a method to identify proteins after separation of a cell or tissue homogenate by SDS-PAGE. It is based on the recognition of a specific epitope on a protein by an antibody.

The dried membrane was rehydrated for 10 minutes in $\mathrm{ddH}_{2} \mathrm{O}$, followed by application of the Quentix Western blot enhancer (Pierce). Briefly, the membrane was washed in reagent A for two minutes, followed by five washings in $\mathrm{dd}_{2} \mathrm{O}$ and 10 minutes incubation in reagent $\mathrm{B}$. After 
further five washings in $\mathrm{ddH}_{2} \mathrm{O}$, unspecific binding sites were blocked with $0.1 \%$ casein (Roche) in TBST (Table 1). The membrane was incubated with primary antibody for 2 hours at room temperature, followed by seven times extensive washing in $\mathrm{ddH}_{2} \mathrm{O}$ and 5 minutes in TBST and addition of a horseradish peroxidase-coupled secondary antibody for one hour. The blot was developed using the Millipore Immobilon system, which is based on the reaction of Luminol and $\mathrm{H}_{2} \mathrm{O}_{2}$ with horseradish peroxidase. The chemoluminescence was detected in a ChemDoc luminescence detector (BioRad). When required, the membrane was stripped with a Western blot Stripping Agent (Pierce) and reincubated with other antibodies following the same protocol.

\subsection{Electrophysiology}

\subsubsection{Whole-cell patch clamp of neurons in acute slices}

\subsubsection{Preparation of acute slices}

\subsection{Mouse and rat MNTB}

Acute slices from the brainstem were prepared as described in (Borst et al., 1995) and (Forsythe and Barnes-Davies, 1993). Postnatal day (p) 8-10 Wistar rats or p9-11 C57/Black 6 mice were decapitated according to the German law on animal protection. The head was placed in ice-cold artificial cerebrospinal fluid (aCSF, see Table 1) with the modification that the calcium concentration was reduced to $0.1 \mathrm{mM}$ and magnesium concentration was increased to $3 \mathrm{mM}$ to reduce damage from anoxia and metabolic activity of the cells. The skull was opened by a medial cut from the neck to eye-level and two mediolateral cuts in the front and back. The brainstem was separated from the cerebrum by a slightly rotated coronal cut at the rostral base of the cerebellum (Figure 3, black line). Meninges and superficial blood vessels were carefully removed to prevent straining of the tissue during slicing. The brainstem was glued by its caudal side to the slicing chamber using cyanoacrylate glue in such a way that the ventral side faced the

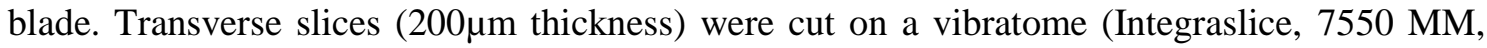
Campden Instruments, Leicester, UK) with the lateral vibration set to $70 \mathrm{~Hz}$ and the advancing speed to $0.18 \mathrm{~mm} / \mathrm{s}$. The seventh cranial nerve served as a landmark for the beginning of the MNTB. After the $7^{\text {th }}$ nerve became visible, 5-6 slices in rats and 3-4 slices in mice usually contained the MNTB and were collected on a nylon mesh in a glass beaker filled with aCSF with $2 \mathrm{mM}$ calcium and $1 \mathrm{mM}$ magnesium at $37^{\circ} \mathrm{C}$ and constantly bubbled with $95 \% \mathrm{O}_{2} / 5 \%$ $\mathrm{CO}_{2}$. Slices were allowed to regenerate for one hour before the experiment and were viable 3 to 4 hours after slicing. 


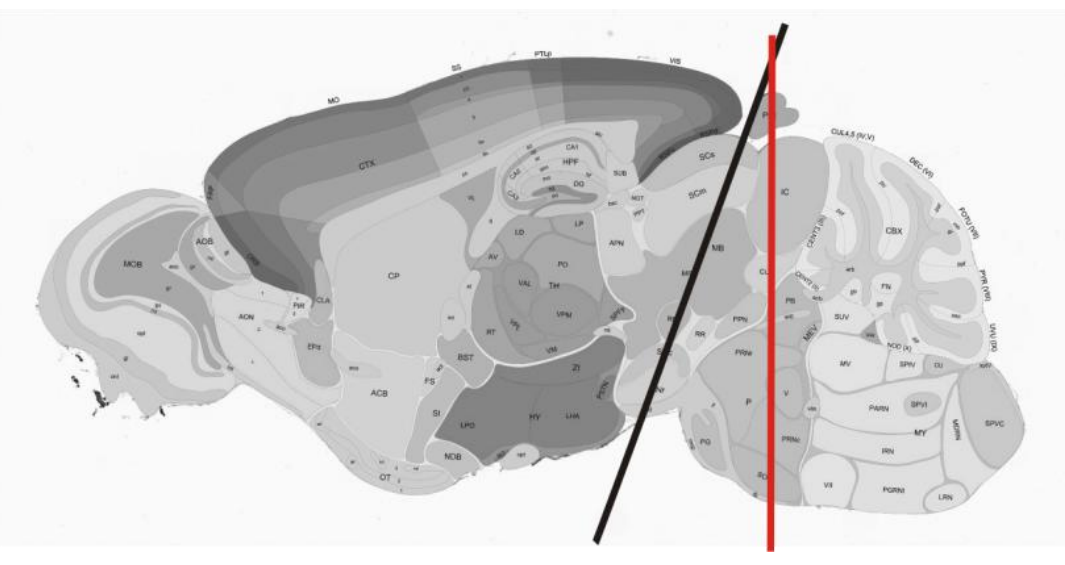

Figure 3: Parasagittal view of the mouse brain. The black line denotes the position of the cut that was used for preparation of MNTB sections; the red line marks the position for the cut during preparation of the cerebellum. Modified from www.brain-maps.org.

\subsection{Mouse cerebellar slices}

Acute slices from the cerebellum were cut from male and female Eag1 KO mice aged 20 to 28 days (p20-28) and their WT littermates. Animals were deeply anaesthetised by Isoflurane (Essex) inhalation and decapitated according to the German law on animal protection. The skull was laterally cut open to expose the brain without damaging the cerebellar vermis. The cerebellum was cut from the hemispheres with a coronal cut (Figure 3, red line) and placed in ice-cold sucrose-based aCSF. Coronal slices from the vermis were cut on a Vibratome (Leica VT1200S) in ice-cold sucrose solution. The sucrose solution is supposed to reduce damage from anoxia and improve the texture of the tissue for slicing. The advancing speed of the blade was set to the lowest possible value $(0.04 \mathrm{~mm} / \mathrm{s})$ to reduce strain damage on the tissue. Slices were immediately transferred to a nylon mesh in a beaker containing normal aCSF at $36^{\circ} \mathrm{C}$ that was constantly bubbled with $95 \% \mathrm{O}_{2} / 5 \% \mathrm{CO}_{2}$. After 45 to 60 minutes, the beaker was transferred to room temperature. Slices were suitable for recordings up to 5 hours after slicing.

\subsubsection{Whole-cell patch clamp of the Calyx of Held}

Slices were placed in a custom-made plastic chamber and held in place by a U-shaped platinum wire with parallel nylon threads spanned across it. The recording chamber was connected to a gravity-driven perfusion system and the slice was continuously perfused with aCSF bubbled with $95 \% \mathrm{O}_{2} / 5 \% \mathrm{CO}_{2}$. Slices were visualised with a $\mathrm{BX} 51 \mathrm{WI}$ upright microscope (Olympus, Japan) with a 60x objective (Olympus). Patch pipettes were pulled to resistances of 5 to $6 \mathrm{M} \Omega$ with a vertical, temperature controlled, two-step pipette puller (PIP 5, Heka) from borosilicate capillaries (Hilgenberg, Germany) with $2 \mathrm{~mm}$ outer diameter and $1.4 \mathrm{~mm}$ inner diameter. For postsynaptic recordings, resistances of 3 to $5 \mathrm{M} \Omega$ were used. Whole cell recordings from the pre- or postsynaptic terminal were performed at room temperature with an 
EPC 10/2 amplifier (Heka) controlled by the Patchmaster software (v. 2.20, Heka). A caesiumbased intracellular solution (Calyx intracellular, CIS, Table 1) supplemented with $1 \mu \mathrm{M}$ tetrodotoxin (TTX) was used to block some of the voltage-gated conductances present at the calyx of Held synapse. In some experiments, 5-10mM tetraethylammonium (TEA) was used in the extracellular solution. Eag1-mediated currents were identified by the presence of the "ColeMoore-Shift" (Cole and Moore, 1960; Terlau et al., 1996), which is characterised by a slowing of the activation kinetics by a hyperpolarizing prepulse. The Cole-Moore Shift in Eag1 is so pronounced that it is a good indicator of the presence of the channel (Terlau et al., 1996; Meyer and Heinemann, 1998). The terminal was held at $-60 \mathrm{mV}$ or $-120 \mathrm{mV}$ for 5 seconds before a $500 \mathrm{~ms}$-depolarizing pulse to $+40 \mathrm{mV}$ was given. Data were sampled at $50 \mathrm{kHz}$ and low-pass filtered at $6 \mathrm{kHz}$ with a Bessel filter and stored on a computer. The pipette- and cell capacitances were cancelled by the built-in compensation mechanism. Series resistances $\left(R_{S}\right)$ were usually $10-20 \mathrm{M} \Omega$ for the presynaptic terminal and $5-10 \mathrm{M} \Omega$ for the postsynaptic cell. $\mathrm{R}_{\mathrm{S}}$ was electronically compensated by up to $80 \%$.

\subsubsection{Whole-cell patch clamp of neurons of the cerebellar cortex}

\section{Experimental setup}

Cerebellar slices were placed in a custom-made plastic chamber and held in place by a Ushaped platinum wire with parallel nylon threads spanned across it. The recording chamber was connected to a gravity-driven perfusion system and the slice was continuously superfused with aCSF bubbled with $95 \% \mathrm{O}_{2} / 5 \% \mathrm{CO}_{2}$ heated to $32-34^{\circ} \mathrm{C}$ by an in-line solution heater (Warner Instruments). Slices were visualised with an upright microscope (Axioskop, Zeiss) using a 60x water immersion objective (Olympus) and infrared differential interference contrast (DIC) system. Images were acquired with a CCD camera (Imago VGA) controlled by TILLvision software (Till Photonics). All parts were mounted onto an anti-vibration table (Newport) inside a Faraday-cage.

Data were acquired with an EPC10/2 amplifier (Heka) controlled by Patchmaster (v. 2.20, Heka). Whenever possible, series of experiments were programmed in a protocol file to ensure constant repetition times between sweeps or experiments. The amplifier triggered the optical stimulus isolator (AMPI) used for extracellular stimulation (see also below).

\section{Identification of neurons in the slice}

The three-layered structure of the cerebellar cortex makes the identification of target neurons relatively easy. The granule layer is characterised by many densely-packed small cells 
and a few larger Golgi cells. The Purkinje layer is a monocellular layer made up of the large Purkinje cell bodies lying between granule and molecular layers. The molecular layer is mainly made up of the axons of the granule cells and two types of inhibitory interneurons; stellate cells (SC) and basket cells (BC). While basket cells are located close to the Purkinje cell soma, stellate cells are found between the pia and the middle of the molecular layer (Palay and ChanPalay, 1974). To ensure recordings from the desired type of interneuron, only those cells were patched that were located in the inner third (basket cells) or outer third (stellate cells) of the molecular layer.

\section{Whole-cell recordings}

Patch pipettes were prepared as described above (section 2.6.3.2) to resistances of 3-4 M $\Omega$ for Purkinje cells, 4-6 M $\Omega$ for interneurons and 5-7 $\mathrm{M} \Omega$ for granule cells. The pipette was inserted into the bath with positive pressure to prevent clogging of the tip with tissue fragments. When the pipette comes in contact with the cell, a bubble on the surface or a small displacement of the cell can be observed. The pressure was then released and mild suction applied until a G $\Omega$ seal was achieved. The pipette capacitance was then cancelled automatically. A brief suction pulse was usually sufficient to break the membrane and establish the whole-cell configuration. The cell capacitance was cancelled and the series resistance compensated by 20 to $80 \%$ with manually selected parameters. Before compensation, series resistance was $\leq 15 \mathrm{M} \Omega$ in Purkinje cells and $\leq 20 \mathrm{M} \Omega$ in interneurons and granule cells. For voltage-clamp recordings of EPSCs, a potassium gluconate-based intracellular solution was used (KIS, table 1) supplemented with $5 \mathrm{mM}$ QX-314 (Tocris) to block voltage-gated sodium channels. Cells were held at $-60 \mathrm{mV}$ and the GABA $_{\mathrm{A}}$ blocker SR95531 (Tocris) was added to the aCSF. Currents were sampled at 50 $\mathrm{kHz}$ and low-pass filtered at with a $2.9 \mathrm{kHz}$ Bessel filter. For current-clamp recordings, the EGTA concentration in the intracellular solution was lowered to $0.1 \mathrm{mM}$. In some experiments, cells were held at approximately $-60 \mathrm{mV}$ by current injection, otherwise no holding current was injected. Voltages were recorded at $100 \mathrm{kHz}$ and low-pass filtered at $10 \mathrm{kHz}$.

For extracellular stimulation, the tip of a glass pipette was broken to a diameter of $\sim 10 \mu \mathrm{m}$, filled with aCSF and placed in the granule layer. By stimulation in the granule layer, fibre recruitment during train stimulation is avoided (Barbour, 1993; Marcaggi and Attwell, 2005; Beierlein et al., 2007). Very short $(20-100 \mu \mathrm{s})$ voltage pulses were applied to the slice through the pipette while the bath ground electrode was connected to the ground output of the stimulator. Like this, the whole slice was stimulated but the stimulus intensity decayed with increasing distance between the stimulation- and recording pipette, thus making a direct stimulation of the recorded cell unlikely. Further, the delay between stimulation artefact and onset of the EPSC indicated no direct stimulation. 


\subsubsection{Analysis of electrophysiological data}

Data were analysed with Igor Pro (Wavemetrics) and custom-written macros. For the detection and analysis of EPSCs, 10 to 20 sweeps in a given cell were averaged and the leak subtracted. The stimulus artefact was blanked out and EPSCs were detected as a local minimum. An exponential curve was fitted to the decay part of the EPSC and the fit was extended to the baseline. In Purkinje cells, the EPSC sometimes did not decay to the baseline completely and the offset was subtracted from the following EPSC. Percentual facilitation in the $\mathrm{n}^{\text {th }}$ stimulus was calculated as $\left(\mathrm{EPSC}_{\mathrm{n}}-\mathrm{EPSC}_{1}\right) / \mathrm{EPSC}_{1} \times 100$. For analysis of current-clamp data, the Neuromatic software package (ThinkRandom) was used together with custom-written macros. Action potentials were detected as a local maximum. The first ten spontaneously occurring action potentials after breaking into a cell were averaged and analysed. The threshold and de-/repolarisation speed was determined by analyzing the first differential of the spike. Statistical analysis was performed with Prism (GraphPad) using an appropriate test for the type of experiment as indicated.

A number of mathematical models for STP have been proposed, most of which are a simplified phenomenological interpretation based on the postsynaptic response $\mathrm{R}$ being the product of a dynamic facilitation variable $\mathrm{F}$, a dynamic depression variable $\mathrm{D}$ and the initial response $\mathrm{R}_{0}$ (Tsodyks and Markram, 1997; Varela et al., 1997).

$$
R=R_{0} \cdot F \cdot D
$$

A variation of this model includes also variables for the $\mathrm{Ca}^{2+}$ dependence of facilitation and depression, and for the recovery from depression (Dittman et al., 2000). In brief, release is proportional to the product of $F$ and $D$ at a time point $t . F$ is the facilitation component and ranges from 0 to $1 . D$ is the fraction of release sites capable of releasing a vesicle and also ranges from 0 to 1 . After an action potential, a calcium-driven reaction enhances release $(F$ increases) and release sites enter in refractory states, which depresses release (decreases $D$ ).

In this model, facilitation is assumed to be directly related to the occupancy of the release site by a $\mathrm{Ca}^{2+}$ - bound molecule $\mathrm{CaX}_{F}$. Calcium - dependent recovery from depression is a process governed by the concentration of a $\mathrm{Ca}^{2+}$ - bound molecule $\mathrm{CaX}$. After an AP at time $t_{0}$, $\mathrm{CaX}_{F}$ and $\mathrm{CaX}_{D}$ increase by $\Delta_{\mathrm{F}}$ and $\Delta_{\mathrm{D}}$, respectively, and decay exponentially back to zero with first - order dynamics:

$$
\begin{aligned}
& \frac{d \operatorname{CaX}_{F}}{d t}=-\frac{\operatorname{CaX}_{F}(t)}{\tau_{F}}+\Delta_{\mathrm{F}} \cdot \delta\left(\mathrm{t}-\mathrm{t}_{0}\right) \\
& \frac{d \operatorname{CaX} X_{D}}{d t}=-\frac{\operatorname{CaX}_{D}(t)}{\tau_{D}}+\Delta_{\mathrm{D}} \cdot \delta\left(\mathrm{t}-\mathrm{t}_{0}\right)
\end{aligned}
$$


$F$ and $D$ are coupled, since with an increase in $F$, more release sites enter the refractory states and $D$ decreases.

A detailed description of the model can be found in Dittman et al., (2000).

\subsection{Two-photon calcium imaging in the parallel fibre}

While the idea of two-photon excitation was proposed by Maria Göppert-Mayer in 1931, it was not until 1990 that it was used for fluorescence microscopy (Denk et al., 1990). Twophoton microscopy offers the possibility to observe calcium dynamics as a response to the invasion of an action potential in the presynaptic bouton of the cerebellar parallel fibre. The main idea is that two low-energy photons arrive at a very short time interval $\left(10^{-18} \mathrm{~s}\right)$ and get absorbed by a fluorophore in a single quantitised event. For example, two photons with 780nm wavelength (i.e. in the near-infrared range) can excite a fluorophore that normally requires excitation in the UV range (390nm). For this, the two photons need to arrive with a high temporal and special overlap, meaning that the photon density has to be about 1,000,000 times higher than required for single-photon excitation. This needs a very high laser power, which can be achieved by focusing a mode-locked (pulsed) laser through an objective on the sample plane. Like this, the average laser power remains rather low while during the peak of a pulse the photon density is high enough to cause significant two-photon excitation. In comparison to the wavelengths used in conventional confocal microscopy, the low-energy photons can penetrate deeper into the tissue. Further, only in the focal plane the photon density is high enough for significant two-photon excitation. No excitation occurs above and below, thus reducing photobleaching and phototoxicity and eliminating the need for a pinhole to reduce background (Piston et al., accessed Feb. 2012).

In two-photon calcium imaging, cells are loaded with a calcium indicator and changes in fluorescence caused by calcium dynamics are imaged with a two-photon system.

Transversal slices from the cerebellum were prepared from 20-28-day-old Eag1 KO mice and WT littermates as described in section 2.8.1.1.2 with small modifications. Slices were prepared in normal aCSF instead of sucrose-based solution (see Table 1). During slicing, the solution was also bubbled with $95 \% \mathrm{O}_{2} / 5 \% \mathrm{CO}_{2}$ to ensure a stable $\mathrm{pH}$. After cutting, the slices were allowed to recover for 30 minutes and then transferred to room temperature. Successful experiments were conducted up to 8 hours after slicing.

For measurements, slices were transferred to a custom-built recording chamber, held in place by a platinum-nylon grid and constantly perfused with aCSF at $32^{\circ} \mathrm{C}$. Cells were visualised with an upright Fluoview-300 microscope (Olympus) with a 60x/0.9 NA water 
immersion objective. Granule cells were visually identified based on their size and position in the cerebellar cortex. The highest probability of successful recording was obtained by choosing a granule cell that was tightly surrounded by other cells and located in the second or third cell layer from the surface of the slice. Patch pipettes were pulled to resistances of 6-9 $\mathrm{M} \Omega$ with a temperature-controlled two-step vertical puller (Narishige) and filled with a potassiumgluconate based intracellular solution (K1, Table 1) containing $0.1 \mathrm{mM}$ Oregon Green 488 BAPTA-1 (OGB).

Granule cells were whole-cell patch clamped and the holding potential was selected to minimize leak currents (usually -80 to $-90 \mathrm{mV}$ ). The dye was allowed to diffuse in the cell for at least 10 minutes before a visual search for the axon began. The axon can be identified by its long, thin morphology and by its extension into the molecular layer. Further, varicosities are usually not found on dendrites. A prominent feature of dendrites useful for distinguishing them from an axon is the glomerulus, the postsynaptic terminal of the mossy fibre synapse. The success rate of finding an intact axon on the granule cell was approximately $50 \%$. Experiments were conducted 30 to 60 minutes after establishing the whole-cell configuration. The axon was followed in the molecular layer and synaptic boutons were visible as beads in both the ascending axon and parallel fibre part. After selection of a bouton, the recording mode was switched to current clamp and cells were held at approximately $-80 \mathrm{mV}$ by current injection. Short (1ms) current pulses were given to elicit 1 to 3 action potentials at 50 to $100 \mathrm{~Hz}$. Stimulation intensity was adjusted to elicit reliable firing of a single action potential per stimulus. Fluorescence signals in the boutons were recorded by performing a line scan across the bouton with a confocal laser-scanning microscope (Fluoview-300, Olympus). The microscope was custom-modified for two-photon excitation with a mode-locked Ti/sapphire laser (Tsunami) set to a centre wavelength of $770 \mathrm{~nm}$. The laser was intensity-modulated with a Pockel's cell (model 350-80 LA-BR, Conoptics) and focused on the slice with a 60x/0.9 NA water immersion objective (Olympus).

Offline analysis was performed in Fluoview (Olympus) and Igor Pro with custom-written macros. Fluorescence traces were background subtracted and the change in intensity was divided by the pre-stimulus baseline fluorescence to yield the $\mathrm{dF} / \mathrm{F}_{0}$ values. The traces were subsequently filtered using a sliding average of 9 points. After manual identification of a maximum, the decay of the signal was fitted with an exponential function. The maximal value of the fit was used for statistical analysis. 


\section{Results}

\subsection{Eag1 is enriched in the synaptic plasma membrane}

Previous results have suggested an axo-synaptic localisation of Eag1 (Gómez-Varela et al., 2010). To confirm the synaptic localisation of Eag1, I performed an SDS-PAGE and subsequent western blot with subcellular fractions of a whole-brain homogenate of C57/Black 6 WT mice (Figure 4A). The samples were kindly provided by Dr. C. Biesemann, Dept. of Molecular Neurobiology, MPI für experimentelle Medizin, and essentially prepared as described previously (Kalla et al., 2006) by a series of centrifugations through sucrose gradients. The fractions obtained were cell bodies, cytosolic synaptosomal proteins, synaptic plasma membrane, and crude synaptic vesicles. Whole-brain homogenates from WT and Eag1 KO were used as positive and negative control, respectively. A signal for Eag1 was detected in all fractions except the cytosolic synaptosomal proteins. The strongest signal was seen in synaptic plasma membranes. The signal in the synaptic vesicles fraction arises probably from endocytotic or transport vesicles, which are not discriminated from neurotransmitter-containing vesicles by this technique. The synaptic plasma membrane fraction does not discriminate between glial membranes and neuronal membranes, or between pre-and postsynaptic membranes. Astroglia have very low or no expression of Eag1 as seen in real-time PCR experiments (R. Ufartes, personal communication). However, as a control I performed a western blot with isolated protein from cultured WT and Eag1 KO astrocytes (Figure 4B). The immunoblot showed a clear signal in WT whole-brain homogenate with no signal in WT astrocytes, $\mathrm{KO}$ whole brain or $\mathrm{KO}$ astrocytes. This indicates that the signal in the synaptic plasma membrane fraction is indeed due to Eag1 in the synaptic membrane. These results are in line with earlier findings from our laboratory (Gómez-Varela et al., 2010) that Eag1 gets "trapped" in synaptic regions by interaction with cytoskeletal proteins. The same study showed that Eag1 is located mainly in axonal regions of hippocampal neurons. Although we cannot exclude a postsynaptic localisation, these results make an enrichment of Eag1 in the presynaptic plasma membrane probable. 


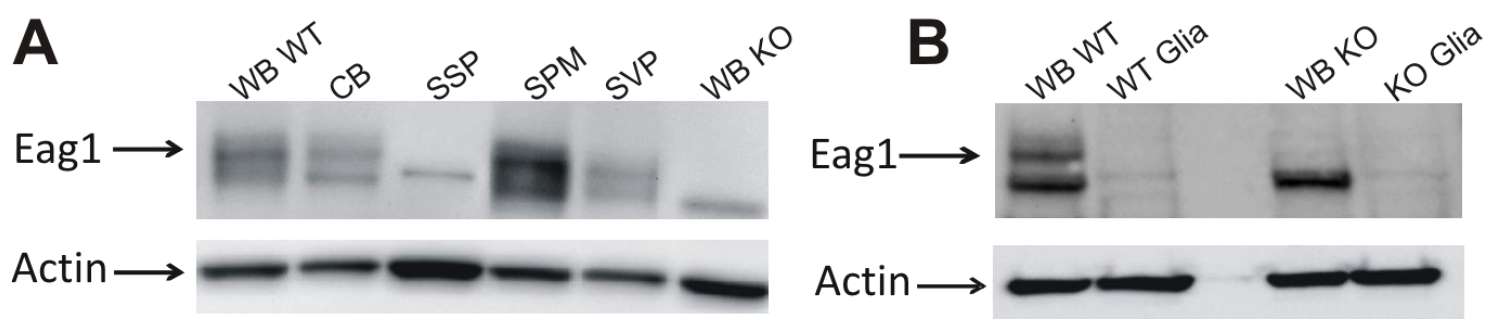

Figure 4 Eag1 is enriched in synaptic plasma membranes. A, Several subcellular fractions of the mouse brain were isolated and separated by SDS-PAGE. The samples used here are whole brain homogenate as a positive control (WB wt), cell bodies (CB), cytosolic synaptosomal proteins (SSP), synaptic plasma membrane (SPM), crude synaptic vesicles (SVP), and whole brain homogenate of an Eag1 KO mouse as a negative control (WB KO). Eag1 protein was detected in all fractions except cytosolic synaptosomal proteins and homogenate from the $\mathrm{KO}$ animal. B, No Eag1 is detected in astrocytes. WB wt, WT whole-brain homogenate; WT Glia, WT astrocytes; WB KO, Eag1 KO wholebrain homogenate; KO Glia, Eag1 KO astrocytes.

\subsection{Eag1 in the rat calyx of Held}

Although biochemical experiments reproducibly show high expression levels of Eag1 in the CNS (Ludwig et al., 2000; Saganich et al., 2001; Martin et al., 2008) no native Eag1 current has been identified in the cell bodies of neurons. If Eag1 is indeed located synaptically, the current elicited at the synapse might be too small to be detectable in the soma among the vast amount of potassium currents expressed there (Hille, 2001). The small size of synaptic boutons makes them normally difficult to access for electrophysiological recordings, but the giant calyx of Held synapse in the auditory brainstem has been proven to be very useful for recordings from the preand postsynaptic terminal (Borst et al., 1995). There, axons from the ventral cochlear nucleus make synapses onto principal neurons of the medial nucleus of the trapezoid body (MNTB).

Data about expression levels of Eag1 are contradicting. In-situ hybridisation studies (Ludwig et al., 2000; Saganich et al., 2001) did not find mRNA for Eag1 in the ventral cochlear nucleus and only partly in the MNTB, but mRNA for Eag2. On the other hand, Martin et al. (2008) reported staining for Eag1 in the trapezoid body. I performed whole-cell patch clamp on the calyx of Held and the MNTB principal neuron in young rats to explore the possibilities to use this synapse as a model system for the function of Eag1 in the brain. Rats have the advantage that more MNTB-containing slices can be cut from an animal and that the cells generally show a longer survival during experiments. To reduce the number potassium channels contributing to the currents, $\mathrm{Cs}^{+}$was used in the intracellular solution. The hallmark of Eag1 channels is the strong dependence of the activation kinetics on the holding potential (ColeMoore Shift) (Ludwig et al., 1994). When a depolarizing step is preceded by a hyperpolarisation, the activation is slowed down. This was observed in 10 out of 14 presynaptic terminals, a sample recording is shown in Figure 5A. In Figure 5B, the $20-80 \%$ rise time of the current is plotted against the prepulse potential. In four of the tested cells, no dependence on 
the prepulse was observed; these currents were also markedly faster (grey coloured symbols). On average, the difference in rise time between a prepulse holding potential of -120 and $-60 \mathrm{mV}$ was $3.1 \pm 0.3 \mathrm{~ms}$ (Figure 5C), excluding the cells that did not show a Cole-Moore Shift. Since no specific chemical blocker of Eag1 is available, I used a monoclonal antibody against the pore region (mAB56) that has been shown to block Eag1 currents by $60 \%$ after 20 minutes of incubation. Since mAB56 is an open channel blocker, one has to give a depolarizing pulse of $500 \mathrm{~ms}$ every ten seconds to achieve the reported blocking (Gómez-Varela et al., 2007). The application of the antibody together with 15 minutes stimulation at $0.1 \mathrm{~Hz}$ resulted in a reduction of the steady state current by $25.9 \pm 9.7 \%$ (Figure 5D,E).
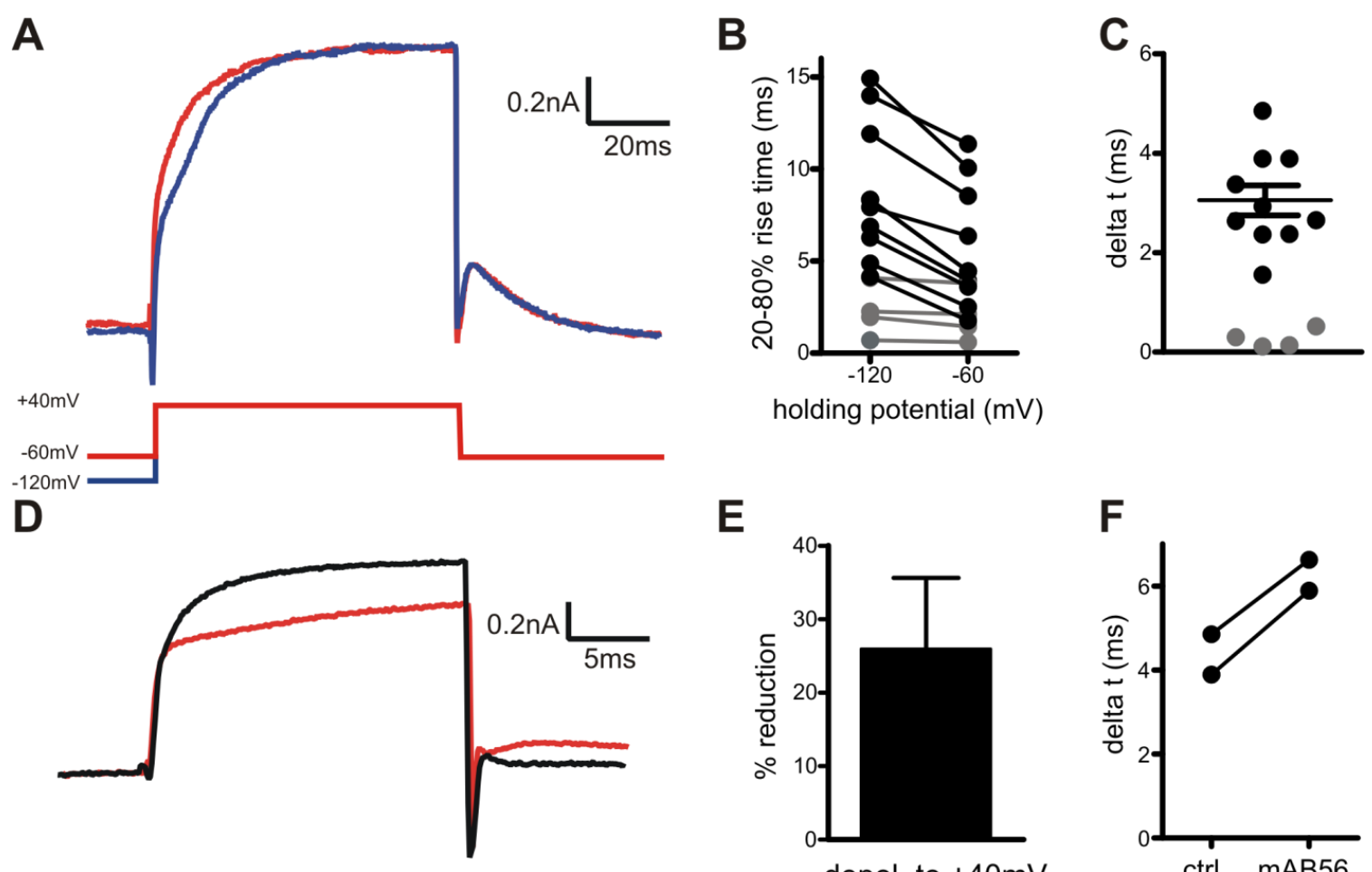

E

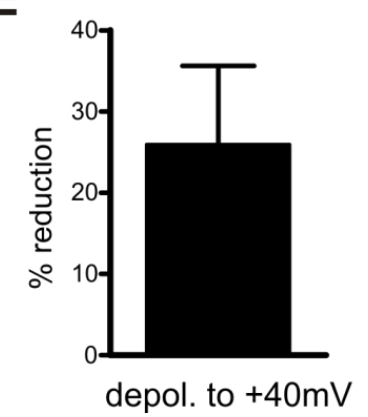

$\mathbf{F}$

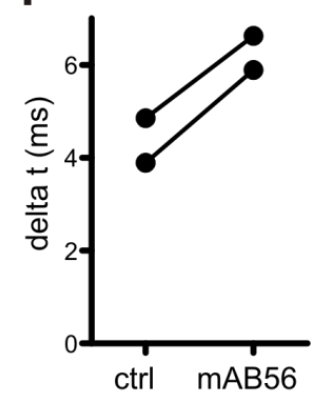

Figure 5. An Eag1 compatible current in the rat calyx of Held. A, a depolarisation of the presynaptic terminal to $+40 \mathrm{mV}$ evokes an outward current which activation kinetics depend on the prepulse potential. Red trace, $-60 \mathrm{mV}$ prepulse; blue trace, $-120 \mathrm{mV}$ prepulse. B, the rise time of the outward current plotted against the prepulse potential. One pair of markers represents one terminal. In four terminals, no dependence on the prepulse potential was detected (grey symbols). C, the difference in rise times after depolarisations from -120 and $-60 \mathrm{mV}$ holding potential. Mean $=3.1 \pm 0.3 \mathrm{~ms}, \mathrm{n}=10$. Terminals without Cole-Moore Shift (grey) were excluded. D, representative recording of a current elicited by a depolarisation to $+40 \mathrm{mV}$ before (black) and after (red) $15 \mathrm{~min}$ application of mAB56. E, after the application of mAB56, the maximal current was reduced by $25.9 \pm 9.7 \%, \mathrm{n}=2$. The Cole-Moore Shift was slightly increased $(\mathbf{F})$.

The Cole-Moore Shift was slightly larger after application of the antibody (Figure 5F). This is an indication for the presence of Eag2 channels, which are not blocked by mAB56 but also show the Cole-Moore Shift. Next, I wanted to test if an Eag1-compatible current was also 
present in the MNTB principal neuron, but no signal similar to the Cole-Moore shift was found in all 6 cells tested (data not shown).

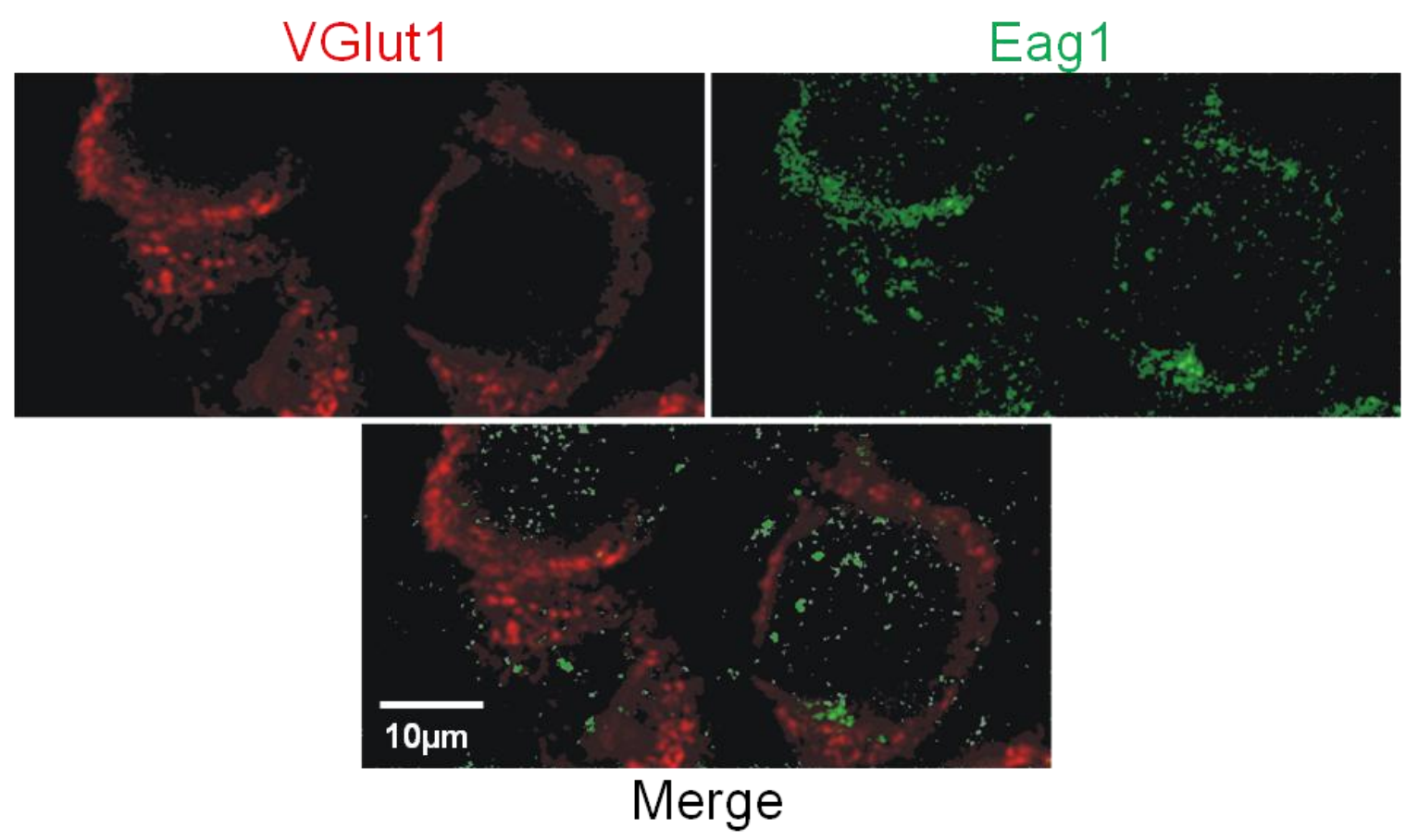

Figure 6. Eag1 expression in the calyx of Held. Double staining with antibodies against VGlut1 (red) as a presynaptic marker and Eag1 (green) in the MNTB of a p9 rat. Staining is seen predominantly in presynaptic regions.

In order to confirm the presence of Eag1 channels in the rat calyx of Held, I performed immunostainings in the brain stem of young rats. An antibody against VGlut1 was used as presynaptic marker. Calyces were clearly identifiable by the prominent VGlut1 signal (Figure 6, red). The signal for Eag1 (green signal in Figure 6) was mostly observed close to the VGlut1 signal. Sometimes, a signal for Eag1 was visible outside of the presumed presynaptic terminal, which could result from postsynaptically localized protein, however, no electrophysiological evidence for this was found.

The electrophysiology experiments were repeated in calices and MNTB neurons of mice, but it was not possible to isolate a current similar to that recorded in rat (data not shown). The potassium currents even with $\mathrm{Cs}^{+}$in the pipette were considerably larger and faster, so that any possible contribution of Eag1 was masked. To reduce some of the currents, 5mM TEA was added to the extracellular solution, a concentration that should block less than $50 \%$ of Eag1 channels (García-Ferreiro et al., 2004). This resulted in almost complete abolishment of outward currents and did not lead to the emergence of a Cole-Moore shift. Taken together, these results suggest that Eag1 is present in the presynaptic terminal of the rat, but not or only very little in mice. It seemed therefore not feasible to continue in this brain area to elucidate the physiological function of Eag1. 


\subsection{Eag1 in the cerebellum}

The calyx of Held was excluded as a suitable brain region for investigation of Eag1 function. The areas with the highest expression of Eag1 in the brain are the cortex, the hippocampus and the cerebellum. In the cortex and hippocampus, Eag2 is also present and could form heteromultimers with Eag1 (Ludwig et al., 2000; Saganich et al., 2001; Schönherr et al., 2002a). This makes the cerebellum the most promising region for analysis of Eag1.

The data from western blot with subcellular fractions (Figure 4) showed an increased signal for Eag1 in the synaptic plasma membrane in comparison to the cell body fraction, and voltageclamp experiments in the rat calyx of Held further indicated a synaptic localisation of the channel (Figure 5). In-situ-hybridisation data suggest an expression of Eag1 in the granule cell layer of the cerebellum (Ludwig et al., 2000; Saganich et al., 2001), while immunostainings in the adult rat shows a signal in the soma of Purkinje cells (Martin et al., 2008). In case of a somatic localisation of the channel, I would expect to see differences in either the resting potential of firing properties of cerebellar granule or Purkinje cells, while in case of a synaptic localisation I would expect differences in synaptic transmission and/or facilitation.

\subsubsection{Granule cell soma is unaffected}

To test if Eag1 plays a role in regulation of excitability and firing of granule cells, I performed whole-cell patch-clamp in cells from WT and Eag1 KO mice in acute cerebellar slices. The resting potential at $0 \mathrm{pA}$ current injection did not differ significantly between WT and Eag1 KO- granule cells $(-79.26 \pm 1.48 \mathrm{mV}, \mathrm{n}=11$ and $-76.03 \pm 1.79 \mathrm{mV}, \mathrm{n}=5$, respectively, p $>0.05$, Student's t-test). Neither WT nor Eag1 KO cells showed spontaneous firing at resting potential. Active cell membrane properties were evaluated by measuring the voltage response to injection of square current pulses ranging from -35 to $+35 \mathrm{pA}$ in steps of $5 \mathrm{pA}$ into the soma. During subthreshold current injections, the current-voltage relationship increased steeply between -10 and $+10 \mathrm{pA}$ and less steeply between -35 and $-10 \mathrm{pA}$ as well as between 10 and 35pA (Figure 7A, B) (Prestori et al., 2008). 
A

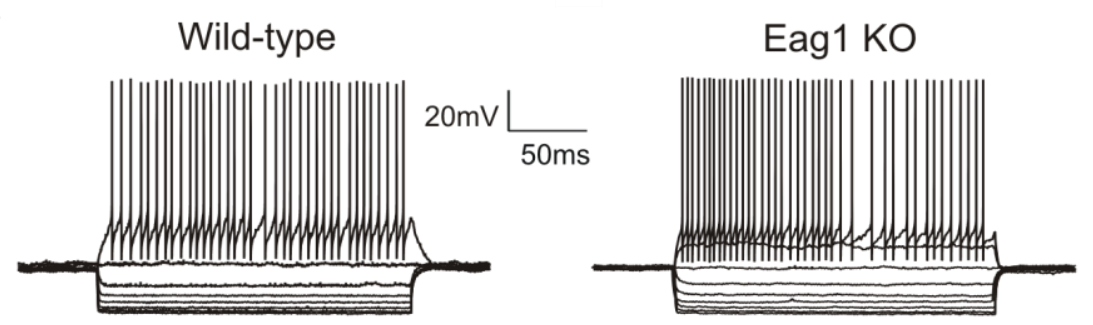

B

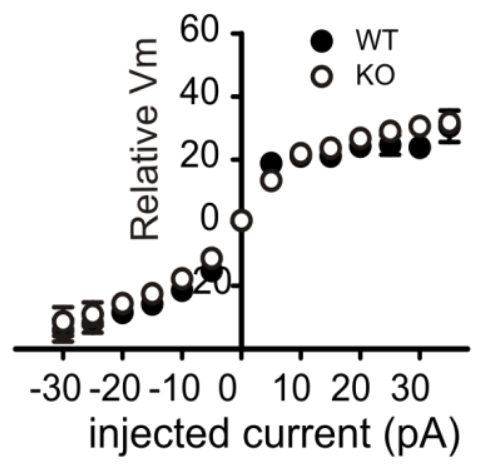

C

Figure 7: Electroresponsiveness of cerebellar granule cells of WT and Eag1 KO mice. A, Representative traces recorded in granule cells from WT (left) and Eag1 KO mice (right). Both genotypes showed inward rectification of the membrane potential during hyperpolarizing pulses and regular spiking after reaching a threshold potential. B, Membrane potential recorded in whole-cell current clamp mode in response to injection of square current pulses of two seconds duration. C, Firing frequency of WT and Eag1 KO cells upon injection of $2 \mathrm{~s}$ square current pulses ranging between -35 and $+35 \mathrm{pA}$ in $5 \mathrm{pA}$ increments.

WT cells fired their first action potential after injection of $6.36 \pm 0.98 \mathrm{pA}, \mathrm{n}=11$, while Eag1 KO cells started firing upon injection of $9.00 \pm 1.00 \mathrm{pA}$, ( $\mathrm{n}=5$, no significant difference). In accordance with previous studies (D'Angelo et al., 1998; Chadderton et al., 2004; Brickley et al., 2007), granule cells of WT and Eag1 KO displayed fast repetitive firing of action potentials in regular trains with little or no adaptation during the depolarisation (Figure 7A). Evoked firing frequencies increased with the amplitude of the injected current. Current-frequency diagrams (Figure 7C) could be fitted with a straight line and resulted in slopes of $5.182 \pm 0.15 \mathrm{~Hz} / \mathrm{pA}$ for WT cells; $n=11$ and $4.714 \pm 0.32 \mathrm{~Hz} / \mathrm{pA}$ for Eag1 KO cells; $\mathrm{n}=5$; $\mathrm{ns}$. Besides the slightly slower onset of firing of Eag1 KO cells, I conclude no difference in excitability between granule cells of WT and Eag1 KO mice.

Another possible role for Eag1 channels would be in repolarisation of the action potential. The first ten action potentials recorded just after reaching spike threshold were averaged and spike threshold, amplitude, afterhyperpolarisation, half-width and depolarisation/repolarisation speeds were evaluated. None of the parameters tested resulted in significant differences between WT and Eag1 KO- cells (Figure 8A). These data further speak in favour of a non-somatic localisation of Eag1 channels in cerebellar granule cells. 
A

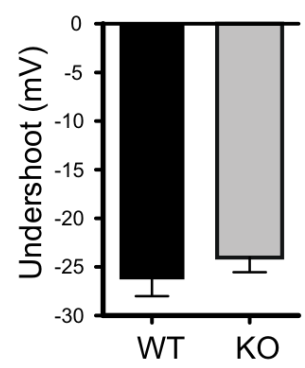

iii

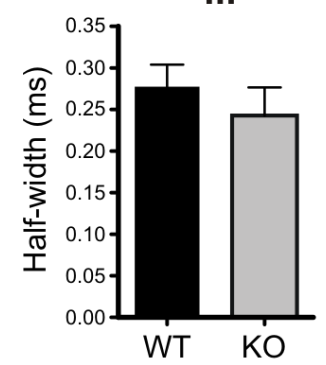

ii

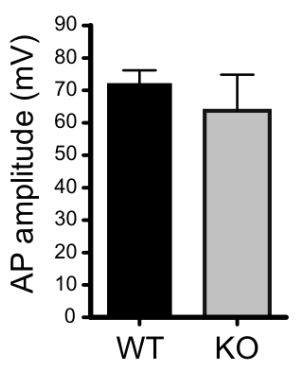

iv

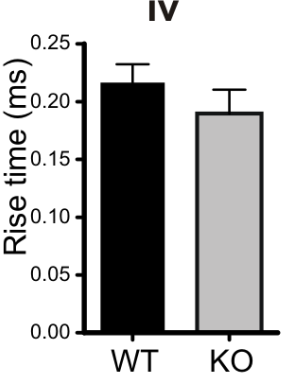

B
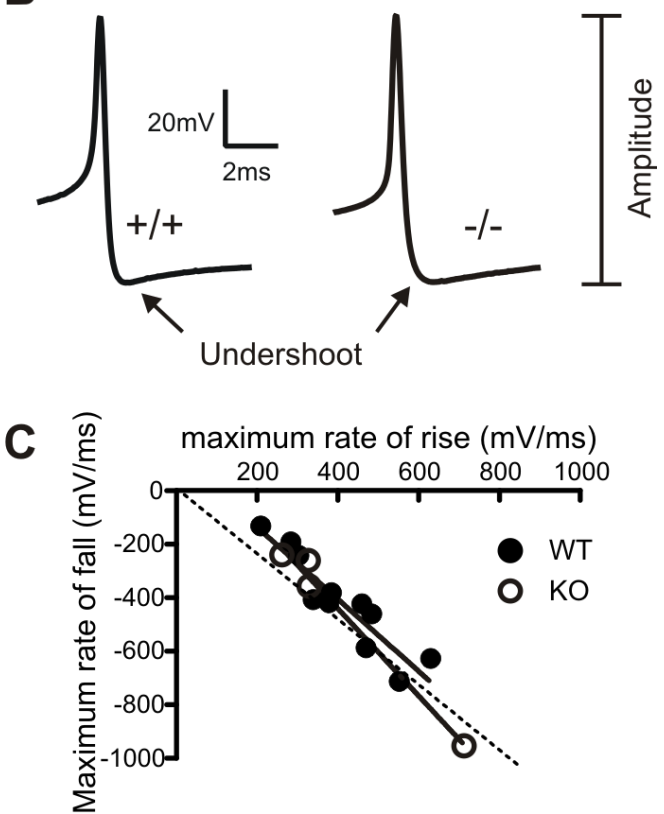

Figure 8: Action potential properties are not altered in Eag1 KO mice. A, The undershoot (i), action potential amplitude (ii), half-width (iii) and 10-90\% rise time (iv) are compared. Black bars, WT, n=11 cells; grey bars, Eag1 KO n=5 cells. B, Representative action potentials recorded in a WT (left) and Eag1 KO (right) granule cell. The trace shown is an average of the first ten occurring action potentials after breaking into the cell. $\mathbf{C}$, the maximum rate of rise of the action potential is plotted against the maximum rate of fall as determined by analyzing the first differential. Solid circles, WT; open circles Eag1 KO. The data points were fitted with straight lines, which were not significantly different.

\subsubsection{Purkinje cell soma is unaffected}

Purkinje cells are reported to spontaneously fire simple spikes at frequencies up to $300 \mathrm{~Hz}$ in vitro and in vivo, with the frequency depending on synaptic inputs as well as intrinsic ion channels (Llinás and Sugimori, 1980; Raman and Bean, 1999; Williams et al., 2002; Swensen and Bean, 2003; Haghdoust et al., 2007). I examined the firing properties as well as the passive membrane properties and action potential properties of Purkinje cells by performing whole-cell patch clamp in the current clamp mode.

Without current injection, $\mathrm{V}_{\mathrm{mem}}$ was $-63.90 \pm 3.33 \mathrm{mV}(\mathrm{n}=8)$ in WT cells vs. $-54.78 \pm$ $2.31 \mathrm{mV}(\mathrm{n}=8)$ in Eag1 KO cells. However, since the potential measured by whole-cell patch clamp is influenced by the quality of the preparation as well as the damage to the cell caused by the patch pipette, the result has to be interpreted carefully. Cells from both genotypes showed spontaneous action potential firing without current injection. To evaluate whether Eag1 is involved in shaping the action potential, the first ten action potentials occurring after breaking the membrane were averaged and analysed for each cell. Figure 9A shows a representative action potential recorded in a WT (left) and Eag1 KO (right) cell. The comparison of the afterhyperpolarisation (Bi), full width at half max (Bii), overshoot (Biii) and threshold (Biv) of the action potential revealed no significant differences between Eag1 KO neurons and WT cells. 

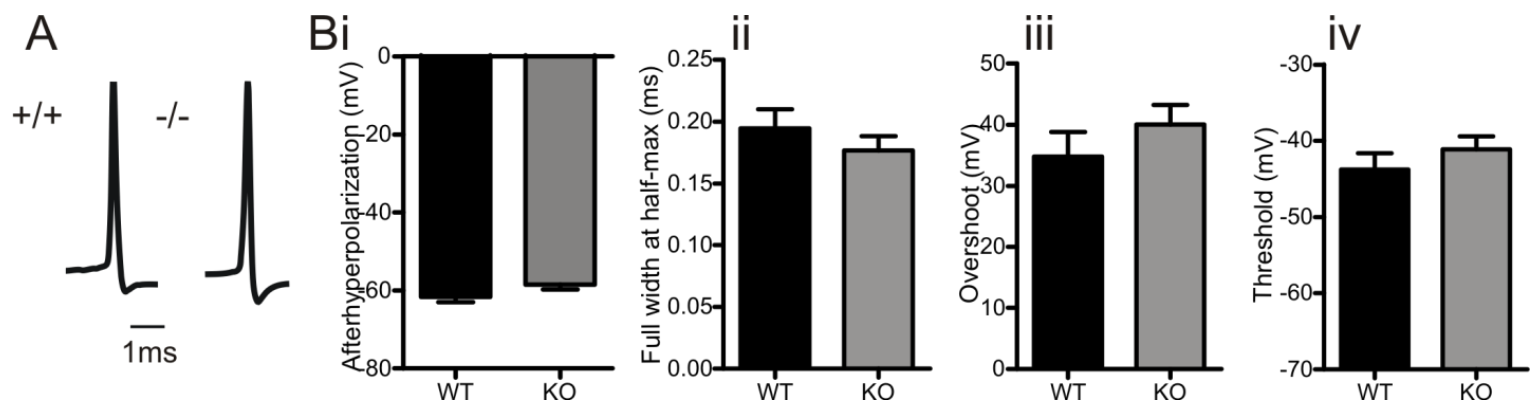

Figure 9. Action potential properties in Purkinje cells of WT and Eag1 KO mice. A, representative action potentials recorded in WT (left) and Eag1 KO (right) cells. B, action potential properties of WT (black bars) and Eag1 KO (grey bars) Purkinje cells. The first 10 spontaneously occurring action potentials were averaged in a given cell and afterhyperpolarisation (i), full width at half max (ii), overshoot (iii) and threshold (iv) were compared.

Eag1 opens close to the resting potential (Ludwig et al., 1994), so I examined the input resistance and membrane potential of Purkinje cells. In order to calculate the input resistance, cells were held at $-60 \mathrm{mV}$ by current injection and square current pulses $(-100$ to $+100 \mathrm{pA}$ in steps of 20pA) were injected into the soma and the resulting change in membrane voltage was recorded. The obtained current-voltage (I-V) relationship for hyperpolarizing current injection was close to linear with the slope representing the membrane resistance (Llinás and Sugimori, 1980). Neither the obtained values for $\mathrm{V}_{\text {mem }}$ nor the slope of the fit were significantly different between WT (solid circles) and Eag1 KO cells (open circles) (Figure 10B).

Next, we examined if injection of depolarizing voltage pulses led to changes in the firing frequencies of Purkinje cells. Cells were held close to $-60 \mathrm{mV}$ in current clamp mode and were injected with square current pulses ranging from -100 to $+100 \mathrm{pA}$ in steps of $10 \mathrm{pA}$ and from +100 to $+1000 \mathrm{pA}$ in steps of $50 \mathrm{pA}$. The minimal current injection to elicit an action potential was not significantly different in WT and Eag1 KO cells $(104.0 \pm 38.68 \mathrm{pA}, \mathrm{n}=5$ and $61.67 \pm$ 21.51pA, n=6). Figure 10A shows a typical recording from a WT (top) and Eag1 KO (bottom) cell. Spikes were detected as a local maximum, and the resulting spike frequencies were plotted against the injected current (Figure 10C). Eag1 KO neurons showed slightly, but not significantly, increased evoked firing frequencies in comparison to WT cells upon injection of currents $<100 \mathrm{pA}$. These results, as well as the results obtained in the cell bodies of granule cells, speak against a functional somatic localisation of Eag1 channels. 

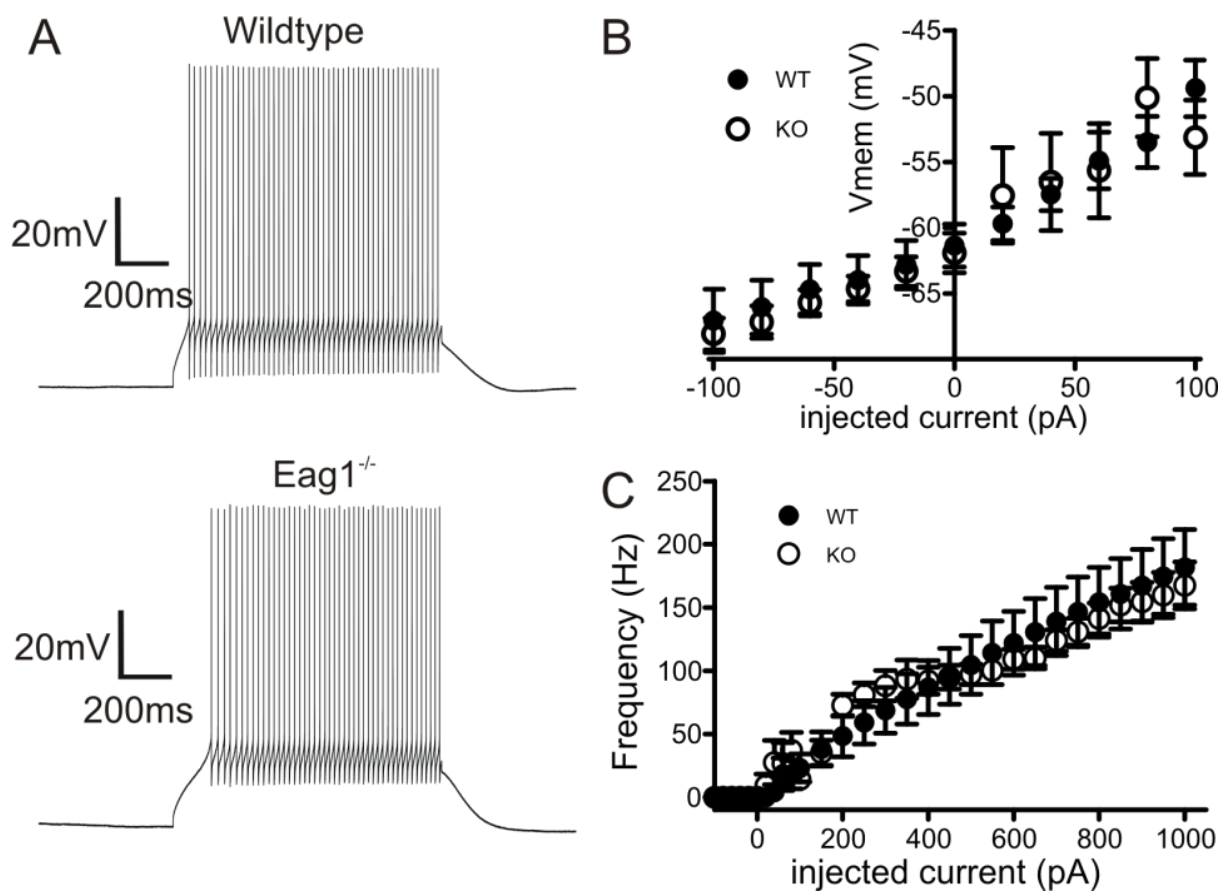

Figure 10. Electroresponsiveness of cerebellar Purkinje cells of WT and Eag1 KO mice. A, top, representative recording of a spike train in response to a suprathreshold current injection in a Purkinje cell from a WT mouse. Bottom, same from an Eag1 KO mouse. B, Membrane voltage in response to current injections ranging from -100 to $+100 \mathrm{pA}$ in steps of $20 \mathrm{pA}$ as measured in the cell bodies of WT (solid circles) and Eag1 KO (open circles) Purkinje cells. C, firing frequencies of WT (solid circles) and Eag1 $\mathrm{KO}$ (open circles) Purkinje cells in response to somatic current injection ranging from -100 to $+100 \mathrm{pA}$ in $10 \mathrm{pA}$ steps and from +100 to $+1000 \mathrm{pA}$ in $50 \mathrm{pA}$ increments.

\subsubsection{Synaptic transmission in cerebella of WT and Eag1 KO mice}

The lack of evidence for an involvement of Eag1 in the regulation of the membrane potential or action potential firing despite the clear signal for Eag1 mRNA expression (Ludwig et al., 2000; Saganich et al., 2001) is an indication for synaptic localisation of the channel. The synapses that seemed reasonable to explore were either the parallel fibre synapse due to the mRNA expression in the granule cells or the climbing fibre - Purkinje cell synapse due to the signal in the immunostaining on the Purkinje cell body. I chose to use the parallel fibre synapse for several reasons. Firstly, no expression of Eag2 has been reported there (Saganich et al., 1999; Ludwig et al., 2000; Saganich et al., 2001). Secondly, the same in-situ hybridisation studies suggested no expression of Eag1 in the inferior olive, where the climbing fibre originates. Thirdly, the parallel fibre synapse is suitable for presynaptic calcium imaging experiments, whereas the climbing fibre is not. Extracellular loading with calcium dye would inevitable also load the Purkinje cell soma, which is known for its calcium dynamics, and would distort, if not cover, the synaptic signals. 
The first step was to characterize synaptic transmission at the parallel fibre - Purkinje cell synapse.

I measured the EPSCs in Purkinje cells in response to extracellular stimulation. Feed-forward inhibition in the cerebellar cortex causes an inhibitory response from the molecular layer interneurons to shorten the EPSC (Bao et al., 2010). To measure exclusively glutamatergic currents resulting from granule cell activity, the specific $\mathrm{GABA}_{\mathrm{A}}$ blocker SR 95531 was added to the extracellular solution. The tip of the stimulation pipette was inserted into the granule layer about $150-200 \mu \mathrm{M}$ away from the recording site to avoid direct stimulation of the Purkinje cell and of the ascending fibre synapses, which have different transmission properties and different susceptibilities to synaptic plasticity (Barbour, 1993; Sims and Hartell, 2006). A cartoon of the positions of stimulation- and measuring electrode is pictured in Figure 14a.
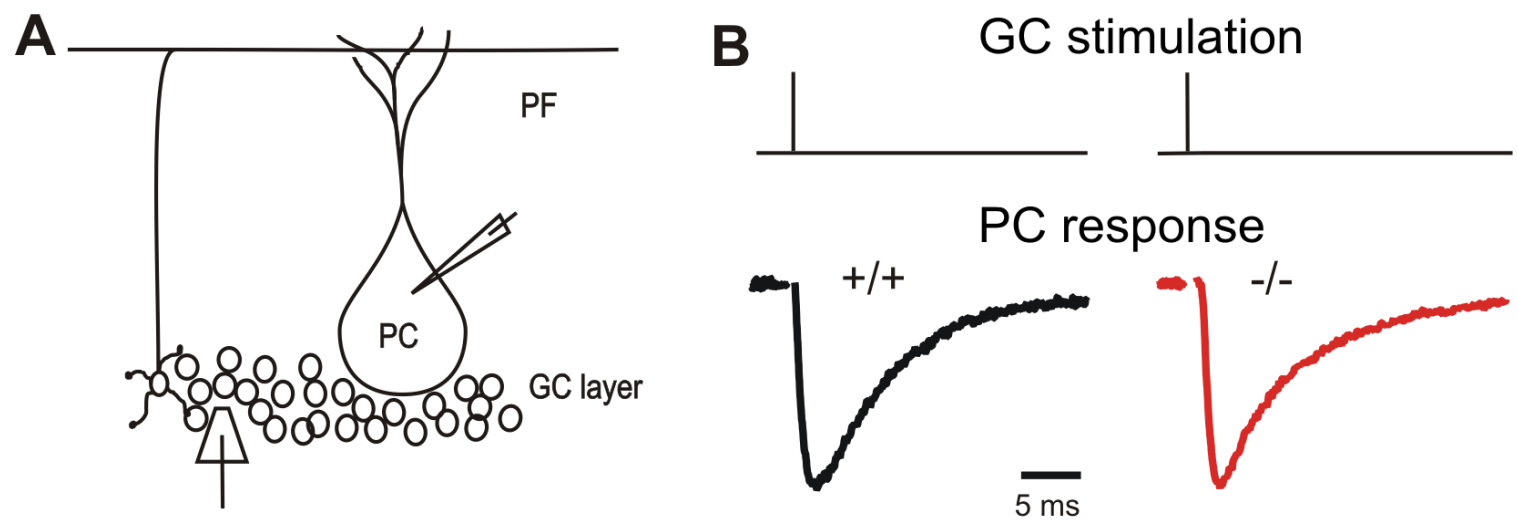

Figure 11. Extracellular stimulation causes EPSCs in Purkinje cells. A, illustration showing the positions of the stimulation and measurement pipettes in the cerebellar cortex. PCs were whole-cell voltage clamped during extracellular stimulation in the granule layer in the presence of SR 95531. B, Sample traces in response to a single stimulus. Each trace is the average of 20 consecutive recordings. Black trace, WT; Red trace, Eag1 KO.

Upon delivery of a brief voltage stimulus, an inward current was observed whose amplitude depended on the stimulation strength and positioning of the electrode. A sample trace is shown in Figure 11. Each trace is the average of 20 sweeps. Stimulation strength and position of the electrode were selected to yield reliable and constant EPSC amplitudes for several minutes before beginning of the experiments.

The kinetics of the EPSCs were compared between WT and Eag1 KO. It is not feasible to compare the amplitudes due to the variability introduced by extracellular stimulation. In normal extracellular solution, no difference in rise or decay time was observed (Figure 12). 

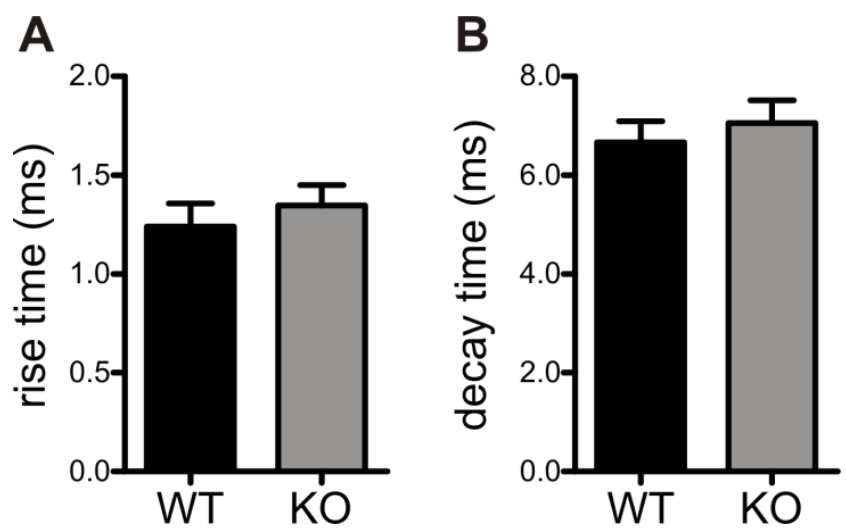

Figure 12 EPSC kinetics in PF-PC synapses of WT and Eag1 KO mice. A, 10 to $90 \%$ rise time (in ms) of a single EPSC in standard aCSF measured in WT $(n=16)$ and Eag1 KO $(n=13)$ Purkinje cells as response to extracellular stimulation in the granule cell layer. B, Decay time constant of a single EPSC in WT $(n=16)$ and Eag1 KO $(n=13)$ cells.

\subsubsection{Calcium dependence of synaptic transmission in WT and Eag1 KO cells}

The EPSC size is directly dependent on the calcium influx (Dodge and Rahamimoff, 1967; Sabatini and Regehr, 1997; Bollmann and Sakmann, 2005). It has been reported that the relationship between calcium influx and EPSC amplitude can be approximated by a power law of the form

$$
E P S C=k\left(C a_{\text {influx }}\right)^{n}
$$

with $k$ being a constant, $\mathrm{Ca}_{\text {influx }}$ the total presynaptic calcium influx during an action potential and $n$ between 2.9 and 4 depending on the preparation and temperature. Calcium influx in turn is highly sensitive to changes in the external calcium concentration $\left(\mathrm{Ca}_{\mathrm{e}}\right)$. With increasing $\mathrm{Ca}_{\mathrm{e}}$, the EPSC amplitude starts to saturate, resulting in a sublinear relation of $\mathrm{Ca}_{\text {influx }}$ and $\mathrm{Ca}_{\mathrm{e}}($ Dodge and Rahamimoff, 1967; Mintz et al., 1995; Schneggenburger and Neher, 2005). At concentrations where saturation is not visible, the form

$$
E P S C=k\left(C a_{e}\right)^{n}
$$

is valid (Foster et al., 2005). I altered $\mathrm{Ca}_{\mathrm{e}}$ to further explore the role of an increased calcium influx in regulation of transmitter release. Figure 13C (left) shows representative traces from a WT cell in 0.5, 2 and $4 \mathrm{mM} \mathrm{Ca}_{\mathrm{e}}$, while on the right the responses to the same changes in an Eag1 $\mathrm{KO}$ cell are displayed. In Figure 13A, the EPSC amplitude is normalised to the amplitude at $2 \mathrm{mM}$ and plotted against $\mathrm{Ca}_{\mathrm{e}}$. Lowering $\mathrm{Ca}_{\mathrm{e}}$ to $0.5 \mathrm{mM}$ reduced the EPSC amplitude in the WT to $8.4 \pm 2.8 \%$ of its original size, while the EPSC in the knockout was reduced to $20.5 \pm 4 \%$ ( $\mathrm{p}<0.05, \mathrm{n}=5$, Student's t-test). An increase in $\mathrm{Ca}_{\mathrm{e}}$ to $4 \mathrm{mM}$ increased the EPSC in the WT to 183 $\pm 13 \%$ of control and to $134 \pm 23 \%$ in Eag1 KO cells $(\mathrm{p}<0.05, \mathrm{n}=5)$. For $\mathrm{Ca}_{\mathrm{e}} \leq 2 \mathrm{mM}$, the WT data are well approximated by Eq. (6) with $n=1.94 \pm 0.09$. The data from Eag1 $\mathrm{KO}$ cells for $\mathrm{Ca}_{\mathrm{e}}$ 
$\leq 2 \mathrm{mM} \mathrm{Ca}_{\mathrm{e}}$ can be fitted to $\mathrm{Eq}(6)$ with $\mathrm{n}=2.02 \pm 0.45$. For $\mathrm{Ca}_{\mathrm{e}}>2 \mathrm{mM}$, the EPSC amplitude starts to saturate, possibly due to postsynaptic receptor saturation and multivesicular release (Foster et al., 2005). The saturation of the EPSC amplitude in elevated $\mathrm{Ca}_{\mathrm{e}}$ is more pronounced in the $\mathrm{KO}$ than in the WT. Upon increase of $\mathrm{Ca}_{\mathrm{e}}$ to 3 and $4 \mathrm{mM}$, the EPSC amplitude does not increase by the same amount as in the WT. These results suggest that the kinetics of the EPSC in Eag1 KO cells are not changed, however, the reaction to de- and increased $\mathrm{Ca}_{\mathrm{e}}$ differ slightly between the mutant and the WT. This might point towards an increased $\mathrm{Ca}^{2+}$ influx during an action potential in the Eag1 $\mathrm{KO}$, as a lower $\mathrm{Ca}_{\mathrm{e}}$ leads to more release than in the WT. Calcium plays a crucial role in synaptic plasticity (Katz and Miledi, 1968; Atluri and Regehr, 1998; Zucker and Regehr, 2002), and a possible change in $\mathrm{Ca}^{2+}$ entry in the Eag1 KO might subsequently cause alterations in synaptic plasticity at cerebellar synapses. Therefore, I proceeded to investigate short-term changes in synaptic efficacy in the cerebellar cortex.
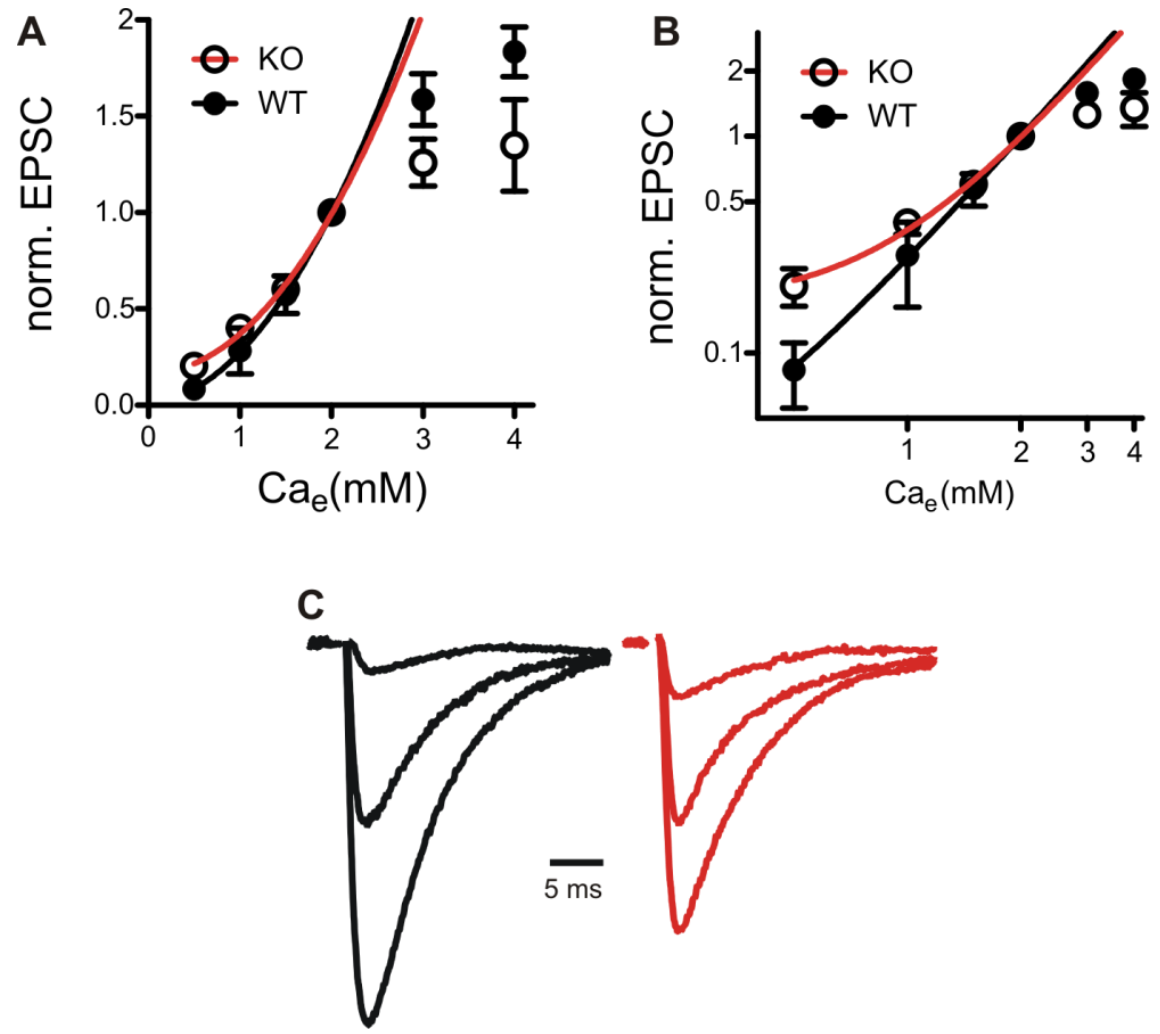

Figure 13 Dependence of transmitter release on extracellular calcium. A, EPSC amplitudes are plotted as a function of $\mathrm{Ca}_{\mathrm{e}}$. Amplitudes are normalised to the EPSC at $2 \mathrm{mM}$. Solid circles, wt, $\mathrm{n}=6$; open circles, Eag1 KO, $\mathrm{n}=6$. Lines are fits to equation 6. Black line, $\mathrm{n}=1.94$; red line, $\mathrm{n}=2.02 \mathbf{B}$, the data in $\mathbf{A}$ are plotted on a logarithmic scale to demonstrate the close-to-linear relationship in the wt for $\mathrm{Ca}_{\mathrm{e}}<2 \mathrm{mM}$, which can be fitted by the equation $\mathrm{EPSC}=k\left(\mathrm{Ca}_{\mathrm{e}}\right)^{\mathrm{n}}$ with $\mathrm{n}=1.94$. For $\mathrm{Ca}_{\mathrm{e}}>2 \mathrm{mM}$, the amplitude starts to saturate. The amplitudes in the $\mathrm{KO}$ cells seem to saturate earlier and are less reduced by a reduction in $\mathrm{Ca}_{\mathrm{e}} . \mathbf{C}$, Representative traces from a WT (left, black) and an Eag1 KO (right, red) Purkinje cell elicited by extracellular stimulation in $0.5,2$, and $4 \mathrm{mM} \mathrm{Ca}$. The EPSCs are normalised to the amplitude at $2 \mathrm{mM}$ (middle) and the stimulus artifact has been blanked out for clarity. 


\subsubsection{Increased facilitation in Eag1 $\mathrm{KO}$ cells}

Parallel fibre (PF) synapses have a very low initial release probability (Dittman et al., 2000), and thus express prominent paired pulse facilitation (PPF) (Konnerth et al., 1990; Atluri and Regehr, 1996; Dittman et al., 2000). Upon repeated stimulation in trains, facilitation reaches a plateau at around the fifth stimulus (Kreitzer and Regehr, 2000). I measured the EPSCs in Purkinje cells in response to extracellular stimulation in the presence of the $\mathrm{GABA}_{\mathrm{A}}$ blocker SR 95531. As in the previous experiment, the tip of the stimulation pipette was inserted into the granule layer about $150-200 \mu \mathrm{M}$ away from the recording site to avoid fibre recruitment during stimulus trains (Barbour, 1993; Marcaggi and Attwell, 2005; Beierlein et al., 2007) and stimulation of the ascending fibre synapses. In both genotypes, strong facilitation was observed. In Figure 14Figure 14A, representative recordings form a WT (middle) and an Eag1 KO cell (bottom) are shown. Each trace is the average of ten consecutive recordings. When tested over a range of intervals, percentual plateau facilitation defined as the ratio $\left(\left(\mathrm{EPSC}_{5}-\mathrm{EPSC}_{1}\right) / \mathrm{EPSC}_{1}\right) \times$ 100 decayed with a time constant of $74.4 \mathrm{~ms}$ in the WT and $46.6 \mathrm{~ms}$ in Eag1 KO cells (Figure 14B). This difference is mainly attributable to the increase in facilitation at interstimulus intervals (ISIs) of $<50 \mathrm{~ms}$. At an ISI of $10 \mathrm{~ms}$, facilitation in the knockout was increased by $70 \%$ to $256 \%$ ( $p<0.001$, Student's t-test) in comparison to the WT, while at an ISI of $25 \mathrm{~ms}$ the increase was $50 \%$, from 134 to $187 \%$ ( $\mathrm{p}<0.01$, Student's t-test).
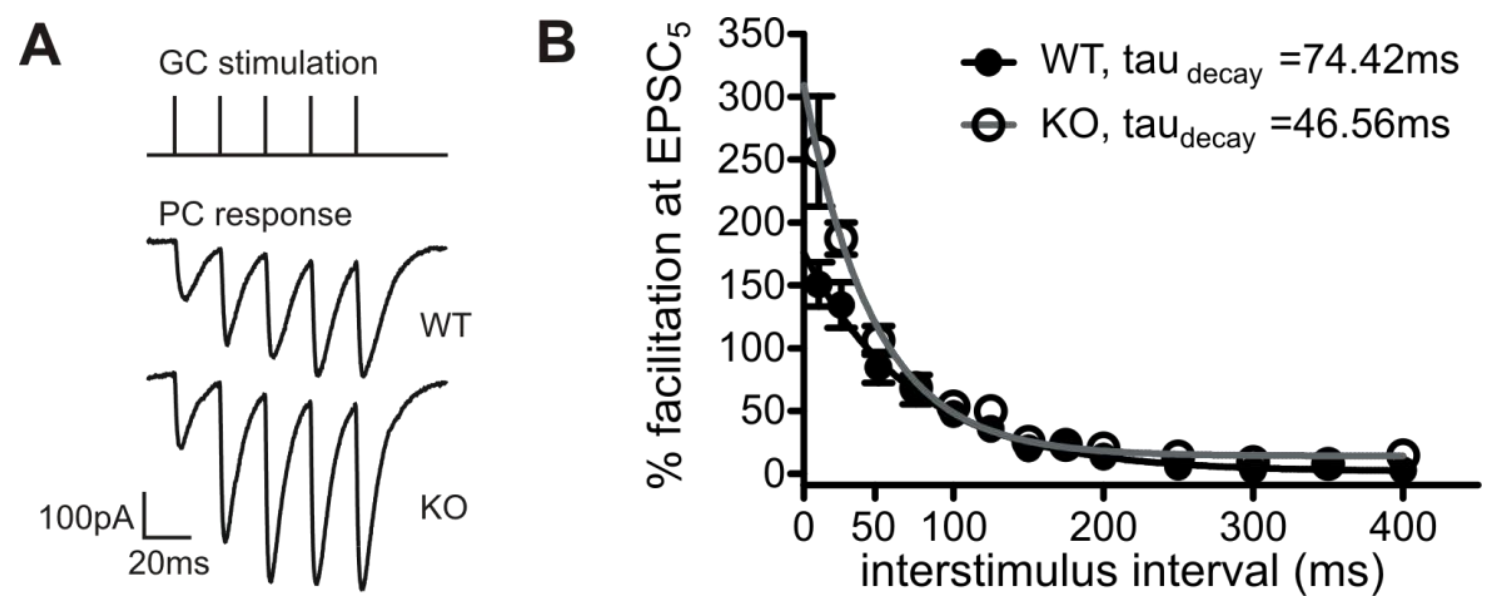

Figure 14. Facilitation is increased in Eag1 KO mice in a frequency dependent manner. A, PCs were whole-cell patch clamped during extracellular stimulation in the granule layer in the presence of SR 95531. 50Hz stimulus train (top) with representative recordings from a WT (middle) and Eag1 KO (bottom) PC. The shown traces are the average of ten sweeps each, and the stimulus artefact has been blanked out. B, Plateau facilitation plotted against the interstimulus interval. The amplitude of facilitation decays exponentially with a time constant of $74.4 \mathrm{~ms}$ in the WT (solid circles) and $46.6 \mathrm{~ms}$ in the KO (open circles). Note the significant differences at intervals $<50 \mathrm{~ms}(\mathrm{p} \leq 0.05$, Student's t-test) 


\section{Facilitation during regular stimulus trains}

When examining the time course of single EPSCs during train stimulations, it became clear that the effect of Eag1 was dependent both on the pulse number and on the stimulation frequency. In Figure 15, the percentual facilitation is plotted against the stimulus number. A regular $10 \mathrm{~Hz}$ stimulus train evoked the same response in WT and Eag1 KO cells (i), namely a stable facilitation of about $30 \%$ that did not decay during the train. Upon $20 \mathrm{~Hz}$ stimulation (ii), the responses started to diverge slightly over the train and reached a significant at difference at pulse $10(61 \pm 8.3 \%, \mathrm{n}=8$ in the WT and $85 \pm 6.7 \%, \mathrm{n}=10$ in Eag1 KO cells; $\mathrm{p}<0.05$, Student's t-test). Stimulation with a $50 \mathrm{~Hz}$ train caused increased facilitation throughout the train in Eag1 $\mathrm{KO}$ cells in comparison to the WT (iii). In both genotypes, the plateau was reached between the $3^{\text {rd }}$ and $5^{\text {th }}$ pulse and maintained until the tenth pulse. The difference between Eag1 KO and WT cells however was largest after the $3^{\text {rd }}$ pulse. When stimulated with a $100 \mathrm{~Hz}$ train (iv), the difference between WT and KO increased until the fifth pulse. Facilitation in both genotypes declined after reaching the peak value. These findings suggest that Eag1 is involved in modulation of synaptic strength during high-frequency stimulus trains.
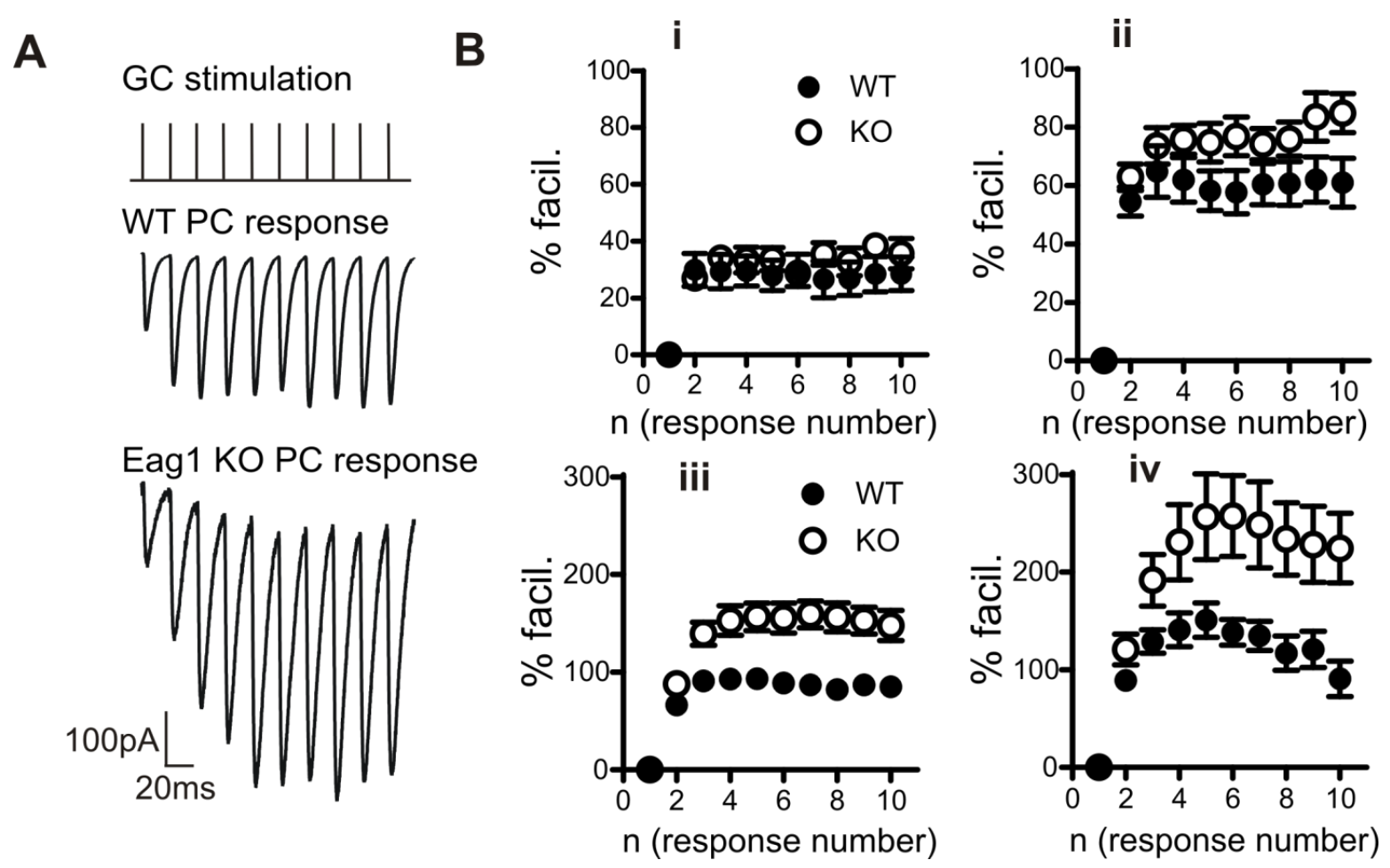

Figure 15. Facilitation is increased in Eag1 KO mice in a frequency- and pulse number-dependent manner. A, $50 \mathrm{~Hz}$ stimulus train with representative recordings from a WT (top) and Eag1 KO (bottom) Purkinje cell. The shown traces are the average of ten sweeps each. $\mathbf{B}$, Response to train stimulations with $10 \mathrm{~Hz}$ (i), $20 \mathrm{~Hz}$ (ii), $50 \mathrm{~Hz}$ (iii) and $100 \mathrm{~Hz}$ (iv). The percentual facilitation is defined as $\left(\mathrm{EPSC}_{\mathrm{n}^{-}}\right.$ EPSC $_{1}$ )/EPSC $\mathrm{EP}_{1} 100$ and plotted against the response number. At 10 and $20 \mathrm{~Hz}$, no significant difference in the response is seen, while at $50 \mathrm{~Hz}$ and $100 \mathrm{~Hz}$ the Eag1 $\mathrm{KO}$ cells showed a strongly increased facilitation. The effect is also dependent on the stimulus number and is strongest between pulse two and five. 


\section{Facilitation at changed $\mathrm{Ca}_{\mathrm{e}}$}

I proceeded to determine the effect of changed $\mathrm{Ca}_{\mathrm{e}}$ on the responses to regular stimulus trains. Changes in external calcium and calcium influx also have strong effects on the steady state amplitude of facilitation, since the release probability is altered. A reduction in release probability has been related to increased facilitation and vice versa (Kreitzer and Regehr, 2000; Foster et al., 2005). In the WT, facilitation in 2 and $3 \mathrm{mM} \mathrm{Ca}_{\mathrm{e}}$ reaches a plateau after pulse 3 and stays constant during the train. Lowering $\mathrm{Ca}_{\mathrm{e}}$ to $1 \mathrm{mM}$ caused the facilitation to build up during the train until approximately the eighth pulse. In Eag1 $\mathrm{KO}$ cells, facilitation in $3 \mathrm{mM} \mathrm{Ca}$ reached a plateau around the third pulse, at $2 \mathrm{mM} \mathrm{Ca}_{\mathrm{e}}$ at the fifth pulse and in $1 \mathrm{mM} \mathrm{Ca}_{\mathrm{e}}$ around pulse 8 . The steady state facilitations (defined as $\mathrm{EPSC}_{8} / \mathrm{EPSC}_{1}$ ) in different concentrations of $\mathrm{Ca}_{\mathrm{e}}$ for WT and Eag1 KO cells are show in Figure 16C. Earlier studies report a decrease in facilitation as $\mathrm{Ca}_{\mathrm{e}}$ increases (Kreitzer and Regehr, 2000; Foster et al., 2005). I found that in the WT, steady-state facilitation was largest in $1.5 \mathrm{mM} \mathrm{Ca}_{\mathrm{e}}$ and decreased upon further increase in $\mathrm{Ca}_{\mathrm{e}}$.
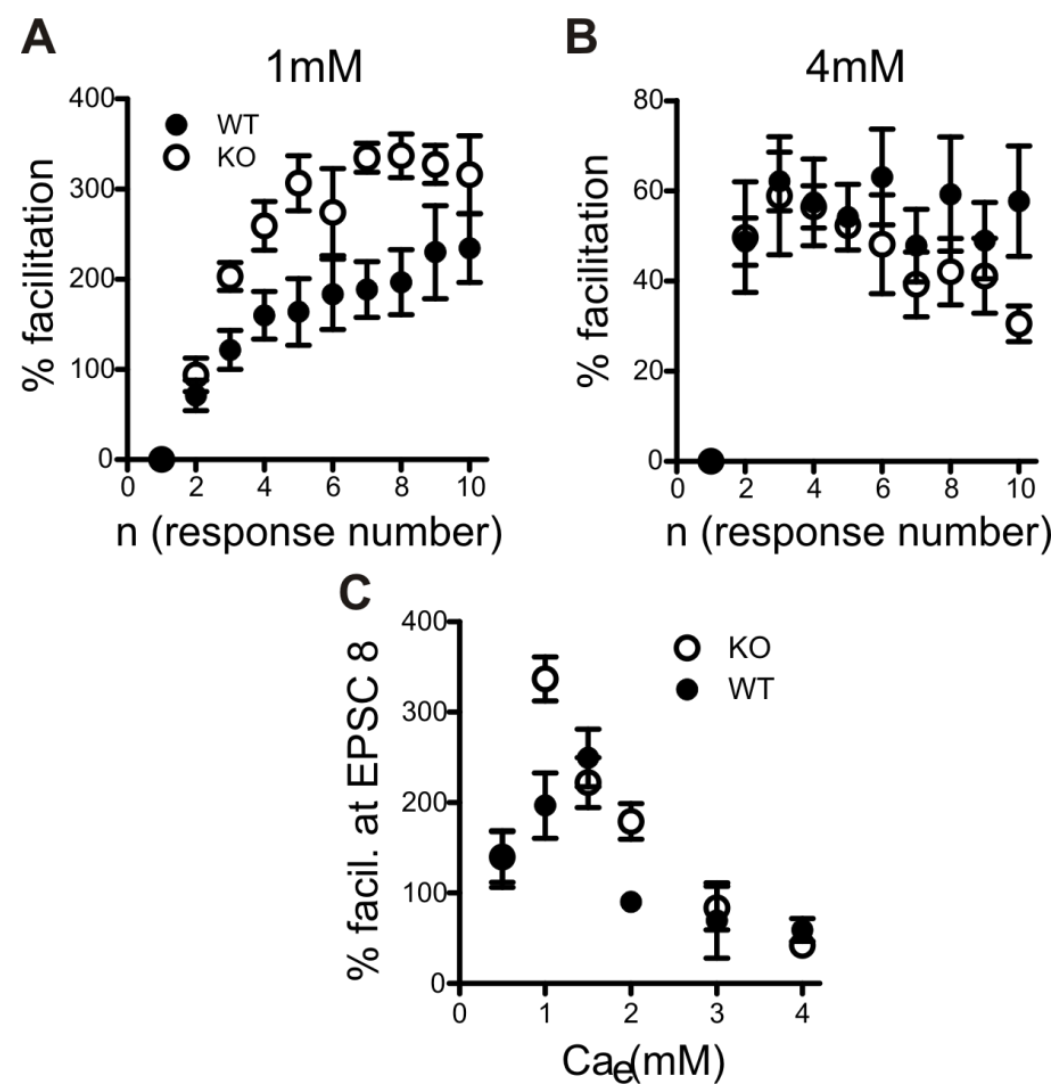

Figure 16 Facilitation at the PF-PC synapse at different concentrations of $\mathbf{C a}_{\mathrm{e}}$. $\mathbf{A}$, Response to $50 \mathrm{~Hz}$ train stimulation in $1 \mathrm{mM}$ external calcium. B, same in $4 \mathrm{mM}$ external calcium. C, Percentual facilitation at the 8th EPSC of a $50 \mathrm{~Hz}$ train, when facilitation reached a plateau. Open circles, Eag1 KO; solid circle, WT. Each data point is the average of five to ten cells. 
A possible reason is that the calcium influx in very low $\mathrm{Ca}_{\mathrm{e}}$ is too small to cause a significant increase in residual calcium, which is the most important factor for facilitation in the parallel fibre synapse (Atluri and Regehr, 1996). In the knockout, the largest facilitation is observed already at $1 \mathrm{mM} \mathrm{Ca}_{\mathrm{e}}$. Assuming an increased calcium influx already at lower $\mathrm{Ca}_{\mathrm{e}}$, the calcium influx at $1 \mathrm{mM} \mathrm{Ca}$ e would be enough to lead to a strong increase in residual calcium. Interestingly, the peak facilitation in the WT $\left(249 \pm 31 \%\right.$ at $\left.1.5 \mathrm{mM} \mathrm{Ca}_{\mathrm{e}}\right)$ is still smaller than the peak facilitation in the Eag1 KO cells $\left(337 \pm 24 \%\right.$ at $\left.1 \mathrm{mM} \mathrm{Ca}_{\mathrm{e}}\right)$.

\section{Decrease of facilitation during long stimulus trains}

An increased facilitation can also mean increased transmitter release and should accordingly lead to an earlier depletion of the vesicle pool. It has been reported, that the PF-PC synapse can sustain high rates of firing for more than 100 pulses without depression (Kreitzer and Regehr, 2000). I tested the response to a train of 50 stimuli given at $50 \mathrm{~Hz}$ to see if the EPSC size decreased and if yes, if there were differences between WT and Eag1 KO cells. Figure 17 shows the percentual facilitation plotted against the response number. The time course of facilitation during the train was different between WT and Eag1 KO. As seen in Figure 15B and Figure 17, facilitation rose to a plateau at the $3^{\text {rd }}$ pulse in the WT, from which it decayed nearly linearly to $42.6 \%$ at pulse 50. Facilitation in the Eag1 $\mathrm{KO}$ cells showed a sharp peak between the 2nd and $10^{\text {th }}$ pulse before decaying also close to linear after pulse 10 to $84.7 \%$ at pulse 50 . The slopes of the decay were $-1.023 \pm 0.023$ in the WT and $-1.408 \pm 0.053$ in the Eag1 KO $(p<0.0001$, Student's t-test).

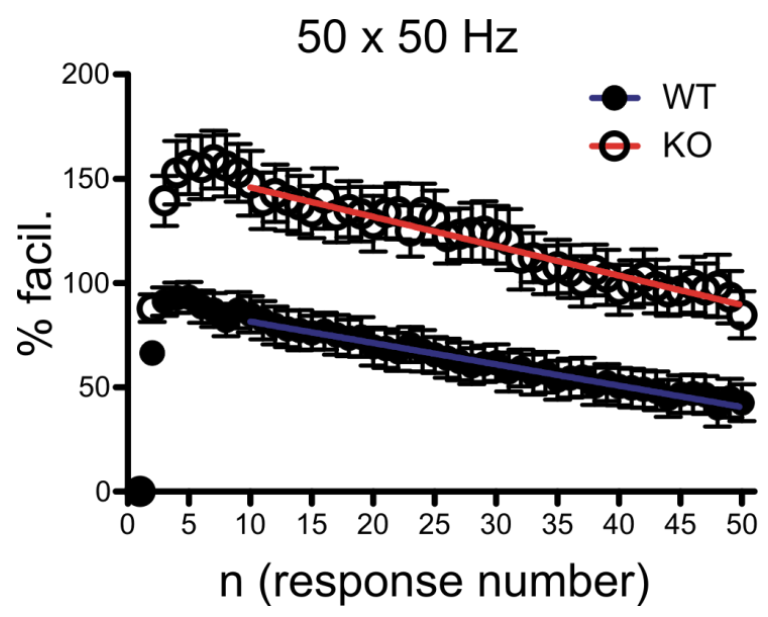

Figure 17: Facilitation decays during a stimulus train. During prolonged stimulation at $50 \mathrm{~Hz}$, the facilitation in both genotypes decays close to linearly after an initial peak. The slopes of the decay are significantly different between WT and Eag1 KO (-1.023 \pm 0.023 and $-1.408 \pm 0.053$, respectively). 
This suggests that in the Eag1 KO synapses, more transmitter is released in the first phase of the train, which causes a slightly faster reduction in the vesicle pool or a faster saturation and desensitisation of postsynaptic receptors.

\section{Kinetics of the EPSC during trains}

To gain more insight about the reasons for increased facilitation, it is crucial to determine the kinetics of the EPSCs and compare them between the WT and Eag1 KO cells.

The rise time of the EPSC is tightly related to the calcium signal in the presynaptic terminal. Changes in the rise time might reflect changes in the action potential and the subsequent duration of the calcium microdomain, which causes fast, phasic release of neurotransmitter (Bollmann and Sakmann, 2005). A broadening of the EPSC during the train can be evidence for glutamate pooling or spillover (Carter and Regehr, 2000). Anatomical studies have shown that parallel fibre - Purkinje cell synapses are well ensheathed by glia cells, which makes spillover and pooling less likely to occur (Xu-Friedman et al., 2001). Further, by extracellular stimulation I activated granule cells that give disperse input throughout the dendritic tree, and not just a single "beam" as observed during extracellular stimulation (Marcaggi et al., 2003). An increased decay time can also be caused by an increase in delayed release, which is driven by residual calcium (Chen and Regehr, 1999).

Figure 18A shows the absolute values of the $10-90 \%$ rise time of EPSCs recorded in Purkinje cells during extracellular stimulation in the granule layer at $50 \mathrm{~Hz}$. The first EPSC had a rise time of $1.24 \pm 0.12 \mathrm{~ms}$ in the WT and $1.35 \pm 0.10 \mathrm{~ms}$ in the Eag1 $\mathrm{KO}$ ( $\mathrm{n}=17$ and 14 , n.s.). In WT cells, the rise time increased very little during the train, indicating that the calcium current triggering release did not increase in duration. In Purkinje cells of Eag1 KO animals, the rise time of the EPSC increased during the first five stimuli of the train before reaching a plateau at $1.67 \pm 0.14 \mathrm{~ms}$ in comparison to $1.31 \pm 0.08 \mathrm{~ms}$ in the WT ( $\mathrm{p}=0.0235$, unpaired $\mathrm{t}$-test). On the right side of Figure 18A, the rise times were normalised to the first value and plotted against the stimulus number. The time course of the rise times resembled closely that of the facilitation in response to a $50 \mathrm{~Hz}$ train (Figure 15B). While the rise time in the WT increased slightly during the first three pulses, the rise time in the Eag1 KO cells rose more steeply until the fifth pulse where it reached a plateau $(1.25 \pm 0.052 \mathrm{~ms}$ in the Eag1 KO and $1.068 \pm$ $0.03873 \mathrm{~ms}$ in the WT, respectively. $\mathrm{p}=0.0066$, unpaired t-test).

The decay times of the EPSCs are pictured in Figure 18B. On the left, the absolute values are plotted against the stimulus number. Decay times in the Eag1 KO cells were slightly, but not significantly larger than in the WT. The diagram on the right side shows that the time course of the decay times is not different in both genotypes. These data suggest a prolongation of 
neurotransmitter release during a regular $50 \mathrm{~Hz}$ - stimulus train. The effect is visible in both genotypes, but markedly stronger in Eag1 KO cells.
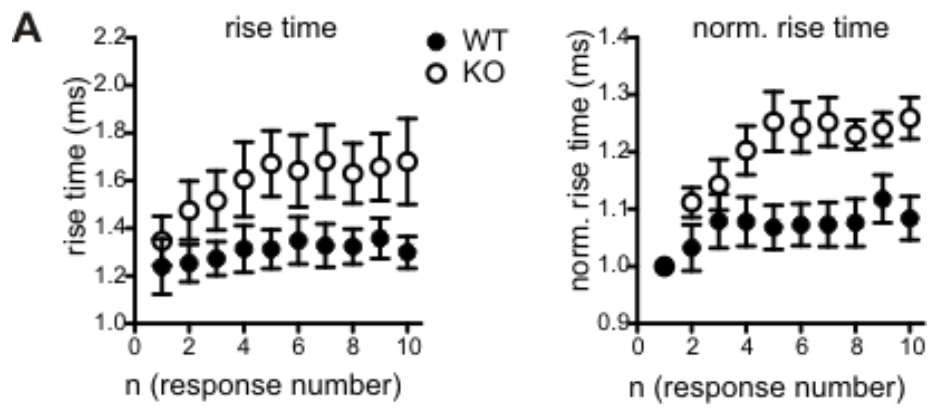

B
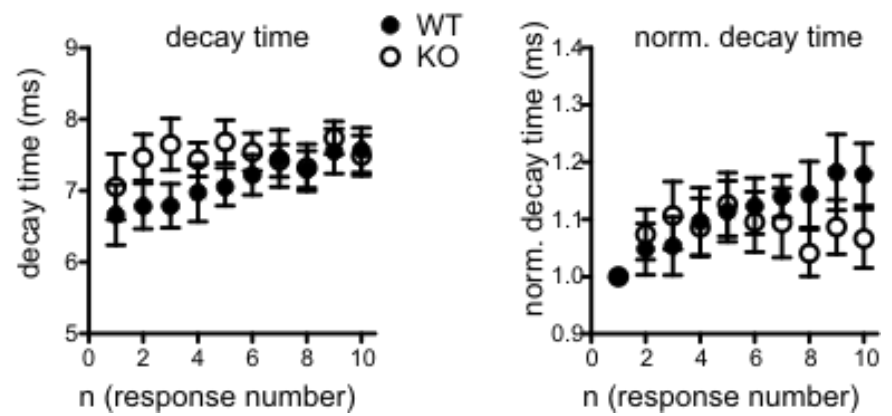

Figure 18. EPSC kinetics of WT and Eag1 KO mice. A, left The 10-90\% rise time of the EPSCs measured in Purkinje cells during stimulation with $50 \mathrm{~Hz}$ in the granule layer are plotted against the stimulus number. In the WT (solid circles), the rise time increases only nonsignificantly during the stimulus train. In Eag1 KO cells (open circles), the rise time increases during the first five stimuli of the train before reaching a plateau. Right, the rise time values are normalised to the first one in the train. It becomes clear that the increase is more pronounced in the Eag1 KO cells (open circles) than in the WT (solid circles). B, left, the decay of the EPSCs was fitted with a single exponential and the time constant plotted against the stimulus number. In both genotypes, a slight increase in the decay time is observed, which is a little more pronounced in the WT (solid circles) than in Eag1 KO cells (open circles). Right, the data points are normalised to the first one in the train. The time course of the increase in the decay time is very similar between WT and Eag1 KO. Data points are averages of 14-17 cells each, error bars are s.e.m.

Bollmann et al. (2005) showed that a broadening of calcium current leads to an increase in rise time. This finding points towards a role for Eag1 in action potential repolarisation. The decay times of EPSCs do not differ between WT and KO, providing evidence against Eag1 being located postsynaptically. Further, only a small increase occurs during trains of stimuli, suggesting that glutamate spillover and pooling does not cause the increase facilitation seen in Eag1 KO cells. 


\subsubsection{Target-dependent plasticity in the cerebellar cortex}

Axons of granule cells form synapses onto Purkinje cells as well as onto molecular layer interneurons. Basket cells (BC) are located close to the Purkinje cell soma and receive input mainly from the ascending part of the axon while stellate cells (SC) are located between the pia and the middle of the molecular layer (Palay and Chan-Palay, 1974). The different synapses formed by the granule cell axon have been shown to express target-dependent plasticity (Bao et al., 2010). I wanted to test if the loss of Eag1 affects all three synapses in the same way, so I performed whole-cell patch clamp on the cell bodies of SC and BC during extracellular stimulation of granule cells. Facilitation in the stellate cells was smaller than that observed in Purkinje cells from WT animals. The time course however was similar (Figure 19A). This is different from the results reported in Bao et al. (2010), who observed a strong facilitation followed by a decay of the EPSC amplitude. Facilitation at pulse 3 was $51.1 \pm 9.2 \%$ in the WT (Figure 19C, solid circles), and $48.7 \pm 9.1 \%$ in the KO (Figure 19C, open circles).

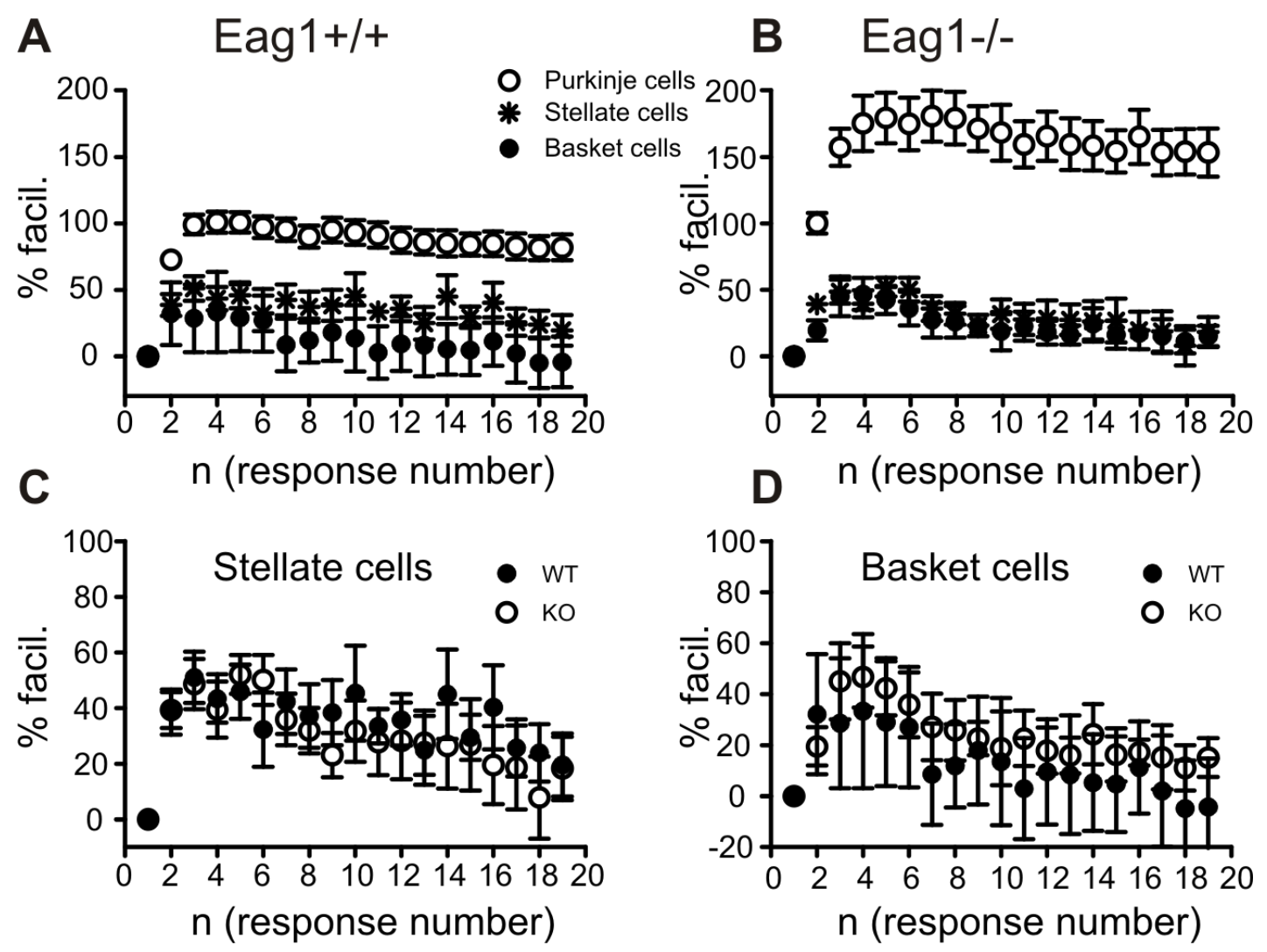

Figure 19. Eag1 does not alter facilitation at PF - BC and PF - SC synapses. A, PF synapses express target-dependent plasticity in the WT. The percentual facilitation is defined as $\left(\mathrm{EPSC}_{\mathrm{n}}-\mathrm{EPSC}_{1}\right) / \mathrm{EPSC}_{1} \mathrm{X}$ 100 and plotted against the response number. Each point is the average of 24 Purkinje cells (open circles), 6 stellate cells (stars) and 7 basket cells (solid circles). B, Loss of Eag1 acts only on PF-PC synapse (24 cells, open circles) but not on PF - SC (6 cells, stars) or PF - BC (6 cells, solid circles) synapses. C, PFSC synapses are not changed by loss of Eag1. D, PF-BC synapses are not changed by loss of Eag1. 
Facilitation in basket cells showed a slightly different time course during the train than in Purkinje or stellate cells. While the EPSCs in PCs and SCs reached a stable plateau in the WT (Figure 19A), responses in basket cells of both genotypes reached a peak value around the third pulse followed by a decrease in facilitation until the size of the first response was almost recovered (Figure 19D). Facilitation at $\mathrm{EPSC}_{3}$ in the WT was $28.6 \pm 25.5 \%$ (Figure 19D, closed circles), $45.1 \pm 15.0 \%$ in Eag1 KO cells (Figure 19D, closed circles).

This is in line with previous findings (Bao et al., 2010), that see the PF-BC synapse as a depressing synapse. While in my hands no clear depression is observed, a strong decrease in facilitation is obvious. Neither synapse was significantly affected by loss of Eag1. This speaks in favour of a selective localisation of Eag1 channels at parallel fibre - Purkinje cell synapses and against localisation on the ascending axon

\subsubsection{EGTA application does not rescue increased facilitation}

The residual calcium hypothesis is a widely accepted theory that states that accumulation of calcium ions in the presynaptic terminal leads to an increased release upon arrival of the next action potential (Zucker and Regehr, 2002). Residual calcium can be reduced by the introduction of the low-affinity calcium chelator EGTA into the terminal (Atluri and Regehr, 1996). Due to the slow time constant of EGTA, the peak $\mathrm{Ca}^{2+}$ transient is not affected, while the decay of residual $\mathrm{Ca}^{2+}$ is accelerated in a dose-dependent manner. A simple and straightforward explanation for the increased facilitation at the PF-PC synapse in Eag1 KO animals (Figure 14, Figure 15) is an increase in residual calcium, either due to prolonged opening of $\mathrm{Ca}^{2+}$ channels in the presynaptic terminal or to generally elevated basal $\mathrm{Ca}^{2+}$ levels due to a less polarised resting potential of the terminal. It has been shown on several studies that subthreshold depolarisations can lead to an increased resting $\mathrm{Ca}^{2+}$ and enlarged EPSCs (Awatramani et al., 2005; Hori and Takahashi, 2009; Christie et al., 2011). To test this hypothesis I performed facilitation experiments after incubating the slices with 50 $\mu \mathrm{M}$ EGTA tetra(acetoxymethylester) (AM), which enables it to permeate cell membranes. Inside the cell, the acetoxymethylester is cleaved off and the now membrane-impermeable EGTA accumulates inside the cell. I started by determining the paired-pulse ratio for interstimulus intervals (ISIs) between 100 and 25ms, since the loss of Eag1 did not affect facilitation during long ISIs (Figure 14). Paired-pulse facilitation, defined as $\left(\mathrm{EPSC}_{2}-\mathrm{EPSC}_{1} / \mathrm{EPSC}_{1}\right) \times 100$ decayed with a time constant of $42.11 \mathrm{~ms}$ in the WT and $27.91 \mathrm{~ms}$ in the KO (Figure 20A). 
A

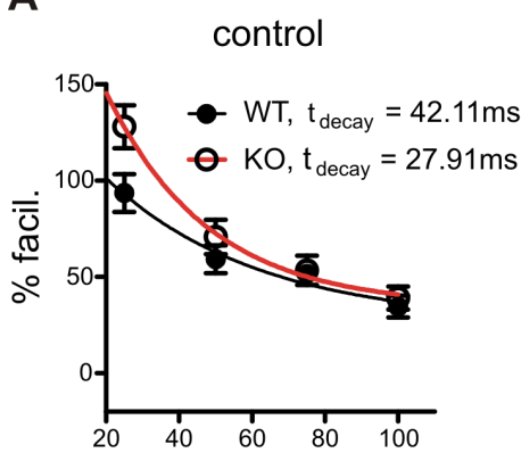

interstimulus interval (ms)
B

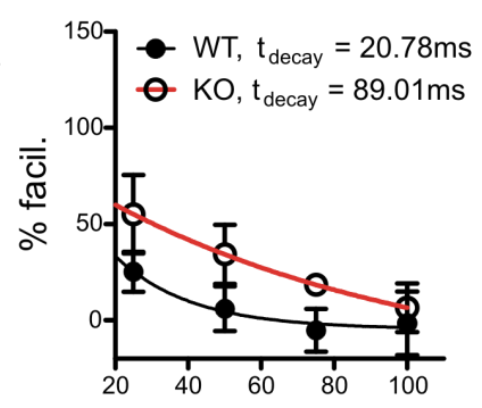

interstimulus interval (ms)
C

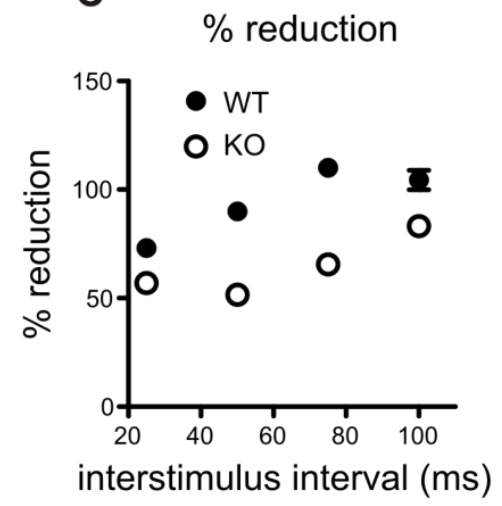

D

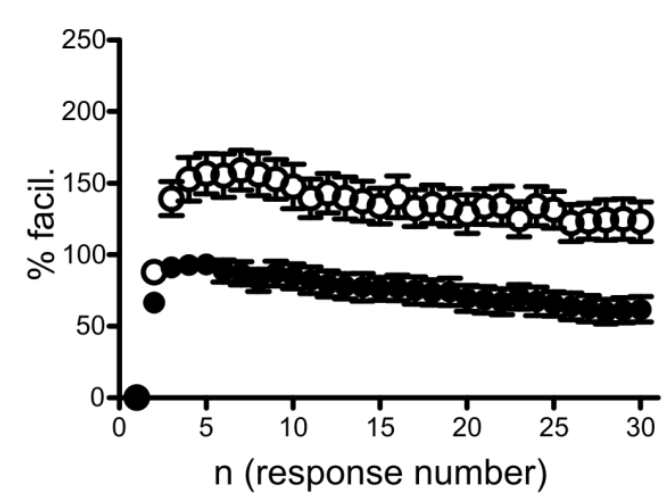

E

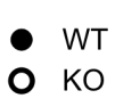

$50 \mu \mathrm{M}$ EGTA-AM

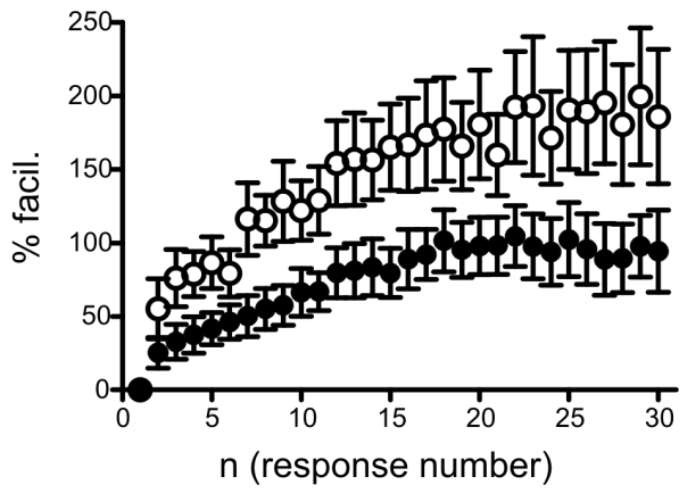

Figure 20. Alteration of calcium dynamics with EGTA-AM reduces facilitation in the WT and to a lesser extent in Eag1 KO mice. A, The time course of facilitation in $2 \mathrm{mM} \mathrm{Ca}$ without EGTA-AM. Facilitation at $25 \mathrm{~ms}$, but not longer interstimulus intervals (ISI) is increased in the KO, resulting in a faster decay constant. B, After 15min incubation with EGTA-AM, facilitation in the WT is strongly reduced at all ISIs. The decay constant is reduced to $20.78 \mathrm{~ms}$. In the $\mathrm{KO}$, the time constant is increased to 89.01ms. C, Percentual reduction of the facilitation after EGTA-AM application. Facilitation is reduced to la larger extent in the WT than in the KO. Data points are mean values calculated from $\mathbf{A}$ and $\mathbf{B}$, error bars are calculated from the pooled variance. Some error bars are obscured by points. D, Percentual facilitation in response to a $50 \mathrm{~Hz}$ train recorded in Purkinje cells. E, Percentual facilitation after incubation with 50 $\mu \mathrm{M}$ EGTA-AM. Each data point is the average of 4 to 6 cells, error bars are s.e.m.

These values are considerably shorter than those reported in Figure 14, but one has to keep in mind that the fit here was performed to only 4 values instead of 13 data points in Figure 14. The ratio of the decay constants between WT and Eag1 KO is similar (0.64 and 0.67). The slices were incubated with $50 \mu \mathrm{M}$ EGTA-AM for 15 minutes, followed by extensive washing with normal aCSF. Facilitation was considerably reduced in both genotypes (Figure 20B,C) for all ISIs. However, the time constants of facilitation were dramatically different. While in the WT, the decay time was only one-half of control, it was more than tripled in the KO. Comparing the reductions in facilitation caused by EGTA (Figure 20C), it became obvious that EGTA had less effect in the Eag1 KO than in the WT. The reduction in the WT increased with the ISI, reflecting a decrease in $\mathrm{Ca}_{\mathrm{res}}$ at longer time intervals between the pulses. In the $\mathrm{KO}$, the reduction was also more intense, but slower and starting from a lower value at $25 \mathrm{~ms}$ ISI. This 
suggests higher levels of $\mathrm{Ca}_{\text {res }}$ in the knockout, since we can assume that the concentration of EGTA in the terminals is very similar between WT and Eag1 KO.

I proceeded to determine the effect of EGTA on facilitation during a $50 \mathrm{~Hz}$ stimulus train. The percentual facilitation under control conditions is pictured in Figure 20D. As expected, the response to the $50 \mathrm{~Hz}$ train was changed after incubation with $50 \mu \mathrm{M}$ EGTA. Instead of rising sharply and reaching a plateau after few stimuli, facilitation continued to build up until reaching a plateau around the $20^{\text {th }}$ pulse This behaviour suggests a continuous increase in $\mathrm{Ca}_{\text {res }}$ in the terminal. With every pulse, more EGTA binds to $\mathrm{Ca}^{2+}$ and is thus not available for buffering at the following pulse. The equilibrium shifts towards $\mathrm{Ca}_{\mathrm{res}}$ and subsequently, facilitation increases. Facilitation is higher in the KO than in the WT, in line with the results in Figure 20AC.

These data suggest that the $\mathrm{Ca}^{2+}$ concentration is indeed higher in Eag1 KO terminals. Nevertheless, one could argue that the concentration of EGTA in the terminal should be high enough to reduce increased free $\mathrm{Ca}_{\text {res }}$ in the KO to WT levels. Thus, I cannot rule out the possibility of another factor contributing to the enhanced facilitation seen in the Eag1 KO synapses.

\subsubsection{Increased calcium influx into the presynaptic terminal}

To investigate how the observed modulation of synaptic strength by Eag1 is related to presynaptic calcium dynamics, I performed two-photon calcium imaging in presynaptic boutons of the parallel fibre. Although it is impossible to distinguish between PF-PC and PF-SC synapses in this preparation, we don't expect that the different properties of PF-SC synapses (Figure 19) significantly influence our results, since it is estimated that $\sim 94 \%$ of parallel fibre synapses form onto Purkinje cell dendrites (Palkovits et al., 1971).

After loading the granule cell for at least 20 minutes with the high-affinity calcium indicator Oregon Green BAPTA-1, the axon was visible far into the molecular layer and individual boutons appeared as bead-like swellings on both the ascending axon and parallel fibre (Figure $21 \mathrm{~A}, l e f t$ ). After selection of a bouton (Figure 21A, top right), a line scan was performed while one to three action potentials were elicited by injection of current pulses into the granule cell soma. Stimulation led to a rapid, transient increase in fluorescence (Figure 21A, bottom right). Figure 21B shows sample recordings in boutons of an Eag1 KO cell (red trace) and a WT cell (black trace) in response to three action potentials at $100 \mathrm{~Hz}$. Changes in fluorescence are plotted as $\mathrm{dF} / \mathrm{F}_{0}$, i.e. the background-subtracted change in fluorescence was divided by the baseline value (Figure 21B). Traces were fitted with an exponential decay function (red lines). A single action potential evoked a slightly but not significantly increased response in Eag1 KO cells in comparison to the WT (Figure $21 \mathrm{C}$, i). Increasing the number of action potentials to three at 
$50 \mathrm{~Hz}$ (Figure $21 \mathrm{C}$, ii) nearly doubled the peak $\mathrm{dF} / \mathrm{F}_{0}$ in WT and in Eag1 $\mathrm{KO}$ synapses $(\mathrm{p}<0.01$ and $\mathrm{p}<0.001$, respectively), but an increase in frequency from 50 to $100 \mathrm{~Hz}$ did not cause a further increase in the WT (Figure 21C, iii). This is in line with the earlier findings that the increase in facilitation at higher frequencies is not due to an increase in calcium influx, for example by calcium-dependent facilitation of calcium currents, but caused by downstream mechanisms like increase in $\mathrm{Ca}_{\text {res }}$ or saturation of endogenous calcium buffers (Mintz et al., 1995; Regehr and Atluri, 1995; Atluri and Regehr, 1996; Kreitzer and Regehr, 2000; Brenowitz and Regehr, 2007).

In the knockout however, increasing the frequency from 50 to $100 \mathrm{~Hz}$ further increased the peak $\mathrm{dF} / \mathrm{F}_{0}$ by $23.4 \%(\mathrm{p}<0.01)$. This would speak in favour of an increased calcium influx during the second and/or third pulse of the burst. This could be due to a prolonged opening of calcium channels due to a broadened action potential (Sabatini and Regehr, 1997; Bollmann and Sakmann, 2005). Due to its dependence on the holding potential, Eag1 would take part in repolarisation of the membrane depending on the frequency and pulse number. Comparing the results from WT and Eag1 KO boutons, it was observed that the peak $\mathrm{dF} / \mathrm{F}_{0}$ after 3 action potentials at $50 \mathrm{~Hz}$ was increased by $33.5 \%$ in the knockout ( $\mathrm{p}<0.05$, Fig $4 \mathrm{C}$ ii) and by $78.3 \%$ after 3 action potentials at $100 \mathrm{~Hz}(\mathrm{p}<0.001$, Figure $21 \mathrm{C}$ iv). 

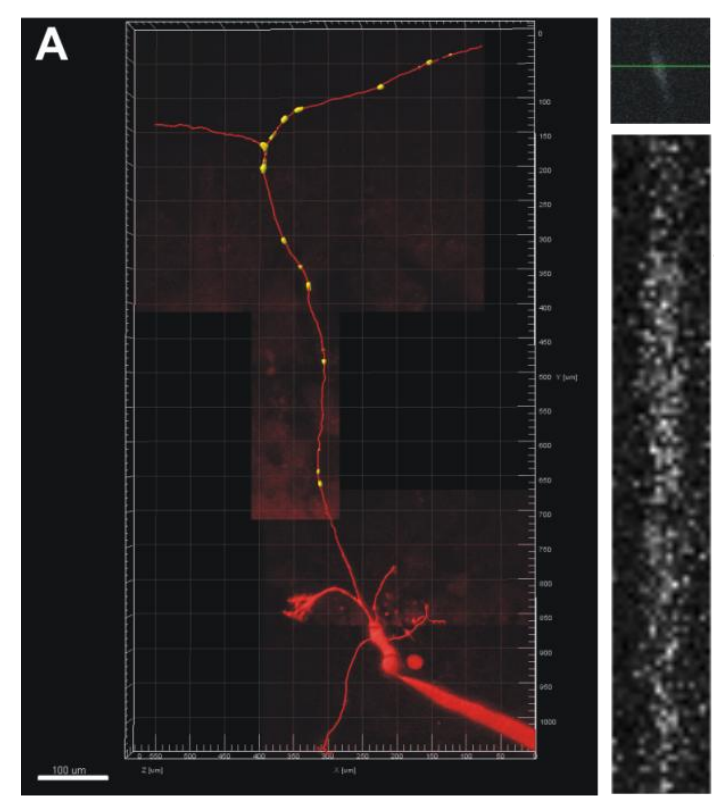

C $1 \mathrm{AP}$

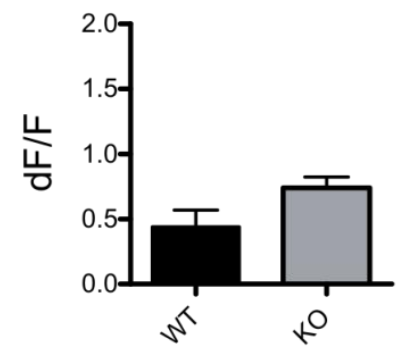

B $3 \mathrm{AP}, 100 \mathrm{~Hz}, \mathrm{WT}$

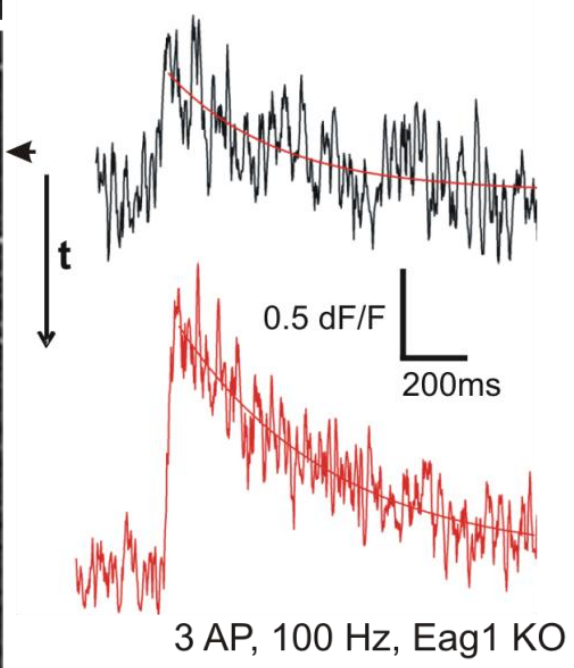

$3 \mathrm{AP}, 100 \mathrm{~Hz}$, Eag1 KO

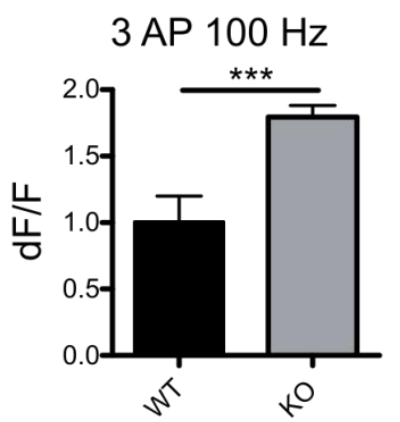

Figure 21. Two-photon-imaging in the parallel fibre bouton. A, left 3D-recontruction of a cerebellar granule cell filled with the high-affinity calcium indicator Oregon Green-BAPTA-1.The pipette is visible in the lower right corner. Synaptic boutons are pictured as yellow. Scale bar 100 $\mu$ m. Top right fluorescence was measured by performing a line scan across a bouton (horizontal line). Bottom, fluorescence signal as evoked by 3 action potentials (arrowhead). B, representative traces measured in a bouton of an Eag1 KO (bottom, red) and WT (top, black) in response to 3 action potentials given at $100 \mathrm{~Hz}$ to the granule cell soma. Traces were fitted with an exponential function (red line). C, The fluorescence ratio $\mathrm{dF} / \mathrm{F}_{0}$ measured in response to $1 \mathrm{AP}$ (left), $3 \mathrm{AP}$ at $50 \mathrm{~Hz}$ (middle), and $3 \mathrm{AP}$ at $100 \mathrm{~Hz}$ $($ right $)$. The calcium influx in the knockout is increased in a frequency dependent manner.

\subsubsection{Fitting a model of synaptic plasticity to the data}

The data I presented so far speak in favour of an increased facilitation although the action potential is broadened by loss of Eag1. A broadening of the action potential and subsequent increased calcium influx should lead to a higher release probability and thus to less facilitation. Simulations of synaptic plasticity offer a way to change a given parameter of a system and directly observe the consequences. Several mathematical models of synaptic plasticity have been developed to simulate the time course of facilitation and depression (Tsodyks and Markram, 1997; Varela et al., 1997; Dittman et al., 2000). All of them are phenomenological models, which describe the postsynaptic response without including a detailed biophysical 
description of the process. The model proposed by Dittmann et al. contains many free parameters but includes the concentration of calcium-bound sites as variables $\mathrm{CaX}_{\mathrm{F}}$ and $\mathrm{CaX}$ for facilitation and recovery from depression, respectively. After each action potential, $\mathrm{CaX}_{\mathrm{F}}$ and $\mathrm{CaX}_{\mathrm{D}}$ increase by a step of the size $\Delta_{\mathrm{F}}$ and $\Delta_{\mathrm{D}}$, respectively, and decay exponentially back to 0 with time constants $\tau_{\mathrm{F}}$ and $\tau_{\mathrm{D}}$. By fitting the model to the data obtained during $50 \mathrm{~Hz}$ stimulation, I tried to gain more insight in the interplay between the different parameters during facilitation and elucidate which parameters need to be changed in the WT to obtain the characteristics of the Eag1 KO. The fits were performed with the Mathematica software. Start values for parameters were chosen according to the results obtained in this study and, for parameters that were inaccessible, to resemble those published earlier (Dittman et al., 2000) and are summarised in Table 5 .

To compare the time course of facilitation during a train between WT and Eag1 KO, the normalised amplitudes obtained by stimulation with a $50 \mathrm{~Hz}$ pulse train were plotted against each other (Figure 22A). If the difference were mainly caused by a parallel shift due to the addition of a constant, the slope of the linear regression through the data points would be not significantly different from 1 .
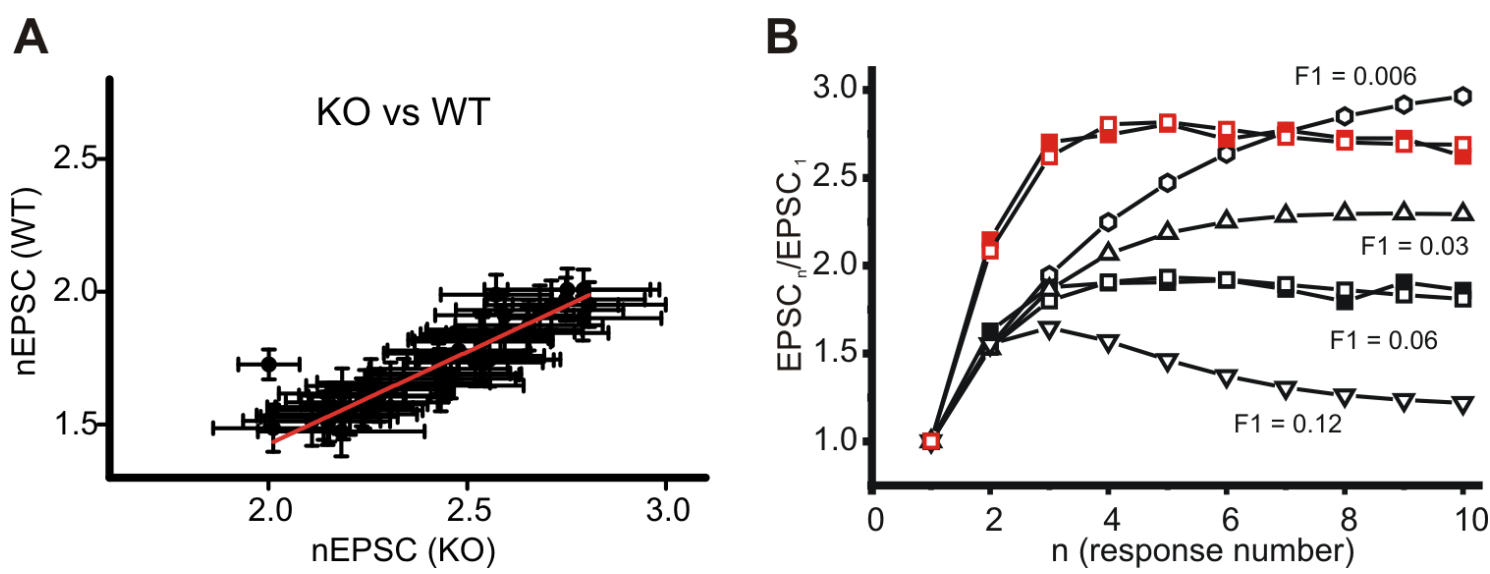

Figure 22. Fit to a phenomenological model of synaptic plasticity. A, normalised EPSC amplitudes recorded in WT and Eag1 $\mathrm{KO}$ cells in response to a $50 \mathrm{~Hz}$ stimulation are plotted against each other and fitted with linear regression. The slope is $0.7 \pm 0.03$, indicating that the two curves do not run in parallel to each other. B, fitting a model of synaptic plasticity to the data revealed that a good fit to the WT data (black squares for data, open squares for fit) cannot be converted into a good fit to the Eag1 KO data (red squares for data, open red squares for fit) by lowering the initial release probability (open circles, upright triangles) or increasing initial release probability (inverted triangles).

The linear fit yielded a slope of $0.7 \pm 0.03\left(\mathrm{R}^{2}=0.92\right)$. This is a strong indication that the two curves do not run in parallel to each other. The first data point was excluded, as the normalszation causes it artificially to be equal in both genotypes

Following this, the set of equations described in the Methods section were fitted to the first ten WT responses. The later pulses were excluded because the probable effects of postsynaptic receptor saturation and desensitisation, which can obscure presynaptic dynamics. 
Experimentally obtained values for facilitation (here, as in Dittmann et al. presented as normalised to the first response) in the WT (black squares) and Eag1 KO (red squares) are pictured in Figure 22B. The best fits are added as open symbols in the same colour. It soon became clear that the model is "underrepresented" by the data, meaning that several sets of parameters can result in a satisfactory fit. However, it was interesting to see that a good fit to the WT data cannot be converted into a good fit for the Eag1 KO data by only changing release probability. An increase in the initial release probability (termed F1, as in Dittman et al.) caused always less facilitation (inverted triangles), while a decrease in the release probability caused more facilitation but with a time course that does not match the KO data (Figure 22B, open circles, open triangles).

Table 5: Parameters used for fitting the model to the WT data. *, values used according to Dttiman et al. (2000). ' obtained experimentally.

\begin{tabular}{|c|c|c|}
\hline Parameter & Definition & $\begin{array}{c}\text { Value for fit to the WT } \\
\text { data }\end{array}$ \\
\hline $\mathrm{F} 1$ & Initial release probability & 0.06 \\
\hline $\mathrm{K}_{\mathrm{D}}$ & Affinity of $\mathrm{CaX}_{\mathrm{D}}$ for the release site & 4.5 \\
\hline $\mathrm{K}_{\mathrm{F}}$ & Affinity of $\mathrm{CaX}_{\mathrm{F}}$ for the release site & 10.6878 \\
\hline$\tau_{\mathrm{F}}$ & Decay constant of $\mathrm{CaX}_{\mathrm{F}}$ after an action potential & 0.1515 \\
\hline$\tau_{\mathrm{D}}$ & Decay constant of $\mathrm{CaX}_{\mathrm{D}}$ after an action potential & 0.05 \\
\hline$\Delta_{\mathrm{F}} *$ & Incremental increase of $\mathrm{CaX}_{\mathrm{F}}$ after a stimulus & 1 \\
\hline$\Delta_{\mathrm{D}} *$ & Incremental increase of $\mathrm{CaX}_{\mathrm{D}}$ after a stimulus & 1 \\
\hline $\mathrm{K}_{0} *$ & Baseline rate of recovery from refractory state & 2 \\
\hline $\mathrm{k}_{\max } *$ & Maximal recovery rate from the refractory state & 30 \\
\hline$\rho^{\delta}$ & Facilitation ratio $\mathrm{EPSC}_{2} / \mathrm{EPSC}_{1}$ & 1.7 \\
\hline $\mathrm{r}$ & frequency & $50 \mathrm{~Hz}$ \\
\hline
\end{tabular}




\section{Discussion}

In this thesis, I studied the localisation of Eag1 by biochemical and electrophysiological means and report for the first time an Eag1-compatible current in a mammalian neuron, namely the presynaptic terminal of the calyx of Held. Further, the involvement of Eag1 in synaptic transmission was evaluated at the parallel fibre - Purkinje cell synapse in the cerebellum. It was found that facilitation is increased in a frequency-dependent manner in synapses from Eag1 KO mice. Elimination of residual calcium in the terminal by EGTA-AM did not rescue the phenotype. Calcium imaging revealed that the calcium influx is increased depending on the pulse number and stimulation frequency. This was further supported by assessing the relationship between external calcium and transmitter release and facilitation and by fitting a mathematical model of synaptic plasticity to the data.

\subsection{Subcellular localisation of Eag1 channels}

\section{Western blotting}

It has been reported before that Eag1 is widely expressed in the mammalian brain (Ludwig et al., 2000; Saganich et al., 2001; Martin et al., 2008), however the exact subcellular localisation of the channel was unclear. Electrophysiological studies and immunostainings in Drosophila larvae and adults agree on a presynaptic localisation except for some antennal neurons where dEag is involved in dendritic transduction of odours (Kaplan and Trout, 1969; Ganetzky and Wu, 1983; Wu et al., 1983; Dubin et al., 1998; Wang et al., 2002; Sun et al., 2004). In mammals, the published evidence for a certain localisation of Eag1 in the brain is sparse and contradicting and relies exclusively on immunostainings. Jeng et al. (2005) claimed somatodendritic localisation in hippocampal neurons as well as colocalisation with synaptic markers. However, their conclusion that the staining from Eag1 is "opposite" of that from presynaptic markers has to be interpreted with care. The size of a hippocampal synapse is so small, that a distinction of pre- and postsynaptic site is difficult with standard confocal microscopy. Martin et al. (2008) observed only somatic signals for Eag1 in the adult rat brain. This can be due to the very high turnover rate of the channel, so that a lower expression in axons or dendrites falls below the detection limit after optimisation of the signal to noise ratio. The most recent study dealing with the localisation of Eag1 used single-particle tracking on cultured hippocampal neurons to determine the lateral mobility of Eag1 (Gómez-Varela et al., 2010). They report an axonal localisation for $80 \%$ of the particles and a drastic slowing down of mobility in synaptic regions. Further, electron micrographs of suggest a predominantly presynaptic localisation of Eag1. 
I performed a Western blot with subcellular fractions of the adult mouse brain to gain more insight in the subcellular localisation of Eag1. A signal was detected in all fractions except in cytosolic synaptosomal proteins. This was expected, as Eag1 is a transmembrane protein. Taking into account the high turnover rate of the channel, a signal in the cell bodies as well as the crude synaptic vesicle fraction was also expectable. The strongest signal was observed in the synaptic plasma membrane fraction. This fraction also contains glial membranes, so I performed a western blot with protein lysates from cultured glia cells. No band was detected, indicating that the signal in the synaptic plasma membrane fraction most probably originates from Eag1 in neuronal membranes. This is further corroborated by real time PCR results from cultured glia cells, which shows only very low or no expression of Eag1 mRNA (R. Ufartes, personal communication).

These data suggest a preferentially synaptic localisation of Eag1 channels. The synaptic plasma membrane fraction contains both pre and postsynaptic membranes, so a final conclusion about the exact position of Eag1 cannot be made by biochemical means.

\section{An Eag1-compatible current in the rat calyx of Held}

So far, no endogenous Eag1 current has been measured in neuronal cells. Considering the synaptic localisation of Eag1, one might argue that patch-clamping the soma is not suitable for detection of an Eag1 current among the various potassium conductances in a neuron. The synaptic terminal is usually very small and not accessible by measurements with microelectrodes. An exception to this is the calyx of Held, a giant presynaptic terminal in the auditory brainstem, which is accessible to direct patch-clamp recordings (Borst et al., 1995). I performed whole-cell patch clamp on the presynaptic terminal in young rats and mice with the aim to record a current compatible with Eag1. After adding caesium to the intracellular solution, I was able to measure an outward current whose activation kinetics was dependent on the holding potential (Figure 5). The effect was not so strong as in heterologous expression systems like HEK-293 cells or Xenopus oocytes, but considering the presence of other Cs-conducting potassium channels at the calyx (Schneggenburger and Forsythe, 2006) it is unlikely that a pure Eag1 current was recorded. Since no specific chemical blocker is available, I used a monoclonal antibody against the pore of Eag1, that has been shown to reduce currents through the channel (Gómez-Varela et al., 2007). After 15 minutes of incubation with the antibody and repetitive depolarisation, I observed a reduction in the steady state current by $25.9 \%$ (Figure 5 ), which speaks in favour of a participation of Eag1 in the current. The Cole-Moore shift was only slightly affected by the antibody. This might be due to expression of Eag2, which gives rise to similar currents as Eag1 and also shows a Cole-Moore shift (Saganich et al., 1999). Eag1 and Eag2 can form heteromultimers (Schönherr et al., 2002a), which are not necessarily blocked by the antibody, so the remaining current sensitive to the holding potential probably carried by a 
mixture of unblocked Eag1, Eag2 and heteromultimers of the two channels. No Eag1-like current was detected in the MNTB principal cell of the rat. This speaks in favour of a presynaptic localisation of the channel.

To confirm the expression of Eag1 in the rat calyx of Held, I performed an immunostaining with antibodies against Eag1 and VGlut1 as a presynaptic marker (Figure 6). The signal for Eag1 was mostly overlapping with the signal for VGlut1, albeit some fluorescence was observed in regions without VGlut1. This could point towards a certain level of postsynaptic expression of Eag1; yet the absence of a detectable Cole-Moore shift does not support this hypothesis.

To be able to use the Eag1-deficient mouse generated by Dr. R. Ufartes, I tried to identify an Eag1 current in the calyx of Held of young mice. Despite the use of $\mathrm{Cs}^{+}$in the pipette, no current showing a Cole-Moore shift was detected. The potassium currents in mice were generally larger than those in rats. By adding low concentrations of TEA to the extracellular solution, I tried to reduce the current amplitude. This almost completely abolished outward currents, and subsequent experiments in HEK cells confirmed that Eag1 is reduced by $5-10 \mathrm{mM}$ extracellular TEA (data not shown). An immunostaining for Eag1 in the MNTB of mice did not show any specific signal (data not shown). This could mean that either Eag1 is not expressed in the mouse calyx of Held, unlike in the rat, or that the contribution of Eag1 to the potassium currents of the calyx is too small to be noticed under these experimental conditions. Therefore, it did not seem feasible to use the calyx of Held as a model region to elucidate the physiological role of Eag1 in the brain.

However, I present for the first time a current recorded in a neuronal cell that is compatible with the characteristics of Eag1 and can be blocked by an Eag1-specific antibody. The results also provide further evidence for the synaptic localisation of Eag1, especially when taking into account the staining seen for protein in the MNTB (Martin et al., 2008) and the absence of mRNA (Saganich et al., 2001).

\section{Properties of granule- and Purkinje cell bodies}

After the calyx was excluded as a suitable model system to study Eag1 function, I decided to take advantage of the high expression levels of Eag1 in the cerebellum, where no Eag2 is expressed. As discussed above, there is a discrepancy in the literature concerning exact localisation of Eag1. While mRNA was detected in the granule layer (Ludwig et al., 1994; Saganich et al., 2001), protein was detected by immunohistochemistry in the Purkinje cells (Martin et al., 2008). Preliminary experiments performed by M. Kuscher (MPI of experimental Medicine) suggest the presence of Eag1 mRNA in the cell body of Purkinje cells. To evaluate the membrane properties and excitability of granule cells and Purkinje cells, I performed wholecell current clamp on the cell bodies. Granule cells of Eag1 KO mice did not show any 
difference in membrane properties, excitability, evoked firing frequencies or action potential properties (Figure 7, Figure 8). Purkinje cells of both genotypes showed similar behaviour to already published studies (Llinás and Sugimori, 1980; Fernandez et al., 2007) and here as well, no difference was observed in excitability, firing behaviour or action potential properties. I conclude that Eag1 channels do not play a significant role in controlling the electric behaviour of the cell bodies of granule- or Purkinje cells.

The discrepancies between studies of mRNA and protein distribution can now be interpreted considering the synaptic localisation of Eag1. It has been reported before that potassium channels can have an asymmetric expression pattern in cerebellar basket cells (Southan and Robertson, 1998). Accordingly, the somatic signal for Eag1 does not have to result from an expression in that particular cell, but could also be due to synapses formed onto the soma by other cells. For example, pyramidal cells in the CA1 regions of the hippocampus show less mRNA levels than CA3 cells, but both regions show the same staining for protein. The high signal in the Purkinje cell somata despite no or little evidence for mRNA expression could be explained by Eag1 in the climbing fiber synapses, where it was observed during axonal migration (M. Rubio and L. Pardo, personal communication). However, no mRNA was detected in the inferior olive, the origin of the climbing fiber. If Purkinje cells express Eag1 mRNA, and the functional channel is located at the synaptic terminals, one would expect a staining in the deep cerebellar nuclei, which was reported by Martin et al. (2008).

These experiments, as well as the measurements in the calyx of Held are the first functional assessment of Eag1 localisation. Together, they provide strong evidence for the synaptic localisation and a further way of interpretation to previously published data.

\subsection{Eag1 in synaptic transmission and facilitation}

I used the parallel fibre - Purkinje cell synapse as a model to study Eag1 function. The synapse is well characterised, no recurrent excitation occurs and it is possible to measure presynaptic calcium transients in single boutons. The PF-PC synapse has been described to show pronounced paired-pulse facilitation (Konnerth et al., 1990), possibly due to its very low $\mathrm{p}_{\mathrm{r}}$ (Dittman et al., 2000), which can be sustained during long train of stimuli (Kreitzer and Regehr, 2000). Extracellular stimulation in the granule layer during voltage-clamp of the Purkinje cell body caused increased facilitation in Eag1 KO cells. This effect was dependent on the input frequency and pulse number, furthermore, no effect was seen in PF-SC and PF-BC synapses. Target-dependent plasticity was described before in the cerebellum (Bao et al., 2010) and found to be due to postsynaptic receptor saturation and multivesicular release at the PF-BC synapse. The STP measured in interneurons in that study differed slightly from my results, 
which might be due to different stimulation paradigms, but also to the high variability observed in the $\mathrm{BC}$ responses (Figure 19). Differences between synapses formed by the ascending part of the granule cell axon and the parallel fibre have also been observed (Sims and Hartell, 2006). It was difficult to stimulate synapses formed onto stellate cells and basket cells with the stimulation pipette placed both in the granule layer and laterally distant from the target cell. To reduce effects by fibre recruitment (Kocsis et al., 1983), I decided to stimulate in the granule layer, but closer to the soma of the target cells. Like this, a greater part of the ascending fibre population was stimulated, suggesting that Eag1 is located specifically on the parallel fibres.

Facilitation is generally seen as a transient change in release probability. A number of reasons can account for this.

1. Fibre recruitment during trains of stimulation can increase the synaptic response (Kocsis et al., 1983).

2. The initial release probability could be diminished, as for example seen in Munc-13-3 mutations (Augustin et al., 2001) or CAPS2 (Sadakata et al., 2007).

3. A broadening of the action potential during trains can cause an alteration of the presynaptic calcium current that triggers neurotransmitter release (Klein and Kandel, 1980; Augustine, 1990; Sabatini and Regehr, 1997; Bollmann and Sakmann, 2005).

4. A build-up of residual calcium in the presynaptic terminal is known to facilitate synaptic transmission (Katz and Miledi, 1968; Kamiya and Zucker, 1994; Atluri and Regehr, 1996; Zucker and Regehr, 2002) and accelerate recovery from depression (Dittman and Regehr, 1998; Stevens and Wesseling, 1998; Wang and Kaczmarek, 1998; Sakaba and Neher, 2001).

5. Facilitation of calcium channels during stimulus trains (Borst and Sakmann, 1998; Cuttle et al., 1998; Forsythe et al., 1998) or relieve of tonic G-protein inhibition of $\mathrm{Ca}^{2+}$ channels (reviewed in Tedford and Zamponi (2006)).

I will interpret the results obtained in this study with regards to the factors mentioned above. Enhanced fibre recruitment (1) can almost be excluded, since stimulation in the granule layer activates a more disperse set of parallel fibres than stimulation in the molecular layer, thus reducing the amount of local depolarisation (Marcaggi and Attwell, 2005; Beierlein et al., 2007). Although I cannot exclude a contribution of fibre recruitment, the results described in section 3.4 make other factors more likely.

A reduction of the initial release probability (2) in the Eag1 KO synapses is not in line with the data presented here. Although certain voltage gated potassium channels have been shown to directly interact with proteins of the SNARE complex (Singer-Lahat et al., 2007), Eag1 is not 
known to interact with any protein of the vesicle cycle, so a function in the release machinery seems unlikely. Mutations that lowered initial release probability (Augustin et al., 2001; Sadakata et al., 2007) resulted also in enhanced facilitation at the PF-PC synapse, but the effect was less or not dependent on the frequency or pulse number. Additionally, one could think that a loss of a potassium channel leads to a more depolarised terminal, thus increasing release probability by increasing the resting $\mathrm{Ca}^{2+}$ concentration (Awatramani et al., 2005; Hori and Takahashi, 2009). When a model of synaptic plasticity was fitted to the data (see section 3.3.9, Figure 22B), it became clear that lowering the release probability cannot reproduce the time course of facilitation during a stimulus train in Eag1 KO cells. The release probability (here $\mathrm{F}_{1}$ ) used to fit the model was with 0.06 a little higher than reported in Dittmann et al. This fits to the finding that the facilitation observed here is smaller than the results reported by Dittmann et al. If the increase in facilitation on Eag1 KO cells was due to a decreased initial release probability, it should be possible to obtain a good fit to the data by keeping all parameters nearly constant while lowering the release probability. A reduced release probability causes ultimately more facilitation, albeit it increases in slower steps than observed in the Eag1 KO. The rising phase can be made steeper by adjusting other model parameters, but the resulting curve soon surpassed the Eag1 KO data. The high number of free parameters in the model limits the strength of conclusions that can be drawn, since more than one set of parameters yielded a reasonably good fit. The results can nevertheless be seen as a suggestion for a preferential direction of interpretation of the experimental data.

Several clues point towards a frequency-dependent broadening of the action potential (3) in Eag1 KO synapses. The first hint was the pulse-dependent increase in the EPSC rise time. The rise time of the EPSC is tightly connected to the temporal dimension of the $\mathrm{Ca}^{2+}$ microdomain triggering release, which in turn is highly sensitive to the width of the action potential (Sabatini and Regehr, 1997; Bollmann and Sakmann, 2005). When comparing the absolute rise time values during a $50 \mathrm{~Hz}$ train (Figure 18), one can see that the rise time for the first EPSC is not different between Eag1 KO and WT. This suggests that the first action potential is not significantly broadened. The rise time in the WT increased slightly until a plateau was reached at pulse 3, where the increase was about $10 \%$. In the Eag1 KO however, the rise time both increased more steeply and reached its plateau only at the fifth pulse at a level of $25 \%$ increase. Interestingly, this reflects exactly the time course of facilitation during the trains (Figure 15). An increased rise time could also be caused by high series resistance or noise artifacts. For this reason, only those cells were included that had a particularly low series resistance and the minima of the EPSCs were fitted with $6^{\text {th }}$ grade polynomial functions to remove noise artefacts. If the effect would be due to an increase in series resistance during the train, one would expect it to occur in both genotypes to the same degree. 
Further evidence for use-dependent action potential broadening comes from the $\mathrm{Ca}^{2+}$ imaging experiments (Figure 21). There it was observed that the calcium influx into the presynaptic terminal of the parallel fibre was increased in Eag1 KO cells when stimulated with three pulses at 50 or $100 \mathrm{~Hz}$, but not during a single action potential. This effect can be attributable to the dependence of the activation kinetics of Eag1 on the holding potential, the Cole-Moore Shift. This provides the channel with a kind of very short-term memory for recent activity of the synapse and could cause activation of Eag1 only at repeated stimulation. Upon arrival of the first AP, Eag1 would not take a significant part in repolarisation of the action potential; its kinetics would be too slow. However, the depolarisation would prepare the channel for opening. If now a second stimulus arrives shortly after the first one, Eag1 can open sufficiently fast to take part in repolarisation of the action potential. Thereby, it could balance the effects of cumulative inactivation of $\mathrm{K}^{+}$channels, which have been described at pituitary nerve terminals and at the hippocampal mossy fibre terminal (Jackson et al., 1991; Geiger and Jonas, 2000). This would explain the observed pulse- and frequency dependence (Figure 15, Figure 18). It is noticeable that the $\mathrm{Ca}^{2+}$ influx in the wild type was dependent on the pulse number, as expected, but less on the frequency (Figure 21). In the knockout however, doubling of the frequency from 50 to $100 \mathrm{~Hz}$ caused a further increase in peak fluorescence. This is indicative of an action of Eag1 at high input frequencies. The data from calcium imaging could be interpreted in such a way that the increased EPSCs recorded in the Eag1 KO are caused by an increased calcium influx due to a broadening of the action potential in the first three stimuli, causing directly an enhanced transmitter release. This is different from models of synaptic plasticity that only take into account the intraterminal build-up and action of residual calcium (Katz and Miledi, 1968; Kamiya and Zucker, 1994; Regehr et al., 1994; Atluri and Regehr, 1996), like acting on a highaffinity sensor or saturating endogenous $\mathrm{Ca}^{2+}$-buffers (Neher, 1998; Blatow et al., 2003). An increased vesicle release will ultimately cause faster depletion of the readily releasable pool and thus depression. During long stimulus trains (Figure 17), the responses in both genotypes start to decline after reaching the peak. A nearly linear decrease in the amplitude begins right after reaching the plateau at stimuli $3-5$ in the WT. The peak itself is formed differently in the KO, taking on a more steeply rising and falling shape before declining also nearly linearly after pulse 10. Albeit, the slopes of the declines are significantly different, with the Eag1 KO falling more steeply. The different time courses also become visible when the responses of WT and Eag1 KO are plotted against each other (Figure 22A). This indicates that the depletion of the pool advances faster, in line with an increased transmitter release. However, I cannot exclude an effect of postsynaptic receptor saturation and desensitisation, which has been shown to be present at the PF-PC synapse (Foster et al., 2005). Also in this case, a faster saturation and/or desensitisation would indicate more glutamate release from the presynapse. Since the PF-PC 
synapse can sustain trains up to 200 pulses without falling into depression (Kreitzer and Regehr, 2000), the effect of the slightly faster decline should not interfere greatly with synapse function. Nonetheless, the duration of action of Eag1 has to be limited. Several studies have shown that calmodulin binds and blocks Eag1 channels with an $\mathrm{IC}_{50}$ of $<100 \mathrm{nM}$. This block occurs with a rather slow time constant of 130ms, which leaves enough time for Eag1 to act on a number of action potentials that depends on the frequency. In 100ms, two APs can pass with a stimulation frequency of $20 \mathrm{~Hz}$, five with a frequency of $50 \mathrm{~Hz}$ and 10 with a frequency of $100 \mathrm{~Hz}$. Together with the Cole-Moore Shift, this could further account for the frequency dependence observed.

Many studies about $\mathrm{Ca}^{2+}$ dependence of transmitter release have been published (e.g. (Mintz et al., 1995; Bollmann et al., 2000; Schneggenburger and Neher, 2000; Rozov et al., 2001; Lou et al., 2005)). While all agree on high calcium cooperativity at intermediate concentration of intracellular $\mathrm{Ca}^{2+}\left(\mathrm{Ca}_{\mathrm{i}}\right)$, equivalent to a high exponent of a power function, Lou et al. showed that cooperativity was low at low intracellular $\mathrm{Ca}^{2+}$ and the relation was better fitted by an allosteric model. If the action potential is indeed broadened, one would expect to see an effect upon changing the external $\mathrm{Ca}^{2+}$ concentration $\left(\mathrm{Ca}_{\mathrm{e}}\right)$. At low $\mathrm{Ca}_{\mathrm{e}}$, the response would be increased, since more calcium can enter the terminal and trigger release, while at increased $\mathrm{Ca}_{\mathrm{e}}$, the response should be less enhanced in comparison to the WT due to earlier saturation of postsynaptic receptors or the release machinery (Foster et al., 2005). These effects were observed in Eag1 KO cells. The external calcium concentration was lowered from 2mM to 0.5, 1 , and $1.5 \mathrm{mM}$ and increased to 3 and $4 \mathrm{mM}$ (Figure 13). The resulting relationship could be fitted with a power law for concentrations $<3 \mathrm{mM}$, a range where no postsynaptic receptor saturation occurs (Dodge and Rahamimoff, 1967; Mintz et al., 1995; Foster et al., 2005). The exponents obtained here (1.94 and 2.02) were quite different from the ones previously reported, which ranged between 3 and 4. This is interesting, since the absolute data points have quite similar values to the ones reported in Mintz et al. (1995). The 95\% confidence intervals of the fits were very large and overlapping, suggesting that a range of values for the exponents are possible. Further, it was necessary to introduce an offset to the fit of the Eag1 KO data, because otherwise the data at $0.5 \mathrm{mM} \mathrm{Ca}_{\mathrm{e}}$ would not be included in the fit. Extending the fit to $0 \mathrm{mM} \mathrm{Ca}_{\mathrm{e}}$ would thus lead to the assumption that release occurs without calcium influx. One has to keep in mind, that the relationship $\mathrm{Ca}_{\mathrm{e}} \sim \mathrm{EPSC}$ is not equivalent to $\mathrm{Ca}_{\mathrm{i}} \sim \mathrm{EPSC}$. Lou et al. further suggested an intrinsic fusion "willingness" of the vesicles, which prevented the dose-response curve from going to absolute zero. A possible reason for the low fit quality is that only four data points $(0.5 \mathrm{mM}$ to $2 \mathrm{mM})$ were fit using an equation that contains two (or three, including the offset) free parameters. It is not feasible to fit more data points, since receptor saturation occurs at higher concentration of $\mathrm{Ca}_{\mathrm{e}}$ (Foster et al., 2005). From the data, one can infer that slightly more transmitter is released at $0.5 \mathrm{mM} \mathrm{Ca}_{\mathrm{e}}$, and that the saturation is greater than in the WT. The 
increase in transmitter release likely reflects an increased $\mathrm{Ca}^{2+}$ influx, which combines additively to the assumingly constant "fusion willingness". The results from $\mathrm{Ca}^{2+}$ imaging suggest a significant broadening of the action potential only after the second stimulus. In that case, no effect should be seen when observing single EPSCs, as in this experiment. This apparent contradiction might be explained by low resolution of the imaging. The scatter among the boutons was largest in response to a single action potential, and a small difference is easily lost in noise. In electrophysiological recordings, the failure rate of EPSCs was increased at $0.5 \mathrm{mM} \mathrm{Ca} \mathrm{e}_{\mathrm{e}}$ compared to other conditions. If the release probability in the Eag1 $\mathrm{KO}$ is just slightly increased, it might cause less failure, and so the compound EPSC is larger on average. Both techniques are useful tools to assess synaptic properties; however one has to keep in mind that the measurement focuses on different aspects. While in patch clamping the recorded EPSC is made up of the action of many single boutons and necessarily represents an average value, the signal recorded in $\mathrm{Ca}^{2+}$ imaging represents the behaviour of a single bouton at a given time point. The amount of boutons involved in electrophysiological recordings is thus naturally higher than the number achieved in $\mathrm{Ca}^{2+}$ imaging, resulting in a better average response.

Xu-Friedmann and Regehr (2001) showed that on average 8 vesicles are docked on the presynaptic membrane of parallel fibres. The very low release probability of the PF-PC synapse opens the possibility that a slight increase in release probability still results in prominent facilitation, when the failure rate decreases, but the synapses that have just undergone release still have a high number of vesicles docked.

These considerations are supportive of the broadened-action potential hypothesis, but should not be used to draw definite conclusions about the release machinery.

The local $\mathrm{Ca}^{2+}$ signal triggering release equilibrates quickly with the surrounding cytosol, where it is either bound by endogenous calcium-binding proteins or removed by extrusion. The latter has been identified as the main controlling factor for residual Calcium $\left(\mathrm{Ca}_{\mathrm{res}}\right)$ dynamics in small terminals like the parallel fibre bouton (Regehr and Atluri, 1995). $\mathrm{Ca}_{\text {res }}(4)$ is generally accepted as the driving force behind facilitation (Zucker and Regehr, 2002). Increasing the total $\mathrm{Ca}^{2+}$ entering the terminal, one would expect an increase in $\mathrm{Ca}_{\text {res }}$ accumulation, assuming that the dynamics of calcium extrusion are not altered. A change in calcium extrusion would need further assumptions about Eag1 function such as non-canonical regulatory mechanisms of the $\mathrm{Ca}^{2+}$-ATPase, for which no evidence exists.

Several modes of action have been proposed for $\mathrm{Ca}_{\text {res }}$ in the terminal. A mere addition of $\mathrm{Ca}_{\text {res }}$ to the $\mathrm{Ca}^{2+}$ influx triggered by the subsequent AP seems unlikely, since the relatively small amount of $\mathrm{Ca}_{\text {res }}$ would not be sufficient to cause the large increase in transmitter release. This led to the hypothesis of at least one high-affinity calcium sensor with slow kinetics, that is located at a relatively long diffusional distance from the $\mathrm{Ca}^{2+}$ channels (Zucker and Regehr, 2002; 
Burnashev and Rozov, 2005). Another possibility is that the saturation of endogenous $\mathrm{Ca}^{2+}$ buffers, which will lead to a nonlinear summation of $\mathrm{Ca}_{\text {res }}$ and microdomain $\mathrm{Ca}^{2+}$ (Neher, 1998; Blatow et al., 2003). This issue was however not addressed in this study.

$\mathrm{Ca}_{\text {res }}$ has been shown to drive delayed and transient release (Atluri and Regehr, 1998; Chen and Regehr, 1999), which act between 3 and hundreds of ms after a pulse. Transient release is also involved in shaping the late phase of the EPSC, so an increase in $\mathrm{Ca}_{\text {res }}$ might be visible in a prolonged decay time of the EPSC (Figure 18). The EPSCs in Eag1 KO cells were not significantly broadened in comparison to the WT. Some increase is seen in the absolute values, but the normalised data show that the time course is identical. This speaks against an abnormal increase in transient release, however, the decay time of the EPSC is highly sensitive to external factors like series resistance and quality of the patch, so these results can only serve as general orientation.

Intuitively, one would associate an increase in transmitter release with sooner depletion of the vesicle pool, so the rise in release in the Eag1 KO should be followed by more pronounced reduction in the EPSC amplitude. This is partly what is observed (see above and Figure 17), but nevertheless the high EPSC amplitudes are maintained throughout the duration of the stimulus train. This can be explained by an increase in the replenishment of the readily releasable pool, which is driven by $\mathrm{Ca}_{\mathrm{res}}$ (Dittman and Regehr, 1998; Wang and Kaczmarek, 1998; Dittman et al., 2000; Sakaba and Neher, 2001). Wang and Kaczmarek have forced a broadening of the action potential with TEA and observed an enhancement of the rate of replenishment. The increase in transmitter release is thought to be only transient, the $\mathrm{Ca}_{\text {res }}$ however can act on a longer timescale (Regehr and Atluri, 1995). Assuming an increased $\mathrm{Ca}^{2+}$ influx over 5 stimuli, the amount of $\mathrm{Ca}_{\text {res }}$ is also elevated each pulse by an increased value. The decay of $\mathrm{Ca}_{\text {res }}$ takes several hundred ms, so it is reasonable to assume an effect on vesicle replenishment during the stimulus trains measured here.

If the increased $\mathrm{Ca}_{\mathrm{res}}$ in the terminal plays a role in the increased facilitation observed in the Eag1 KO cells, it should be possible to reduce the effect by decreasing $\mathrm{Ca}_{\text {res }}$. The slow-binding $\mathrm{Ca}^{2+}$ chelator EGTA in its membrane-permeable form has been used before to reduce facilitation and speed the decay of the $\mathrm{Ca}_{\text {res }}$ signal at the PF-PC terminal (Atluri and Regehr, 1996). After incubation with 50 $\mu \mathrm{M}$ of EGTA-AM, facilitation in the WT was greatly reduced at all ISIs tested, proving the crucial role of $\mathrm{Ca}_{\text {res }}$ in facilitation at this synapse (Figure 20). In the $\mathrm{KO}$, the decrease was significantly smaller in all intervals. The facilitation was still larger than in the WT, but not significantly. This suggests that $\mathrm{Ca}_{\text {res }}$ is indeed increased in the $\mathrm{KO}$, but also that it does not account for all of the difference observed. When stimulated with a $50 \mathrm{~Hz}$ train, facilitation continuously built up in both genotypes. However the $\mathrm{KO}$ values rose steeper and were larger throughout the train (Figure 20C). This suggests that $\mathrm{Ca}_{\mathrm{res}}$ in the $\mathrm{KO}$ builds up faster 
than in the WT, or that more $\mathrm{Ca}^{2+}$ enters the terminal than can be buffered by EGTA. As EGTA saturates with $\mathrm{Ca}^{2+}$, an effect called "pseudofacilitation" can occur (Rozov et al., 2001). EGTA gets progressively more saturated during each stimulus and the unbuffered $\mathrm{Ca}_{\text {res }}$ increases with each pulse. This "residual-Cares" adds to the "new $\mathrm{Ca}_{\text {res }}$ " and causes a progressive increase in facilitation. This is supported by the observation that facilitation reaches the level of control experiments after $\sim 20$ pulses and stays constant. There, EGTA would be fully saturated and $\mathrm{Ca}_{\text {res }}$ would have reached equilibrium.

Another possibility to manipulate $\mathrm{Ca}_{\text {res }}$ is to alter the extracellular $\mathrm{Ca}^{2+}$ concentration. This changes the $\mathrm{Ca}^{2+}$ influx and thus the amount of $\mathrm{Ca}^{2+}$ that stays in the terminal after the stimulus. Above, I described the effect of a changed $\mathrm{Ca}_{\mathrm{e}}$ on single EPSC amplitude. During a $50 \mathrm{~Hz}$ train, facilitation peaks at $1.5 \mathrm{mM} \mathrm{Ca}$ (WT) or $1 \mathrm{mM} \mathrm{Ca}_{\mathrm{e}}(\mathrm{Eag} 1 \mathrm{KO}$, Figure 16C) and then decreases with increasing $\mathrm{Ca}_{\mathrm{e}}$. In general, it has been described that facilitation increased with a decrease in $\mathrm{Ca}_{\mathrm{e}}$, as the latter decreases the release probability and with that depression. Even studies at the same synapse repeatedly reported different results (Kreitzer and Regehr, 2000; Foster et al., 2005). However, these studies used rats that were about 10 days younger than the mice used in this study and stimulated differently. Although this is not a satisfactory explanation for the difference observed, it might be an influencing factor. Facilitation and depression interact at synapses to shape the output (Tsodyks and Markram, 1997; Dittman et al., 2000), so by removing one parameter one enhances the influence of the other. The reduction in depression when the release probability is lowered leaves only facilitation to determine the response to a train. When $\mathrm{Ca}_{\text {res}}$, the most influential parameter is diminished, the net facilitation will also decrease. In a synapse that initially has a very low release probability and shows little depression during prolonged activity at high frequencies, like the PF-PC synapse described here, depression might not play a major role during the first pulses (see also FIG8). Thus, the reduced $\mathrm{Ca}_{\mathrm{i}}$ together with the low $\mathrm{Ca}^{2+}$ cooperativity at low $\mathrm{Ca}_{\mathrm{i}}$ (Rozov et al., 2001; Lou et al., 2005) will result in a net decrease in facilitation. Accordingly, when $\mathrm{Ca}_{\mathrm{e}}$ is increased, depression starts to dominate the output, as seen in both WT and Eag1 KO. At 3 and $4 \mathrm{mM} \mathrm{Ca}_{\mathrm{e}}$ WT and Eag1 KO do not differ in their response to train stimulation. We can assume that the release machinery and the postsynaptic receptors start to saturate so that the release cannot be further enhanced by additional $\mathrm{Ca}^{2+}$ influx. In the Eag1 KO, the peak of facilitation is already reached at $1 \mathrm{mM} \mathrm{Ca}_{\mathrm{e}}$; all enhancements at lower and higher $\mathrm{Ca}_{\mathrm{e}}$ were significantly smaller (FIG 14D). If one assumes that due to increased $\mathrm{Ca}^{2+}$ influx $\mathrm{Ca}_{\text {res }}$ is also increased, the outcome of the interplay between facilitation and depression is shifted towards lower $\mathrm{Ca}_{\mathrm{e}}$. Interestingly, the peak of facilitation in the Eag1 KO is higher than the peak of the WT. 
Facilitation of calcium channels (5) has been implicated in shaping the postsynaptic response in the calyx of Held (Borst and Sakmann, 1998; Cuttle et al., 1998; Forsythe et al., 1998; Ishikawa et al., 2005; Xu and $\mathrm{Wu}, 2005)$. In the parallel fibre, this has not been found to be important for shaping the release (Kreitzer and Regehr, 2000). In this study, no evidence for or against facilitation of calcium currents is included, although one could explain the increase in $\mathrm{Ca}^{2+}$ influx observed by calcium imaging (Figure 21) also by an enhancement of calcium current. The slightly increased $\mathrm{Ca}_{\text {res }}$ after the first and second pulse would stimulate facilitation of $\mathrm{Ca}^{2+}$ channels more than observed by Kreitzer et al. (2000) and work together with the other mechanisms triggered by $\mathrm{Ca}_{\text {res }}$ and a broadened action potential to enhance facilitation in the Eag1 KO. However, this is only speculation, as no evidence exists.

Further, one could speculate that in the absence of Eag1, more calmodulin molecules are available to interact with parts of the release or refill machinery, thus contributing to enhanced release and possibly increased vesicle recycling. The proof or disproof of these assumptions needs several intermediate assumptions and experiments, which were not addressed in this work.

\subsection{Summary}


The voltage-gated potassium channel Eag1 is expressed widely in the mammalian brain, yet it had been almost exclusively studied in the context of its oncogenic potential. Its exact subcellular localisation was subject to considerable disagreement. Studies using in-sito hybridisation yielded different results than studies employing immunhistochemical methods. No native Eag1 current had been recorded in a neuron, probably due to its presumably synaptic localisation. No studies have investigated the physiological role of Eag1 in the CNS.

This study aimed at clarifying the functional subcellular localisation in neurons and elucidating the physiological role of Eag1 in neuronal cells.

By immunoblotting with protein from subcellular fractions, it was possible to confirm the predominantly synaptic localisation of Eag1. To be able to record native Eag1 currents, the rat Calyx of Held was used. In $72 \%$ of the terminals, an Eag1-compatible current was identified by the dependence of the activation kinetics on the prepulse holding potential. Further, the current was partially blocked by an Eag1-specific antibody. No Eag1-like current was recorded in the postsynaptic principal cells of the MNTB. This is the first recording of a native Eag1 current in a neuron and shows a preferably presynaptic localisation of the channel.

Since Eag1 expression in the murine Calyx could not be confirmed, further analysis of its physiological importance was conducted in the cerebellar cortex. The membrane properties and evoked firing frequencies of granule- and Purkinje cells were not changed between WT and Eag1 KO mice, as was expected after the confirmation of the synaptic localisation of Eag1. For analysis of synaptic transmission, the parallel fibre - Purkinje cell synapse was chosen. While the properties of the single EPSC were unchanged between WT and Eag1 KO mice, the KO showed less change in reaction to changes in the extracellular $\mathrm{Ca}^{2+}$ concentration than the WT. Further, facilitation at the parallel fibre - Purkinje cell synapse was increased in a frequencyand pulse dependent manner. This was accompanied by a broadening of the EPSC during the train in Eag1 KO mice. Since facilitation is usually due to accumulation of residual calcium in the synaptic terminal, EGTA-AM was used to capture residual calcium and thus reduce facilitation. This was only partially achieved in the Eag1 KO, indicating that residual calcium plays an important, but not the only role. Optical measurement of presynaptic calcium influx by two-photon microscopy confirmed an increased $\mathrm{Ca}^{2+}$ influx into the presynaptic terminal, with the difference between WT and Eag1 KO depending on the frequency and length of the stimulating pulse train. Finally, fitting a model of synaptic plasticity to the data showed that a decrease in release probability, as usually thought to cause increased facilitation, cannot account for the time course of facilitation observed in the Eag1 KO mouse. 
The dependence of the activation kinetics on the membrane potential as well as the presumed block of the channel by calmodulin give a rather short time window for Eag1 action, which could explain the mild phenotype observed in Eag1 KO mice. However, no in-depth screening for motor- or memory function defects in Eag1 KO mice has been performed, and further behavioural studies might prove useful to further shed light on the function of Eag1 in the CNS. Further, this study did not address possible non-canonical functions of Eag1, which might be rooted in the intracellular signal-transducing domains of the channel.

In conclusion, I present here the first recording of a native Eag1 current in a neuron, confirming its presynaptic localisation. Further, my data suggest a role for Eag1 in repolarising the action potential during high-frequency trains, the extent of which is dependent on the immediate past of the state of the synaptic membrane. 


\section{References}

Atluri, P.P., and W.G. Regehr. 1996. Determinants of the time course of facilitation at the granule cell to purkinje cell synapse. J Neurosci. 16(6):5661-5671.

Atluri, P.P., and W.G. Regehr. 1998. Delayed release of neurotransmitter from cerebellar granule cells. J Neurosci. 18(6):8214-8227.

Augustin, I., S. Korte, M. Rickmann, H.A. Kretzschmar, T.C. Südhof, J.W. Herms, and N. Brose. 2001. The cerebellum-specific munc13 isoform munc13-3 regulates cerebellar synaptic transmission and motor learning in mice. The Journal of Neuroscience. 21:1017.

Augustine, G.J. 1990. Regulation of transmitter release at the squid giant synapse by presynaptic delayed rectifier potassium current. The Journal of Physiology. 431:343364.

Awatramani, G.B., G.D. Price, and L.O. Trussell. 2005. Modulation of transmitter release by presynaptic resting potential and background calcium levels. Neuron. 48:109-121.

Bao, J., K. Reim, and T. Sakaba. 2010. Target-dependent feedforward inhibition mediated by short-term synaptic plasticity in the cerebellum. The Journal of Neuroscience. 30:81718179 .

Barbour, B. 1993. Synaptic currents evoked in purkinje cells by stimulating individual granule cells. Neuron. 11:759-769.

Bauer, C.K., and J.R. Schwarz. 2001. Physiology of eag k+ channels. Journal of Membrane Biology. 182:1-15.

Beierlein, M., D. Fioravante, and W.G. Regehr. 2007. Differential expression of posttetanic potentiation and retrograde signaling mediate target-dependent short-term synaptic plasticity. Neuron. 54 (6):949-959.

Bennett, M.V.L., and R.S. Zukin. 2004. Electrical coupling and neuronal synchronization in the mammalian brain. Neuron. 41:495-511.

Bijlenga, P., T. Occhiodoro, J.-H. Liu, C.R. Bader, L. Bernheim, and J. Fischer-Lougheed. 1998. An ether -à-go-go k+ current, ih-eag, contributes to the hyperpolarization of human fusion-competent myoblasts. The Journal of Physiology. 512:317-323.

Biró, Á.A., N.B. Holderith, and Z. Nusser. 2005. Quantal size is independent of the release probability at hippocampal excitatory synapses. The Journal of Neuroscience. 25:223232.

Blatow, M., A. Caputi, N. Burnashev, H. Monyer, and A. Rozov. 2003. Ca2+ buffer saturation underlies paired pulse facilitation in calbindin-d28k-containing terminals. Neuron. 38:79-88.

Bollmann, J.H., and B. Sakmann. 2005. Control of synaptic strength and timing by the releasesite ca2+ signal. Nat Neurosci. 8:426-434. 
Bollmann, J.H., B. Sakmann, and J.G. Borst. 2000. Calcium sensitivity of glutamate release in a calyx-type terminal. Science. 289:953-957.

Borst, J.G., F. Helmchen, and B. Sakmann. 1995. Pre- and postsynaptic whole-cell recordings in the medial nucleus of the trapezoid body of the rat. The Journal of Physiology. 489:825840 .

Borst, J.G.G., and B. Sakmann. 1996. Calcium influx and transmitter release in a fast cns synapse. Nature. 383:431-434.

Borst, J.G.G., and B. Sakmann. 1998. Facilitation of presynaptic calcium currents in the rat brainstem. The Journal of Physiology. 513:149-155.

Borst, J.G.G., and B. Sakmann. 1999. Effect of changes in action potential shape on calcium currents and transmitter release in a calyx-type synapse of the rat auditory brainstem. Philosophical Transactions of the Royal Society of London. Series B: Biological Sciences. 354:347-355.

Brelidze, T.I., A.E. Carlson, and W.N. Zagotta. 2009. Absence of direct cyclic nucleotide modulation of meag1 and herg1 channels revealed with fluorescence and electrophysiological methods. Journal of Biological Chemistry. 284:27989-27997.

Brenowitz, S.D., and W.G. Regehr. 2007. Reliability and heterogeneity of calcium signaling at single presynaptic boutons of cerebellar granule cells. The Journal of Neuroscience. 27 $\% 6: 7888-7898 \% \&$.

Brickley, S.G., M.I. Aller, C. Sandu, E.L. Veale, F.G. Alder, H. Sambi, A. Mathie, and W. Wisden. 2007. Task-3 two-pore domain potassium channels enable sustained highfrequency firing in cerebellar granule neurons. The Journal of Neuroscience. 27:93299340.

Bruggemann, A., L.A. Pardo, W. Stuhmer, and O. Pongs. 1993. Ether-à-go-go encodes a voltage-gated channel permeable to $\mathrm{k}+$ and ca2 + and modulated by camp. Nature. 365:445-448.

Buhl, E.H., G. Tamás, T. Szilágyi, C. Stricker, O. Paulsen, and P. Somogyi. 1997. Effect, number and location of synapses made by single pyramidal cells onto aspiny interneurones of cat visual cortex. The Journal of Physiology. 500:689-713.

Burnashev, N., and A. Rozov. 2005. Presynaptic ca2+ dynamics, ca2+ buffers and synaptic efficacy. Cell Calcium. 37:489-495.

Byrne, J., and E. Kandel. 1996. Presynaptic facilitation revisited: State and time dependence. The Journal of Neuroscience. 16:425-435.

Caillard, O., H. Moreno, B. Schwaller, I. Llano, M.R. Celio, and A. Marty. 2000. Role of the calcium-binding protein parvalbumin in short-term synaptic plasticity. Proceedings of the National Academy of Sciences. 97:13372-13377.

Carter, A.G., and W.G. Regehr. 2000. Prolonged synaptic currents and glutamate spillover at the parallel fiber to stellate cell synapse. J Neurosci. 20(6):4423-4434.

Chadderton, P., T.W. Margrie, and M. Hausser. 2004. Integration of quanta in cerebellar granule cells during sensory processing. Nature. 428:856-860. 
Chen, C., and W.G. Regehr. 1999. Contributions of residual calcium to fast synaptic transmission. J Neurosci. 19(6):6257-6266.

Chen, Y., A. Sánchez, M.E. Rubio, T. Kohl, L.A. Pardo, and W. Stühmer. 2011. Functional kv10.1 channels localize to the inner nuclear membrane. PLOS ONE. 6:e19257.

Christie, J.M., D.N. Chiu, and C.E. Jahr. 2011. Ca2+-dependent enhancement of release by subthreshold somatic depolarization. Nat Neurosci. 14:62-68.

Cole, K.S., and J.W. Moore. 1960. Potassium ion current in the squid giant axon: Dynamic characteristic. Biophys J. 1:1-14.

Cuttle, M.F., T. Tsujimoto, I.D. Forsythe, and T. Takahashi. 1998. Facilitation of the presynaptic calcium current at an auditory synapse in rat brainstem. The Journal of Physiology. 512:723-729.

D'Angelo, E., G.D. Filippi, P. Rossi, and V. Taglietti. 1998. Ionic mechanism of electroresponsiveness in cerebellar granule cells implicates the action of a persistent sodium current. Journal of Neurophysiology. 80:493-503.

de Oliveira, R.M.W., S. Martin, C.L. de Oliveira, H. Milani, A.P. Schiavon, S. Joca, L.A. Pardo, W. Stühmer, and E.A. Del Bel. 2012. Eag1, eag2, and sk3 potassium channel expression in the rat hippocampus after global transient brain ischemia. Journal of Neuroscience Research. 90:632-640.

del Castillo, J., and B. Katz. 1954. Quantal components of the end-plate potential. The Journal of Physiology. 124:560-573.

Denk, W., J. Strickler, and W. Webb. 1990. Two-photon laser scanning fluorescence microscopy. Science. 248:73-76.

Dittman, J.S., A.C. Kreitzer, and W.G. Regehr. 2000. Interplay between facilitation, depression, and residual calcium at three presynaptic terminals. J Neurosci. 20(6):1374-1385\%\&.

Dittman, J.S., and W.G. Regehr. 1998. Calcium dependence and recovery kinetics of presynaptic depression at the climbing fiber to purkinje cell synapse. The Journal of Neuroscience. 18:6147-6162.

Dobrunz, L.E., E.P. Huang, and C.F. Stevens. 1997. Very short-term plasticity in hippocampal synapses. Proceedings of the National Academy of Sciences. 94:1484314847.

Dobrunz, L.E., and C.F. Stevens. 1997. Heterogeneity of release probability, facilitation, and depletion at central synapses. Neuron. 18:995-1008.

Dodge, F.A., and R. Rahamimoff. 1967. Co-operative action of calcium ions in transmitter release at the neuromuscular junction. The Journal of Physiology. 193:419-432.

Downie, B.R., A. Sánchez, H. Knötgen, C. Contreras-Jurado, M. Gymnopoulos, C. Weber, W. Stühmer, and L.A. Pardo. 2008. Eag1 expression interferes with hypoxia homeostasis and induces angiogenesis in tumors. Journal of Biological Chemistry. 283:3623436240 .

Dubin, A.E., M.M. Liles, and G.L. Harris. 1998. The k+ channel gene ether a go-go is required for the transduction of a subset of odorants in adult drosophila melanogaster. The Journal of Neuroscience. 18:5603-5613. 
Eccles, J.C., B. Katz, and S.W. Kuffler. 1941. Nature of the "endplate potential" in curarized muscle. Journal of Neurophysiology. 4:362-387.

Fernandez, F.R., J.D.T. Engbers, and R.W. Turner. 2007. Firing dynamics of cerebellar purkinje cells. Journal of Neurophysiology. 98:278-294.

Forsythe, I.D., and M. Barnes-Davies. 1993. The binaural auditory pathway: Excitatory amino acid receptors mediate dual timecourse excitatory postsynaptic currents in the rat medial nucleus of the trapezoid body. Proceedings of the Royal Society of London. Series B: Biological Sciences. 251:151-157.

Forsythe, I.D., T. Tsujimoto, M. Barnes-Davies, M.F. Cuttle, and T. Takahashi. 1998. Inactivation of presynaptic calcium current contributes to synaptic depression at a fast central synapse. Neuron. 20:797-807.

Foster, K.A., J.J. Crowley, and W.G. Regehr. 2005. The influence of multivesicular release and postsynaptic receptor saturation on transmission at granule cell to purkinje cell synapses. J Neurosci. 25 (6):11655-11665.

Frings, S., N. Brüll, C. Dzeja, A. Angele, V. Hagen, U.B. Kaupp, and A. Baumann. 1998. Characterization of ether-à-go-go channels present in photoreceptors reveals similarity to ikx, a k+ current in rod inner segments. The Journal of General Physiology. 111:583599.

Ganetzky, B., and C.F. Wu. 1983. Neurogenetic analysis of potassium currents in drosophila: Synergistic effects on neuromuscular transmission in double mutants. J Neurogenet. $1: 17-28$.

García-Ferreiro, R.E., D. Kerschensteiner, F. Major, F. Monje, W. Stühmer, and L.A. Pardo. 2004. Mechanism of block of heag1 $\mathrm{k}+$ channels by imipramine and astemizole. The Journal of General Physiology. 124:301-317.

Geiger, J.R.P., and P. Jonas. 2000. Dynamic control of presynaptic ca2+ inflow by fastinactivating $\mathrm{k}+$ channels in hippocampal mossy fiber boutons. Neuron. 28:927-939.

Gómez-Varela, D., T. Kohl, M. Schmidt, M.E. Rubio, H. Kawabe, R.B. Nehring, S. Schäfer, W. Stühmer, and L.A. Pardo. 2010. Characterization of eag1 channel lateral mobility in rat hippocampal cultures by single-particle-tracking with quantum dots. PLOS ONE. 5:e8858.

Gómez-Varela, D., E. Zwick-Wallasch, H. Knötgen, A. Sánchez, T. Hettmann, D. Ossipov, R. Weseloh, C. Contreras-Jurado, M. Rothe, W. Stühmer, and L.A. Pardo. 2007. Monoclonal antibody blockade of the human eag1 potassium channel function exerts antitumor activity. Cancer Research. 67:7343-7349.

Gonçalves, J.T., and W. Stühmer. 2010. Calmodulin interaction with heag1 visualized by fret microscopy. PLoS ONE. 5:e10873.

Griffith, L.C., J. Wang, Y. Zhong, C.F. Wu, and R.J. Greenspan. 1994. Calcium/calmodulindependent protein kinase ii and potassium channel subunit eag similarly affect plasticity in drosophila. Proceedings of the National Academy of Sciences. 91:10044-10048.

Haghdoust, H., M. Janahmadi, and G. Behzadi. 2007. Physiological role of dendrotoxin sensitive k channels in the rat cerebellar purkinje neurons. Physiological Research. 56:807-813. 
Hille, B. 2001. Ion channels of excitable membranes. Sinauer Associates, Inc.

Hori, T., and T. Takahashi. 2009. Mechanisms underlying short-term modulation of transmitter release by presynaptic depolarization. The Journal of Physiology. 587:2987-3000.

Ishikawa, T., M. Kaneko, H.-S. Shin, and T. Takahashi. 2005. Presynaptic n-type and p/q-type ca2+ channels mediating synaptic transmission at the calyx of held of mice. The Journal of Physiology. 568:199-209.

Ishikawa, T., Y. Nakamura, N. Saitoh, W.-B. Li, S. Iwasaki, and T. Takahashi. 2003. Distinct roles of kv1 and kv3 potassium channels at the calyx of held presynaptic terminal. The Journal of Neuroscience. 23:10445-10453.

Jackson, M.B., A. Konnerth, and G.J. Augustine. 1991. Action potential broadening and frequency-dependent facilitation of calcium signals in pituitary nerve terminals. Proceedings of the National Academy of Sciences. 88:380-384.

Jeng, C.J., C.C. Chang, and C.Y. Tang. 2005. Differential localization of rat eag1 and eag2 k+ channels in hippocampal neurons. NeuroReport. 16:229.

Jones, M.V., and G.L. Westbrook. 1996. The impact of receptor desensitization on fast synaptic transmission. Trends in Neurosciences. 19:96-101.

Kalla, S., M. Stern, J. Basu, F. Varoqueaux, K. Reim, C. Rosenmund, N.E. Ziv, and N. Brose. 2006. Molecular dynamics of a presynaptic active zone protein studied in munc13-1enhanced yellow fluorescent protein knock-in mutant mice. The Journal of Neuroscience. 26:13054-13066.

Kamiya, H., and R.S. Zucker. 1994. Residual ca2 + and short-term synaptic plasticity. Nature. 371:603-606.

Kandel, E.R., jessel, and schwartz. 2000. Fundamentals of neural science.

Kaplan, W.D., and W.E. Trout. 1969. The behavior of four neurological mutants of drosophila. Genetics. 61:399-409.

Katz-Sidlow, R.J. 1998. The formulation of the neuron doctrine: The island of cajal. Arch Neurol. 55:237-240.

Katz, B., and R. Miledi. 1968. The role of calcium in neuromuscular facilitation. The Journal of Physiology. 195:481-492.

Katz, B., and R. Miledi. 1969. Spontaneous and evoked activity of motor nerve endings in calcium ringer. The Journal of Physiology. 203:689-706.

Klein, M., and E.R. Kandel. 1980. Mechanism of calcium current modulation underlying presynaptic facilitation and behavioral sensitization in aplysia. Proceedings of the National Academy of Sciences. 77:6912-6916.

Kocsis, J.D., R.C. Malenka, and S.G. Waxman. 1983. Effects of extracellular potassium concentration on the excitability of the parallel fibres of the rat cerebellum. The Journal of Physiology. 334:225-244.

Kohl, T., E. Lörinczi, L.A. Pardo, and W. Stühmer. 2011. Rapid internalization of the oncogenic k+channel kv10.1. PLOS ONE. 6:e26329. 
Konnerth, A., I. Llano, and C.M. Armstrong. 1990. Synaptic currents in cerebellar purkinje cells. Proceedings of the National Academy of Sciences. 87:2662-2665.

Korn, H., A. Triller, A. Mallet, and D. Faber. 1981. Fluctuating responses at a central synapse: $\mathrm{N}$ of binomial fit predicts number of stained presynaptic boutons. Science. 213:898-901.

Kreitzer, A.C., and W.G. Regehr. 2000. Modulation of transmission during trains at a cerebellar synapse. J Neurosci. 20(6):1348-1357.

Lisman, J.E., S. Raghavachari, and R.W. Tsien. 2007. The sequence of events that underlie quantal transmission at central glutamatergic synapses. Nat Rev Neurosci. 8:597-609.

Llinás, R., and M. Sugimori. 1980. Electrophysiological properties of in vitro purkinje cell somata in mammalian cerebellar slices. The Journal of Physiology. 305:171-195.

Llinas, R., M. Sugimori, and R.B. Silver. 1992. Microdomains of high calcium concentration in a presynaptic terminal. Science. 256:677-679.

Lörinczi, É., J. Napp, C. Contreras-Jurado, L. Pardo, and W. Stühmer. 2009. The voltage dependence of heag currents is not determined solely by membrane-spanning domains. European Biophysics Journal. 38:279-284.

Lou, X., V. Scheuss, and R. Schneggenburger. 2005. Allosteric modulation of the presynaptic ca2+ sensor for vesicle fusion. Nature. 435:497-501.

Ludwig, J., H. Terlau, F. Wunder, A. Brüggemann, L.A. Pardo, A. Marquardt, W. Stühmer, and O. Pongs. 1994. Functional expression of a rat homologue of the voltage gated either á go-go potassium channel reveals differences in selectivity and activation kinetics between the drosophila channel and its mammalian counterpart. EMBO Journal. 13:4451-4458.

Ludwig, J., R. Weseloh, C. Karschin, Q. Liu, R. Netzer, B. Engeland, C. Stansfeld, and O. Pongs. 2000. Cloning and functional expression of rat eag2, a new member of the etherà-go-go family of potassium channels and comparison of its distribution with that of eag1. Molecular and Cellular Neuroscience. 16:59-70.

Marcaggi, P., and D. Attwell. 2005. Endocannabinoid signaling depends on the spatial pattern of synapse activation. Nat Neurosci. 8:776-781.

Marcaggi, P., D. Billups, and D. Attwell. 2003. The role of glial glutamate transporters in maintaining the independent operation of juvenile mouse cerebellar parallel fibre synapses. The Journal of Physiology. 552:89-107.

Martin, S., C. Lino-de-Oliveira, S.R.L. Joca, R. Weffort de Oliveira, M.B. Echeverry, C.A. Da Silva, L. Pardo, W. Stühmer, and E.D. Bel. 2010. Eag 1, eag 2 and kcnn3 gene brain expression of isolated reared rats. Genes, Brain and Behavior. 9:918-924.

Martin, S., C. Lino de Oliveira, F. Mello de Queiroz, L.A. Pardo, W. Stühmer, and E. Del Bel. 2008. Eag1 potassium channel immunohistochemistry in the cns of adult rat and selected regions of human brain. Neuroscience. 155:833-844.

Meyer, R., and S.H. Heinemann. 1998. Characterization of an eag-like potassium channel in human neuroblastoma cells. The Journal of Physiology. 508:49-56. 
Mintz, I.M., B.L. Sabatini, and W.G. Regehr. 1995. Calcium control of transmitter release at a cerebellar synapse. Neuron. 15 (6):675-688.

Naraghi, M., and E. Neher. 1997. Linearized buffered ca2+ diffusion in microdomains and its implications for calculation of [ca2+] at the mouth of a calcium channel. The Journal of Neuroscience. 17:6961-6973.

Neher, E. 1998. Usefulness and limitations of linear approximations to the understanding of ca2+ signals. Cell Calcium. 24:345-357.

Neher, E., and T. Sakaba. 2008. Multiple roles of calcium ions in the regulation of neurotransmitter release. Neuron. 59:861-872.

Occhiodoro, T., L. Bernheim, J.-H. Liu, P. Bijlenga, M. Sinnreich, C.R. Bader, and J. FischerLougheed. 1998. Cloning of a human ether-a-go-go potassium channel expressed in myoblasts at the onset of fusion. FEBS Letters. 434:177-182.

Oertner, T.G., B.L. Sabatini, E.A. Nimchinsky, and K. Svoboda. 2002. Facilitation at single synapses probed with optical quantal analysis. Nat Neurosci. 5:657-664.

Palay, S.L., and V. Chan-Palay. 1974. Cerebellar cortex: Cytology and organization. SpringerVerlag, Berlin.

Palkovits, M., P. Magyar, and J. Szentágothai. 1971. Quantitative histological analysis of the cerebellar cortex in the cat. Iii. Structural organization of the molecular layer. Brain Research. 34:1-18.

Papazian, D., T. Schwarz, B. Tempel, Y. Jan, and L. Jan. 1987. Cloning of genomic and complementary DNA from shaker, a putative potassium channel gene from drosophila. Science. 237:749-753.

Pardo, L.A., A. Brüggemann, J. Camacho, and W. Stühmer. 1998. Cell cycle-related changes in the conducting properties of r-eag k+ channels. The Journal of Cell Biology. 143:767775 .

Pardo, L.A., D. del Camino, A. Sanchez, F. Alves, A. Bruggemann, S. Beckh, and W. Stuhmer. 1999. Oncogenic potential of eag k+ channels. EMBO J. 18:5540-5547.

Piston, D.W., T.J. Fellers, and M.W. Davidson. Fundamentals and applications in multiphoton excitation microscopy. http://www.microscopyu.com/articles/fluorescence/multiphoton/multiphotonintro.html

Prestori, F., P. Rossi, B. Bearzatto, J. Lainé, D. Necchi, S. Diwakar, S.N. Schiffmann, H. Axelrad, and E. D'Angelo. 2008. Altered neuron excitability and synaptic plasticity in the cerebellar granular layer of juvenile prion protein knock-out mice with impaired motor control. The Journal of Neuroscience. 28:7091-7103.

Raman, I.M., and B.P. Bean. 1999. Ionic currents underlying spontaneous action potentials in isolated cerebellar purkinje neurons. The Journal of Neuroscience. 19:1663-1674.

Regehr, W., K. Delaney, and D. Tank. 1994. The role of presynaptic calcium in short-term enhancement at the hippocampal mossy fiber synapse. The Journal of Neuroscience. 14:523-537.

Regehr, W.G., and P.P. Atluri. 1995. Calcium transients in cerebellar granule cell presynaptic terminals. Biophys J. 68 (6):2156-2170. 
Robertson, G.A., J.W. Warmke, and B. Ganetzky. 1996. Potassium currents expressed from drosophila and mouse eag cdnas in xenopus oocytes. Neuropharmacology. 35:841-850.

Rozov, A., N. Burnashev, B. Sakmann, and E. Neher. 2001. Transmitter release modulation by intracellular ca2+ buffers in facilitating and depressing nerve terminals of pyramidal cells in layer $2 / 3$ of the rat neocortex indicates a target cell-specific difference in presynaptic calcium dynamics. The Journal of Physiology. 531:807-826.

Sabatini, B.L., and W.G. Regehr. 1996. Timing of neurotransmission at fast synapses in the mammalian brain. Nature. 384:170-172.

Sabatini, B.L., and W.G. Regehr. 1997. Control of neurotransmitter release by presynaptic waveform at the granule cell to purkinje cell synapse. J Neurosci. 17 (6):3425-3435.

Sabatini, B.L., and W.G. Regehr. 1999. Timing of synaptic transmission. Annu Rev Physiol. 61 (6):521-542.

Sadakata, T., W. Kakegawa, A. Mizoguchi, M. Washida, R. Katoh-Semba, F. Shutoh, T. Okamoto, H. Nakashima, K. Kimura, M. Tanaka, Y. Sekine, S. Itohara, M. Yuzaki, S. Nagao, and T. Furuichi. 2007. Impaired cerebellar development and function in mice lacking caps2, a protein involved in neurotrophin release. The Journal of Neuroscience. 27:2472-2482.

Saganich, M.J., E.V.-S. de Miera, M.S. Nadal, H. Baker, W.A. Coetzee, and B. Rudy. 1999. Cloning of components of a novel subthreshold-activating k+ channel with a unique pattern of expression in the cerebral cortex. The Journal of Neuroscience. 19:1078910802 .

Saganich, M.J., E. Machado, and B. Rudy. 2001. Differential expression of genes encoding subthreshold-operating voltage-gated $\mathrm{k}+$ channels in brain. The Journal of Neuroscience. 21:4609-4624.

Sakaba, T., and E. Neher. 2001. Calmodulin mediates rapid recruitment of fast-releasing synaptic vesicles at a calyx-type synapse. Neuron. 32:1119-1131.

Schneggenburger, R., and I. Forsythe. 2006. The calyx of held. Cell and Tissue Research. 326:311-337.

Schneggenburger, R., and E. Neher. 2000. Intracellular calcium dependence of transmitter release rates at a fast central synapse. Nature. 406:889-893.

Schneggenburger, R., and E. Neher. 2005. Presynaptic calcium and control of vesicle fusion. Current Opinion in Neurobiology. 15:266-274.

Schönherr, R., G. Gessner, K. Löber, and S.H. Heinemann. 2002a. Functional distinction of human eag1 and eag2 potassium channels. FEBS Letters. 514:204-208.

Schönherr, R., L.M. Mannuzzu, E.Y. Isacoff, and S.H. Heinemann. 2002b. Conformational switch between slow and fast gating modes: Allosteric regulation of voltage sensor mobility in the eag k+ channel. Neuron. 35:935-949.

Serulle, Y., M. Sugimori, and R.R. Llinás. 2007. Imaging synaptosomal calcium concentration microdomains and vesicle fusion by using total internal reflection fluorescent microscopy. Proceedings of the National Academy of Sciences. 104:1697-1702. 
Silver, R.A. 2010. Neuronal arithmetic. Nat Rev Neurosci. 11:474-489.

Silver, R.A., J. Lübke, B. Sakmann, and D. Feldmeyer. 2003. High-probability uniquantal transmission at excitatory synapses in barrel cortex. Science. 302:1981-1984.

Sims, R.E., and N.A. Hartell. 2006. Differential susceptibility to synaptic plasticity reveals a functional specialization of ascending axon and parallel fiber synapses to cerebellar purkinje cells. J Neurosci. 26 (6):5153-5159.

Singer-Lahat, D., A. Sheinin, D. Chikvashvili, S. Tsuk, D. Greitzer, R. Friedrich, L. Feinshreiber, U. Ashery, M. Benveniste, E.S. Levitan, and I. Lotan. 2007. K+ channel facilitation of exocytosis by dynamic interaction with syntaxin. The Journal of Neuroscience. 27:1651-1658.

Singer, J.H., L. Lassova, N. Vardi, and J.S. Diamond. 2004. Coordinated multivesicular release at a mammalian ribbon synapse. Nat Neurosci. 7:826-833.

Sorensen, J.B. 2004. Formation, stabilisation and fusion of the readily releasable pool of secretory vesicles. Pflügers Archiv European Journal of Physiology. 448:347-362.

Southan, A.P., and B. Robertson. 1998. Patch-clamp recordings from cerebellar basket cell bodies and their presynaptic terminals reveal an asymmetric distribution of voltagegated potassium channels. The Journal of Neuroscience. 18:948-955.

Stansfeld, C.E., J. Röper, J. Ludwig, R.M. Weseloh, S.J. Marsh, D.A. Brown, and O. Pongs. 1996. Elevation of intracellular calcium by muscarinic receptor activation induces a block of voltage-activated rat ether-à-go-go channels in a stably transfected cell line. Proceedings of the National Academy of Sciences. 93:9910-9914.

Stevens, C.F., and Y. Wang. 1995. Facilitation and depression at single central synapses. Neuron. 14:795-802.

Stevens, C.F., and J.F. Wesseling. 1998. Activity-dependent modulation of the rate at which synaptic vesicles become available to undergo exocytosis. Neuron. 21:415-424.

Südhof, T.C. 2004. The synaptic vesicle cycle. Annual Review of Neuroscience. 27:509-547.

Sun, J., Z.P. Pang, D. Qin, A.T. Fahim, R. Adachi, and T.C. Sudhof. 2007. A dual-ca2+-sensor model for neurotransmitter release in a central synapse. Nature. 450:676-682.

Sun, X.X., J.J.L. Hodge, Y. Zhou, M. Nguyen, and L.C. Griffith. 2004. The eag potassium channel binds and locally activates calcium/calmodulin-dependent protein kinase ii. Journal of Biological Chemistry. 279:10206-10214.

Swensen, A.M., and B.P. Bean. 2003. Ionic mechanisms of burst firing in dissociated purkinje neurons. The Journal of Neuroscience. 23:9650-9663.

Tedford, H.W., and G.W. Zamponi. 2006. Direct g protein modulation of cav2 calcium channels. Pharmacological Reviews. 58:837-862.

Terlau, H., J. Ludwig, R. Steffan, O. Pongs, W. Stühmer, and S. Heinemann. 1996. Extracellular mg2+ regulates activation of rat eag potassium channel. Pflügers Archiv European Journal of Physiology. 432:301-312.

Tong, G., and C.E. Jahr. 1994. Multivesicular release from excitatory synapses of cultured hippocampal neurons. Neuron. 12:51-59. 
Trussell, L.O., and G.D. Fischbach. 1989. Glutamate receptor desensitization and its role in synaptic transmission. Neuron. 3:209-218.

Tsodyks, M.V., and H. Markram. 1997. The neural code between neocortical pyramidal neurons depends on neurotransmitter release probability. Proceedings of the National Academy of Sciences. 94:719-723.

Varela, J.A., K. Sen, J. Gibson, J. Fost, L.F. Abbott, and S.B. Nelson. 1997. A quantitative description of short-term plasticity at excitatory synapses in layer $2 / 3$ of rat primary visual cortex. The Journal of Neuroscience. 17:7926-7940.

Wadiche, J.I., and C.E. Jahr. 2001. Multivesicular release at climbing fiber-purkinje cell synapses. Neuron. 32:301-313.

Wang, L.-Y., and L.K. Kaczmarek. 1998. High-frequency firing helps replenish the readily releasable pool of synaptic vesicles. Nature. 394:384-388.

Wang, Z., G.F. Wilson, and L.C. Griffith. 2002. Calcium/calmodulin-dependent protein kinase ii phosphorylates and regulates the drosophila eag potassium channel. Journal of Biological Chemistry. 277:24022-24029.

Warmke, J.W., and B. Ganetzky. 1994. A family of potassium channel genes related to eag in drosophila and mammals. Proceedings of the National Academy of Sciences. 91:34383442 .

Weinshenker, D., A. Wei, L. Salkoff, and J.H. Thomas. 1999. Block of an ether-a-go-go-like k+ channel by imipramine rescues egl-2 excitation defects incaenorhabditis elegans. The Journal of Neuroscience. 19:9831-9840.

Wheeler, D., A. Randall, and R. Tsien. 1996. Changes in action potential duration alter reliance of excitatory synaptic transmission on multiple types of ca2+ channels in rat hippocampus. The Journal of Neuroscience. 16:2226-2237.

Williams, S.R., S.R. Christensen, G.J. Stuart, and M. Häusser. 2002. Membrane potential bistability is controlled by the hyperpolarization-activated current ih in rat cerebellar purkinje neurons in vitro. The Journal of Physiology. 539:469-483.

Wu, C.F., B. Ganetzky, F.N. Haugland, and A.X. Liu. 1983. Potassium currents in drosophila: Different components affected by mutations of two genes. Science. 220:1076-1078.

Xu-Friedman, M.A., K.M. Harris, and W.G. Regehr. 2001. Three-dimensional comparison of ultrastructural characteristics at depressing and facilitating synapses onto cerebellar purkinje cells. The Journal of Neuroscience. 21:6666-6672.

$\mathrm{Xu}$, J., and L.-G. Wu. 2005. The decrease in the presynaptic calcium current is a major cause of short-term depression at a calyx-type synapse. Neuron. 46:633-645.

Yamada, W.M., and R.S. Zucker. 1992. Time course of transmitter release calculated from simulations of a calcium diffusion model. Biophysical journal. 61:671-682.

Ziechner, U., R. Schönherr, A.-K. Born, O. Gavrilova-Ruch, R.W. Glaser, M. Malesevic, G. Küllertz, and S.H. Heinemann. 2006. Inhibition of human ether à go-go potassium channels by ca2+/calmodulin binding to the cytosolic n- and c-termini. FEBS Journal. 273:1074-1086. 
Zucker, R.S. 1973. Changes in the statistics of transmitter release during facilitation. The Journal of Physiology. 229:787-810.

Zucker, R.S., and W.G. Regehr. 2002. Short-term synaptic plasticity. Annu Rev Physiol. 64 (6):355-405. 


\section{Acknowledgments}

I am very grateful to Prof. Walter Stühmer for accepting me as student in his lab and for many once-in-a-lifetime experiences.

I would like to express my deepest gratitude to my supervisor, Prof. Luis Pardo, for teaching me many things not only about science, for lots and lots of help and always having an open ear.

I would like to especially thank Dr. Takeshi Sakaba from the Research Group Biophysics of Synaptic Transmission for continuous support, patience, time, and advice in all sorts of things.

Further, I am grateful to Prof. Anastassia Stoykova, who as a member of my thesis committee was always helpful and supportive.

All the people in the MBNS department in the MPI EM helped to make it a great and special place to work in. A big thanks to Bärbel and Hanna for all the genotyping! Dr. Roser Ufartes was always helpful with everything concerning the KO mice, and Dr. Miso Mitkovski introduced me to confocal imaging. But the biggest thanks belongs to the people who made the lab a cheerful place to be and let me forget the sometimes cruel reality of science; Alonso, Diana, Joasia, Camilo, and Fernandinha, thanks for being my friends.

Not in Göttingen anymore, but unforgotten are Dr. Ye Chen, who always asked the right question; and Aura Jimenez, who let the sun rise wherever she went.

Zohrehcita, you are an amazing person and the best MSc student one can hope for.

I would like to thank the whole department of Membrane Biophysics in the MPI BPC and all members of Biophysics of Synaptic Transmission for the extremely nice atmosphere and for all the help and fun during the last 2 years. Especially Sigrid Schmidt was very helpful preparing solutions and helping in the staining. I am grateful to Dr. Lijun Yao and Dr. Jin Bao for introducing me to the wonderful world of slice electrophysiology, and to Dr. Jens Weber for the NeuroBunny tools, from which the world of NeuroCat emerged.

I am very very grateful to the people from the CLI Leipzig for a great collaboration; especially to Dr. Hartmut Schmidt, who patiently taught me everything about calcium imaging and was always open for discussions. Prof. Jens Eilers and Dr. Oliver Arendt were also very helpful and, together with the other group members, made my days in Leipzig so enjoyable.

I owe a lot the IMPRS Neuroscience and their coordinators, Prof. Michael Hörner and Sandra Drube, who are doing an incredible job to make The Program what it is. Also, all my classmates from Neuro and MolBio had their share in making these years special.

Of course, all my friends in Göttingen and from elsewhere: Thank you for the fun and all the great times we had, and for the support and hugs when the experiments or life in general sucked.

I cannot thank my parents enough for everything they did and did not do. My father for being a role model for scientific thinking, and my mother for being a role model as a woman.

Ihr seid die Besten!

Alonso, tampoco para tí tengo suficientes palabras para agradecerte todo lo que hiciste y dijiste. Lo más importante es jih musha' soh! Elen síla lumenn' omentielvo, rim hennaid. 


\section{Curriculum vitae}

\section{Personal data}

Name:

Lena Sünke Mortensen

Date and place of birth:

February $10^{\text {th }}, 1983$ in Scherzingen, Switzerland

Citizenship:

German

\section{Education}

$10 / 2003-09 / 2006$

B.Sc. in Biological Sciences, Westfälische Wilhelms -

Universität Münster, Germany

$12 / 2006-02 / 2007$

Internship in the group of Prof. Robyn Langdon, Macquarie

Center for Cognitive Science, Macquarie University, Sydney,

Australia

$05 / 2007-08 / 2007$

Internship in the Dept. of Neurobiology with Prof. Randolf

Menzel, Free University Berlin, Germany

$09 / 2007-08 / 2008$

International Max Planck Research School Neurosciences, first segment, Georg - August - Universität Göttingen, Germany

$10 / 2008-04 / 2012$

$\mathrm{PhD}$ thesis in the Max Planck Institute of Experimental Medicine, Dept. Molecular Biology of Neuronal Signals, Göttingen

Second segment of the International Max Planck Research School Neurosciences, Göttingen 


\subsection{Publications}

Mortensen LS, Sakaba T, Schmidt H, Barrantes-Freer A, Ufartes R, Eilers J, Stühmer W, Pardo LA. Loss of Eag1 causes increased $\mathrm{Ca}^{2+}$ influx into the presynaptic terminal. 2012, in preparation

Ufartes Mas R, Schneider T, Mortensen LS, de Juan Romero C, Heintrich K, Knötgen H, Beilinson V, Möbius W, Tarabykin V, Alves, F, Pardo LA, Rawlins N, Stühmer W. $\mathrm{K}_{\mathrm{v}} 10.1$ (Eag1) reactivity to antipsychotic/antidepressant drugs. 2012, in preparation

Barrantes-Freer A, Kim E, Bielanska J, Giese A, Mortensen LS, Stühmer W, Pardo LA. Functional properties of the plasma membrane of human glioma initiating cells. 2012, in preparation

Dannlowski U, Ohrmann P, Konrad C, Domschke K, Bauer J, Kugel H, Hohoff C, Schöning S, Kersting A, Baune BT, Mortensen LS, Arolt V, Zwitserlood P, Deckert J, Heindel W, Suslow T. Reduced amygdala-prefrontal coupling in major depression: association with MAOA genotype and illness severity. Int J Neuropsychopharmacol 2009 Feb;12(1):11-22

Baune BT, Hohoff C, Mortensen LS, Deckert J, Arolt V, Domschke K. Serotonin transporter polymorphism (5-HTTLPR) association with melancholic depression: a female specific effect? Depress Anxiety 2008;25(11):920-5

Domschke K, Hohoff C, Mortensen LS, Roehrs T, Deckert J, Arolt V, Baune BT. Monoamine oxidase A variant influences antidepressant treatment response in female patients with Major Depression. Prog Neuropsychopharmacol Biol Psychiatry 2008 Jan 1;32(1):224-8

Baune BT, Hohoff C, Berger K, Neumann A, Mortensen LS, Roehrs T, Deckert J, Arolt V, Domschke K. Association of the COMT val168met variant with antidepressant treatment response in major depression. Neuropsychopharmacology 2008 Mar;33(4):924-32.

Kersting A, Kroker K, Horstmann J, Baune BT, Hohoff C, Mortensen LS, Neumann LC, Arolt V, Domschke K. Association of MAO-A variant with complicated grief in major depression. Neuropsychobiology 2007; 56(4):191-6 